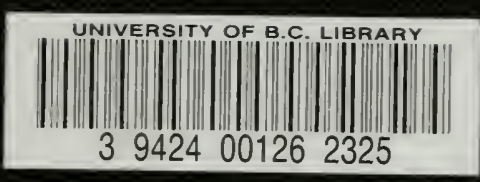

\title{
POULTAY
}

FOR THE

\section{TABLE AND MARKET}

\section{YRIRES}

\section{FANOY FOWLS,}

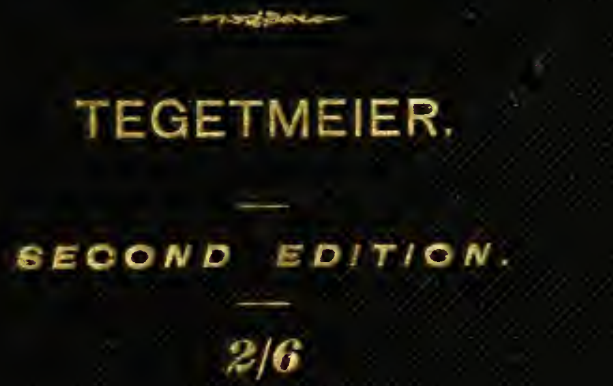

STORAGE ITEM

PFOCESS ING-CNE

$\mathrm{LP} 1-\mathrm{F} 20 \mathrm{~A}$

U.B.C. LIBRARY 


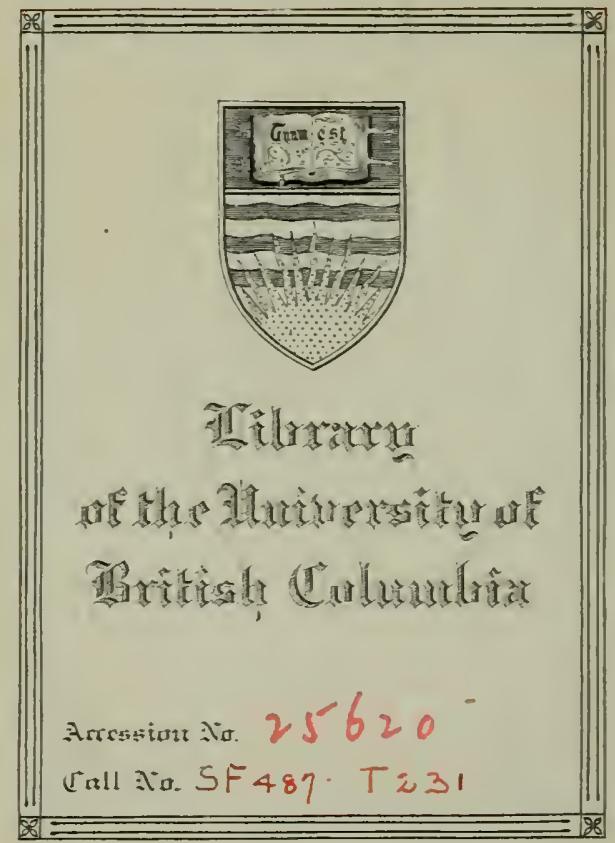







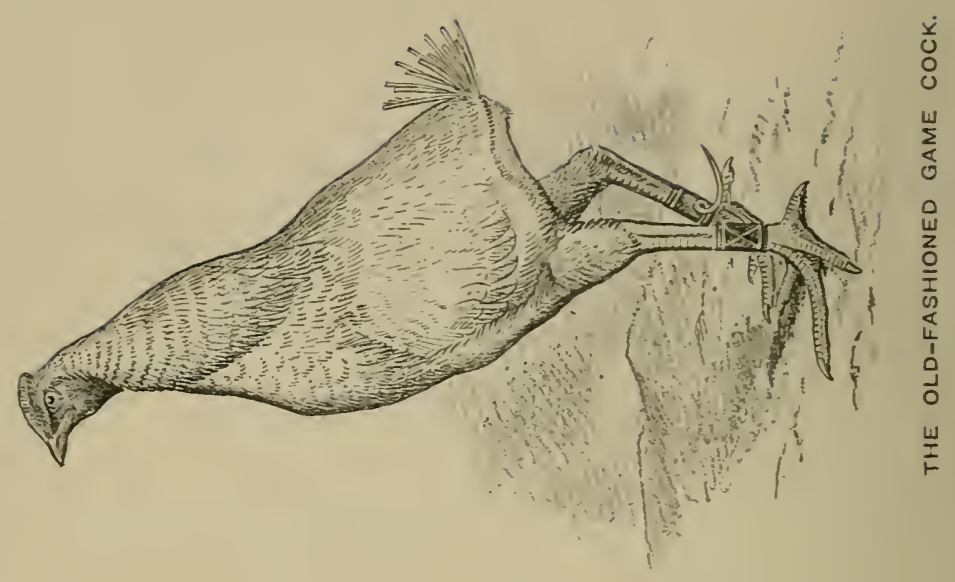

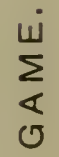

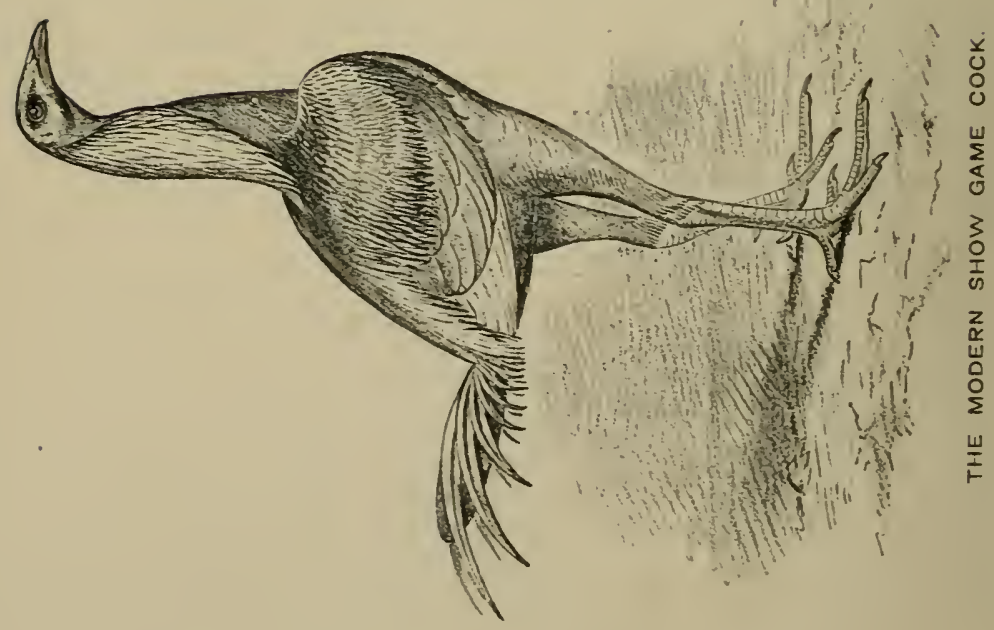




\section{POULTRY \\ roor}

\section{THE TABLE AND MARKET}

TERSUS

\section{FANCY FOWLS.}

WITH AN EXPOSITION OF THE

\section{FALLACIES OF POULTRY FARMING.}

"AS THE RESLLT OF MY EXPERIENCE OF NEARLY HALF A CENTCRY, I DO NOT HESITATE TO AFFIRY THAT NO ONE BREED OF FOWLS HAS BEEN TAKEN IN HAND BY THE FANCIKR, THAT HAS SOT BEEN SELIOUSLY DEPRECIATED AS A USEFUL VARIETY OF POULTRY." - I ide page 1.

THE SECOND EDITION, REVISED AND ENLARGED.

\section{W. B. TEGETMEIER, F.Z.S.,}

Autur of "Profitable Poultry;" "The Poultry Boole;" "Poultry," in the Encyclopadia

Pratannica; "The Modern Breeds of Poultry," in "The Tbis," 1890; "Farm Poultry," in the Journals of Royal Agricultural Society, 1890, the Bath and West of

England Society, and the Yorkshire Agricultural Society. Editor of

the Poultry Department of "The Field;" Davis Lecturer to the Zoological Society; Lecturer to the Agricultural Institute, South Kensington Museum;

One of the Judges at the Royal Agricultural, Bath and West of England, the Birmingham, Crystal Palacc, Dairy Show, and other Exhibitions.

LoNDon :

HORACE COX, "THE FIELD" OFFICE, BREAM'S BUILDINGS, E.C.

1893.

[All rights reserved. 
LONDON :

PRINTED BY HORACE COX, BREAM'S BUILDINGS, E.C. 


\section{PREFACE.}

Is publishing this book I have had but one object in view, and that is, the increase of the quality of marketable poultry, and the quantity of eggs produced in this country. I wish it to be distinctly understood that this work has not been written in opposition to the keeping of ornamental and fancy poultry as such. I am not opposed to the holding of poultry shows by those who are pleased with the cultiration of ornamental fowls; nor am I opposed to the holding of flower shows; but I regard poultry shows, as ordinarily conducted, to have no more to do with the produce of marketable and useful poultry than flower shows have to do with garden or agricultural produce. I think it greatly to be lamented that at our large agricultural exhibitions really useful poultry should have been entirely ignored in favour of feather varieties. I am not sanguine enough to suppose that any variety of poultry can be kept to produce the large amount of chickens and eggs that are required for consumption ir this country. The production of poultry is the business of tre small farmer and small landed proprietor. As many birds can be kept around the homestead of a farm of thirty or fifty acres, as can be maintained about one of 500 or 1000 . To the small farmer the return of the poultrs is of much more 
importance than it is to the larger landed proprietor; and it is with a view of showing that ornamental poultry is not adapted to the use of the breeder for the market that these chapters have been written.

In order to prevent unnecessary correspondence, I may state that I cannot undertake, either directly or indirectly, to procure birds or eggs for my readers, or to accept the responsibility of recommending rendors.

W. B. TegetMEIER.

North Finchles,

January, 1892.

\section{PREFACE TO THE SECOND EDITION.}

IN issuing the second edition of this work, I cannot refrain from expressing the satisfaction its extremely favourable reception has afforded me. I have endeavoured to make it more worthy of the manner in which it has been received by the addition of new chapters on Improving Farm Poultry and on 'Trussing Fowls for the Market; and additional illustrations have been supplied wherever it was thought desirable. March, 1893. 


\section{CONTENTS.}

Chapter I.

Introductory

Chapter II.

Game Fowls

Chapter iII.

Dorkings

Cochins

Chapter IV.

Brahmas ...

Chapter V.

Chapter VI.

Langshans, Plymouth Rocks, and Wyandottes $\quad \ldots . . . \ldots \ldots \ldots \ldots . . . \quad 19$

Chapter VII.

Malays, Indiau Game, and̉ Azeel

Chapter VIII.

French Table Breeds-Houdans, Crèveceur, and La Flèche...

Chapter IX.

Non-sitting Varieties-Spanish, Minorcas, Andalusian, and Leghom

Chapter $\mathrm{X}$.

Non-sitting and other Varieties 38

Chapter XI.

Improving Farm Poultry 


\section{Chapter XIII.}

Feeding page 48

Chapter XIV.

Hatching

Chatter XV.

Rearing the Chicken

Chapter XVI.

Breeding for the Market.-Eggs 64

Chapter xvil.

Breeding for the Market.-Chickens

\section{Chapter XViII.}

Fattening

\section{Chapter XIX.}

Showing and Trussing

Chapter $\mathrm{XX}$.

Turkeys and Guinea Fowl 88

Chapter XXI.

Ducks

Chapter XXil.

Greese 97

\section{Chapter XXIII.}

Diseases of Poultry 100

Chapter XXIV.

Fallacies of Poultry Farming . 106

Chapter XXV.

Fowls in Small Runs 119

Chapter XXVI.

Caponising 


\section{LIST OF ILLUSTRATIONS.}

Game Fowls, Ancient and Modern Frontispiece

Berrick's Farm Yard Fowl

PAGE

Braquemond's Farm Yard Fowl .............................. 6

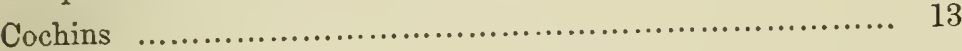

(1)

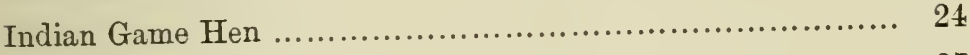

Houdans........... .27

Crèvecœur

La Flèche Cock .............................................. 29

La Flèche Hen ............................................. 30

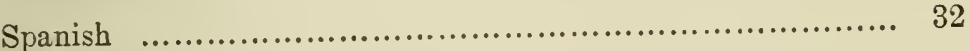

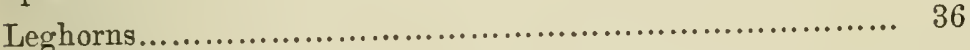

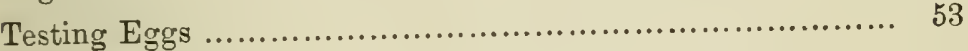

Fatting Coop .............................................. 76

Cramming Machine ....................................... 79

Dead Fowl for Show......................................... 83

Fowl Trussed for Roasting ................................. 83

Fowl Trussed for Boiling .................................... 86

Movable Poultry House .................................... 99

Orpington Poultry Disease ................................... 102

Scurfy Leg Farasite ...................................... 105 


\section{PUBLLGATIONS BY W. B. TEGETMEIER, F.Z.S.,}

Member of the British Ornithologists' Union.

PROFITABLE POULTRY (Darton). 1853.

Out of print.

REARING AND FATINING MARKET AND TABLE POULTRY. 1855.

Out of print.

THE POULTRY B00K, $£ 1$ 1s. (Rontledge and Sons.) Out of date, not having been revised since 1873.

BREEDING FOR COLOUR AND THE PHYSIOLOGY OF BREEDING. By W. B. TEGETMEIER and W. W. BOULTON, M.R.C.S. (Ward, Beverley.) 1873.

Out of print.

THE PRINCIPAL MODERN BREEDS OF DOMESTIC FOWL. Private reprint from The Ibis, 1890.

POULTRY, ENCYCLOP. BRITANNICA. Last Edition.

PIGEONS (Routledge and Sons). 1870. Out of date, not having been revised since its publication.

UTILIZATION OF PIGEONS FOR MILITARY PURPOSES. 1877. Royal Engineers' Institute, Chatham. Printed for private circulation.

THE HOMING PIGEON (Routledge and Sons). 1872. Out of print.

THE NATURAL HISTORY OF THE CRANES. By W. B. TEGETMEIER and E. BLYTH. 1881.

PALLAS SAND GROUSE. 1888.

Out of print.

PHEASANTS FOR COVERTS AND AVIARIES. 2nd Edition, 1883. 15s. (Horace Cox.)

ON THE CONVOLUTIONS OF THE TRACHEA IN BIRDS. Privately printed, 1881.

MANUAL OF DOMESTIC ECONOMY, WITH HINTS ON DOMESTIC MEDICINE AND SURGERY. 12th Edition, 1s. 6d. (Hamilton, Adams, and Co.)

HOUSEHOLD MANAGEMENT. Written at the request of the School Board for London. 60th thousand. 18. (Macmillan and Co., Londou.) 


\section{POULTRY}

\section{FOR THE TABLE AND MARKET}

VERSUS

\section{FANCY AND EXHIBITION \\ FOWLS.}

\section{CHAPTER I. \\ INTRODUCTORY.}

THE subject of poultry, considered as profitable farm stock, has been a matter of interest with me for a very long period Nearly forty years ago I published a work on profitable, as distinguished from fancy or ornamental poultry, which was exceedingly well received. For more than the third of a century I have been engaged in awarding prizes at the poultry shows, held by agricultural and other societies, during which time I have never failed to bear in mind the importance of poultry as yielding a valuable supply of food, in the form of chickens and eggs, but year after year I have seen, with regret, the steadily increasing tendency of poultry shows to encourage mere fancy varieties, and to ignore altogether the profitable value of the birds exhibited. This has gone on to such an extent, that I do not hesitate to affirm, as the result of my experience of half a century, that no one breed of fowls has been taken in hand by the fancier that has not been seriously depreciated as a useful variety of poultry. At shows, as at present conducted, fancy points only have to be considered by the judges. The result is that the economic value of many breeds has been entirely lost. For example, Spanish, from being abundant producers of large white egrs, have become rery indifferent layers, some of the most notorious prize-winners being practically sterile. Cochins, that were formerly the beat. 
layers of any sitting rarieties, are now amongst the worst. Dorkings, that formerly supplied the best form for the London markets, are now lored as show birds, and are not equal to the cross-bred Surrey forls, that are chiefly ralued by the higglers and the feeders. The Game forls, that were formerly bred for the cockpit, and for their value as table fowl, are now elongated out of all knomledge, and look more like the "stilt birds," or waders, of the ornithologist, than a rariets of poultr' fitted for ans practical use.

Nor has the depreciatire effect of competitire sbows been confined to forls; it influences to a greater or less clegree all animals that are exhibited in competition. At dog shows the rarious breeds are shown exclusirelr for fancy points, which have no reference whaterer to the utilits of the animals from a practical point of riew. A prize grerhound, for example, is not an animal that would figure at a coursing meeting, and Fullerton, the winner of four Waterloo Cups, would be passed without a commendation br the judges at a dog show, were ther ignorant of his unexampled performances. For example, no less an authority than the editor of the Kennel Gazette, the recognised organ of the Kennel Club, after speaking of the eril effects of the present show srstem on other breeds, writes, in Juls, 1890: "Turn to the sheep dogs. How many collies of the present day who have won prizes could clear a high hurdle, or scamper orer the backs of a flock of sheep to turn it:"

In the case of pigs, useful rarieties, such as the Berkshire, hare been bred so "dish-faced," in accordance with the requirements of the fancr, that ther have lost their profitable character, and are now no longer in farour with the farmer who breeds for the lig market; consequently, he has to fall back upon the Tamworth and other coarser rarieties, in order to make his pigs pay their expenses. The same is the case with cattle, the enormous sums of moner giren in premiums not going to the rreat body of agriculturists, but into the hands of a few, who breed solely in order to win prizes at the shorrs.

Some years since, the late secretary of the Roral Agricultural Societr, Mr. H. MI. Jenkins, stated that the present show srstem was merely the offering of enormous sums of money to be scrambled for lor a rers few exhibitors. Mr. C. T. Drke Ackland has indorsed the opinion, and has shomn conclusirely that the large sums of money offered gro into the hands of a rers small 
section of the exhibitors. He has published a summary of the prizes awarded for eleven rears at the principal shows, from which it appears that of the 17,2167 . given as prizes to cattle, sheep, and pigs, no less than 93917., or considerably more than one half of the total sum offered went into the pockets of sixty-two exhibitors.

Believing as I do that the value of poultry as a source of food would be largels increased by a different method of procedure, I am induced to publish the present work. It is with considerable regret that I find myself opposed to those poultry keepers with whom I hare acted so long, but my conviction as to the inutility of fancy fowls as profitable poultry leaves me no alternative. I bare no objection to fancr poultry considered as such. A poultry lieeper has every right to breed ornamental fowls up to any pattern that he thinks fit. I am perfectly conscious of the fact that the breeding of fancy poultry is a source of great amusement and interest, to large numbers of people; it affords them pleasant occupation, and is attended with a certain result. What I object to is that fancy poultry should, in this comtry at least, take the place of useful birds that are fitted to supply the markets with poultry and eggs. At present, the aim of the poultry fancier and exhibitor is not to breed fowls for any useful purpose, but to produce them in accordance with the requirements of the fancier, in order to win prizes, so as to sell the birds at enormous prices as winners, which are likely to produce others in their turn.

The aim of the fancier alwars is, as was remarked by Darwin, to go into extremes. He has not eveu a standard of beauty which he regards as final. The greater the extent to which he can make the sirecimens he produces excel others in fancr points, is the object at which he aims; consequently ilideous monstrosities are not unfrequently producer and exhibited, the only advantage of which, from a scientific or practical point of view, is to prove the extent to which living organisms are rariable under the influence of artificial as opposed to natural selection. Cochins are one mass of useless feather, Game hens stand a foot or more from the ground; Houdans, Crèrecours, and Polish are lored with tufts so large that they ran seareely see to feed; and so on, lusre or less, with every variety.

In the present work I propose to compare fowls as they were when regarded as useful producers of meat and eggs for the table with their present condition, after having heen developed 
by the aid of the fancier. The following engraving of a farmyard fowl in the early part of the present century is an exact reproduction of a drawing by the celebrated Bewick, whose marvellous accuracy in delineation of animals is well known. It shows a fine-boned, short-legged, full-chested bird of great value as a table fowl-one that is in strong contrast to the coarse-boned, narrow-chested, feather-legged mongrels that have populated too many of our own farmyards since the introduction of Cochins and

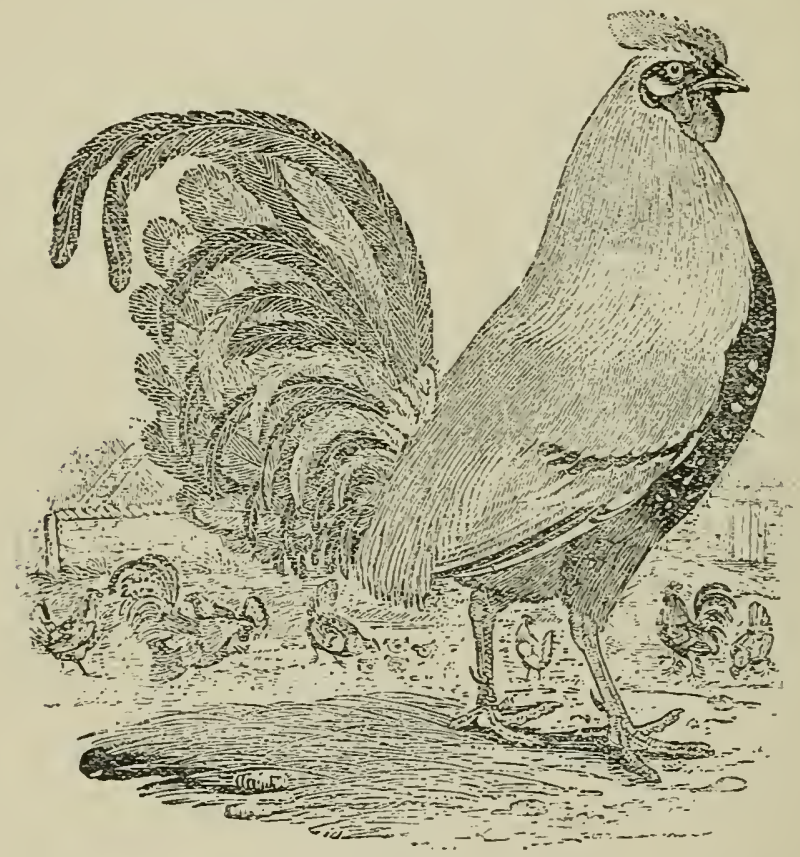

Fariyard Fowl of 1800, Drawx axd Exgraved bT Bewick.

Brabmas into this country, the worthless character of which is shown in the admirable drawing by Braquemond, reproduced at the end of this chapter. I wish to show that for agricultural and economical purposes, the modern fancy breeds are useless, as contrasted with the older varieties. I consider it is absolutely necessary that such views should be set forth, for at the present 
time our agricultural societies are doing what I conceive to be considerable injury by giving prizes for useless birds, and ignoring, at least to a very great extent, the breeds that would be of benefit to the farmer and to the nation at large.

In a recent number of the Journal of the Royal Agricultural Society, it was stated that "The main object of the society in offering prizes for poultry is to encourage agriculturists to devote greater attention to an industry which fits very well with ordinary furm operations, and is often, under skilful management, a source of considerable profit." In the prize list of the Plymouth show, which was held the same rear, there were eight classes for table poultry (fowls and ducks), the prizes offered being 28l., out of a poultry prize list of $275 l$, which sum was devoted almost exclusively to fancy poultry, and was offered as the reward of those who could breed the prettiest feathers and largest combs, without the slightest reference to the useful qualities of the birds. 14l. was offered for the longest foot-feathers and the greatest amount of fluff in Cochins-useless birds to the farmer; an equal amount to laced feathers in Wyandottes, poultry valueless as market fowls; and so on throughout the entire prize list; whilst the Surrey and Sussex fowls, which constitute nine-tenths of the very best and most remunerative birds coming to the London market, were absolutely excluded from competition.

In the same number of the Journal, one of the judges in reporting the society's show of fancy and feathered poultry wrote: "Out of every ten pure-bred chickens successfully reared, only one is suitable for a 'fanciers' exhibition, whilst the remainder are exclusively and admirably adapted for the market and the table!" That the ridiculous statement that fancy poultry are admirably adapted for the market should have appeared in the Journal of the Royal Agricultural Scciety is a circumstance much to be regretted.

The exhibition of dead fancy poultry was tried at the Dairy Show, and the miserable carcases of the dead Wyandottes and other fancy breeds that were exhilited put a stop to the repetition of the experiment. If the Council of the Royal Agricultural Society desire to know what birds have any market value, let them inquire of the proprietors of any poultry fattening establishment where the chickens are bought for the purpose of being prepared for the London market; or let them go to any good West-end poulterer, such as Bellamy, Baily, or Fisher, and ask them their 
opinion of "fanciers" " fowls, as "exclusively and admirably adapted for the table," and the answers they will receive will tend to convince them that the jublication of such statements in their Journal is exceedingly undesirable.

In the following chapters I shall, in the first instance, consider the most important breeds of fowls, not merely as they formerly existed, but also as they now are, after having been bred for fancr points, and then proceed to treat of the management of profitable, agricultural, and market stock, not from a fancier's, but from a productive point of view, taking up successively the subjects of housing, feeding, hatching (by hens, turkeys, and incubators). rearing the chicken, cross breeding for the production of eggs and chicken, fattening, killing, the causes of the failure of poultry farming, and the profitable management of turkess, ducks, and geese for the table and marliet.

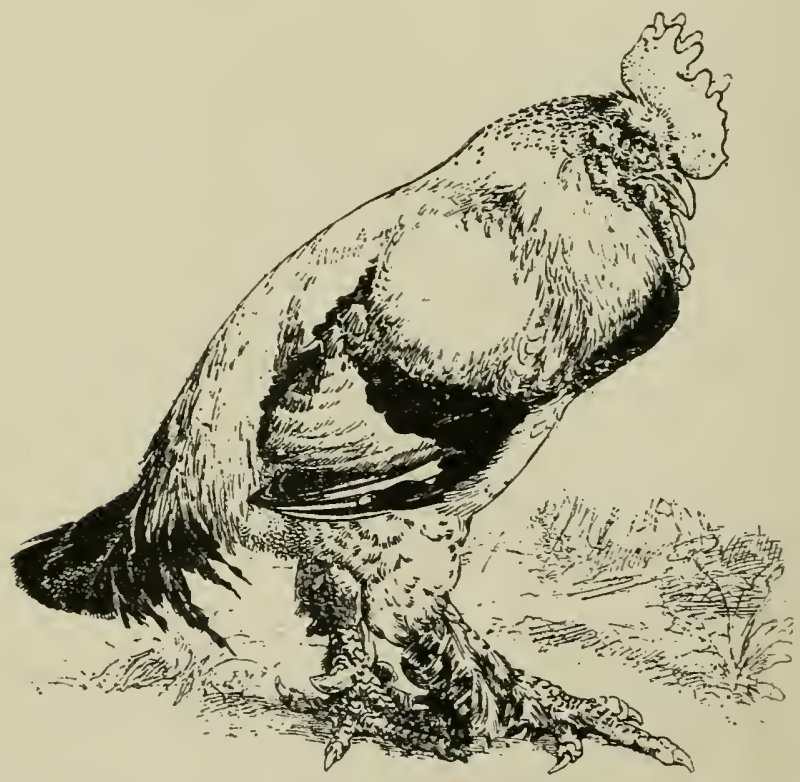

Farmitard Fowl of 1890, Drawn by Braquenond. 


\section{CHAP'TER II.}

\section{GLIIE FOWLS.}

THE alteration which has been effected in the various breeds of fowls within the last twenty-five years, during which time fancy shows have been in the ascendant, has been in no case more evident than in the Game breed. Formerly, when Game fowl were lned for the cockpit, what was required was a close-feathered, vigorous bird, possessed of great strength of leg and wing, the latter necessitating the presence of large fleshy pectoral muscles, which gave plumpness to the breast; together with the absence of anything which could be regarded as useless offal, such as superabundant feathers or comb. As there was no especial point to be exaggerated in Game fowls, they remained for some considerable time unaltered by the competitive shows; but at last the fashion turned strongly in favour of what were termed "reachy" birds, with long necks and limbs, with the plumage reduced to the most scanty proportions. The result may be seen in the present race of show Game, in which the elongation of the neck, limbs, and even body is carried to a most extraordinary degree. Hens nay now be seen in the show pens standing with the keel of the breastbone raised 12in. from the ground, and with necks correspondingly elongated. The tail feathers are reduced to the smallest possible proportions, a cock having no chance of success unless they are, in the terms of the fancier, "whip-like."

Formerly Game hens were characterised by carrying the tail feathers in a somewhat fun-like form; now these are so small, and held so tightly together, that that characteristic has entirely disappeared. It is needless to say that these alterations can only lave been effected by the loss of plumpness, and of the useful character of the birds. The modern Game fowls are of little value on the table. They have lost the character of good mothers which they formerly possessed, have become delicate and difficult to rear, and are despised by the cockers who breed fowls for practical purposes. 
When writing of the English Game forl a quarter of a century ago, I stated that their superiority had been entirely due to the practice of cock-fighting, which was extensively indulged in by all classes until a comparatirely recent legal enactment rendered its practice punishable with heary pecuniary penalties.

The practice of cock-fighting mar be regarded as one which carries out under man's superrision the principle of action which has been so ably described by Darwin and Herbert Spencer as "the surrival of the fittest in the struggle for life." Those cocks which have proved the strongest, most active, and courageous, and hare stricken down their antagonists in the pit, have been preserred by man as the progenitors of their lind. This process of selection had been carried on for a long series of generations, with the ultimate result that the English Game forl was unequalled in form, and was unirersally regarded as the highest type of gal'inaceous beauty.

Since the era of competitive shows all this has been changed. What Game fowl once were and what they now are mar be seen by reference to the illustrations of ancient and modern game forl. The drawings show a joung cock of the modern show type, belonging to Captain Heaton (reproduced by permission from The Stock Keeper), as contrasted with a muscular full-bodied bird as bred for the cockpit in the olden time. I hare purposely chosen to reproduce the latter as trimmed and heeled for fighting, as the full-bodied muscular character of the old breed is more apparent. It is needless to sar that the exhibition Game fowl is of no use to the farmer, being unproductire, delicate, ill-adapted to the table, and useless for the purpose of crossing to gire plumpness to table birds. The delicacy of the exlibition breed of Game fowls, as compared with the old vigorous strain, was forcibly illustrated in an account published in the Field, March 26, 1892. by Mr. Fletcher Moss, who stated that two sears since he borrowed a Lord Derby cock from a man who kept the breed for fighting 1 urposes. He put this cock to those of his hens that approximated most closely to the old sort; that is to sar, were shorter legged than the ordinary black-red hens. With another set of hens, sisters to the first lot, he put a prize modern ganecock, and compared the chickens from the two pens. Thes certainly surprised him, as there was no comparison in the health or hardihood of the chickens from the two cocks; those bred from the fighting cock feathered quickly and lived, those from the 
show bird feathered slowly and died. In one hatch a young hen had nine chickens from the exhibition strain and one from the fighting bird; they were often in wet grass, and the latter lived, while the former all died. Writing in Februarr, 1893, after another year's experience, Mr. Fletcher MIoss, when publishing his poultry balance sheet in the Field of Feb. 11, sars that he has kep,t during the past rear both old-fashioned and exhibition Game. The former, he says, are certainly the most productive and profitable, for the old fighters must have had health and strength - very desirable in all animals. The modern Game he describes as "Only fit for show, languid swells in fact, without much hardihood."

If the old English Game forl-not the mongrels often so called and exhibited at some of our shows where classes for this rariety exist-can be obtained, it will he found of great use as a cross, but it must be sought for, not in the show rards, but in some of those districts where the illegal practice of cock-fighting is still pursued "under the rose."

In making this statement I am not speaking without warrant. It is quite true that I hare nerer crossed the modern show Game with Dorking, as I have the old-fashioned breed, but my friend Mr Parlett, a well-known successful Dorking breeder, tried the experiment, obtaining a bird for the purpose from one of the most successful, if not the most successful, exhibitor of modern Game fowls, whose birds are reared under ererr adrantage of free range and bealthy appliances. Of the offspring thus obtained $\mathrm{Mr}$ Parlett sent me specimens, in order to test on the table. I preferred keeping them in order to see what they would be when mature, and I can only say that in size and plumpness they are very inferior to such birds as would be produced br Mr Parlett's excellent Dorking hens if these were run with an old-fashioned Game cock. 


\section{CHAP'TER III.}

\section{DORKINGS.}

THE Dorking may be regarded as pre-eminently the English forl, which, in conjunction with the large Surrey and Sussex forls, has for mans gears supplied the best specimens of table poultry for the London markets. Before the era of competitive shows, the speckled and cuckoo Dorkings were those most appreciated ly the higrlers, who bought them for the purpose of fattening; but with the poultry exhibitions came the desire for increased size and uniformity of marking. The first was effected mainly by the action of $\mathrm{Mr}$ John Douglas, then poultry keeper to the late Dulic of Newcastle, who crossed the Dorkings with a large gres Kulm or Malay cock obtained from the Zoological Gardens, and subsequentls, by great attention to the selection of brood stock. sneceeded in perpetuating the required characteristics of comb and feather. It was in this way that the present race of exhibition Dorkings was made. It is hardly necessary to say that the desired size was accompanied by a degree of coarseness, loss of table qualities, and by greatl shanks. This latter was so pronounced that it even came to lee looked upon as a merit, and Dorking exhibitors used to expatiate on the excellence of their birds, concluding by directing attention to their legs, and saring, "There's bone!" But bone, unfortunately, is not eatable, and can onl ? be produced at a certain cost of nutriment, which had better be expended in forming flesh. I have alwars failed to see the merit of coarse bones in a table fowl, regarding them with no greater farour than a breeder would coarse legs in a Southdown. That the opinion now expressed is not a new one as far as I am concerned. mar be inferred from the fact that a quarter of a century ago, when writing in "The Poultry Book," I stated that "the alteration effected br Mr Douglas has influenced near! the whole stock of exhibition birds in Great Britain. In place of the rerry compact, short-legged, fine-boned breed of twent? 
rears ago, characterised generally l,y a speckled plumage, we now have exhibited a much larger breed, the hens being generally very dark in colour. . . . The advantages gained by the cross have been great increase of size and beauty of plumage. On the other hand, the original Dorking breeders maintain, with great show of justice, that the old strain are much superior as table fowl, being compacter in form, with shorter limbs and less bone."

At the present time white Dorlings are greatly in farour as exhilition birds, but, as was remarked by as practical an authority as Mr John Baily some thirty years ago, "white fowls have a tendency to jellowness in the fat, which renders them less desiraljo as market poultry." One of the best breeds of Dorkings has had its merits orerloolied in the present rage for fancy poultry. It is that known as the Blue or Cnckoo Dorking, which was formerly regarded as one of the best and earliest to fatten, but as it did not reach the size of the modem Exhibition Dorking, and as it was difficult to breed free from white feather's in the tail of the cocks and a tinge of yellowness in the hackles, in spite of their economical merits, they went out of fashion. They are still, howerer, to be found in many of the districts in Sussex, where the forls are bred for the higglers. Mr. Burnell, one of the most successful Dorking breeder's and exhibitors, acknowledged their merits in his little treatise on the Exhibition Dorking, saying: "The hens were really wonderful layers, and thongh for the table they did not reach the size of the Dark Dorking, their full breasts and juicy flesh, combined with their early maturity, rendered them most aeceptable in the larder. Ther are decidedly," he remarks, "a hardy breed."

The injurious influence of fancy shows has even extended to this variety. The editor of the Stock Keeper, writing on July 29, 1892, regrets the fact that to produce exhibition Cuckoo Dorkings two breeding pens are necessary, one to produce cockerels and the other pullets, as is the case with show Brahmas, Hamburgs, \&c. He says, if Cuckoo Dorkings are once more to make their mark, they must be managed so as to produce cockerels and pullets from the same parents.

It is needless to say that the extra toe, which is supposed to be an indispensable characteristic of the true Dorking, is a considerable drawback from a utilitarian print of view. It is an unquestionable deformity, the presence of which often leads to lameness and bumble foot. Although the modern show Dorking 
is not adapted to the requirements of the producer of fowls for the table, it may, by judicious crossing, lead to the production of cross breeds of very considerable ralue. What is required as a market forl is increased plumpness of breast, greater hardibood of constitution, and the power of producing a larger number of eggs than it does at present. All these requirements, conjoined with a less amount of useless offal, mar be obtained by crossing the birds judiciously. There is a breed of Dorking of somewhat smaller size, known as silver-grers, which were originally called Lord Hill's Dorkings, haring been produced many rears ago by that nobleman br crossing with the Duckwing Game. Ther hare been so closely bred for feather that the hare lost the hardihood and plumpness thes originally derired from the Game.

In confirmation of the preceding statements respecting the inferiorits of the present show Dorking to the birds that it has supplanted, I beg leare to quote the following passages from an article $b r$ one of the best known and most successful exhibitors of the lireed, Mr. O. E. Cresswell, who wrote as follows:

"The Dorking was formerly a more uniforml! square-shaped, short-legged, ronnd, deep-breasted, and white-footed bird than it now is. When exhibitions became frequent breeders found that judges of poultrr gare great weight to size and weight in Dorkings; indeed, at the Birmingham Shom ther used to weigh them, and in spite of the well-known rule about 'purity of breed, \&c.,' being rather taken into account 'than mere weight,' seemed to ignore many of the old points. Every tyro in breeding knows that a first cross gives increased size and weight ; naturalls, therefore, breeders - some through utter ignorance of the effects of crossing and of the rears it mar take to eradicate a taint; others from mere selfishness, caring alone for their own present success-began to try crosses. Their birds so produced won prizes, were bought as prize birds, and spread far orer the country; hence long legs, dark feet, want of breast, and manr defects which hare long been the trouble of the real Dorking fancier."-Journal of Horticulture, Aug. 25, 1881. 


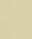



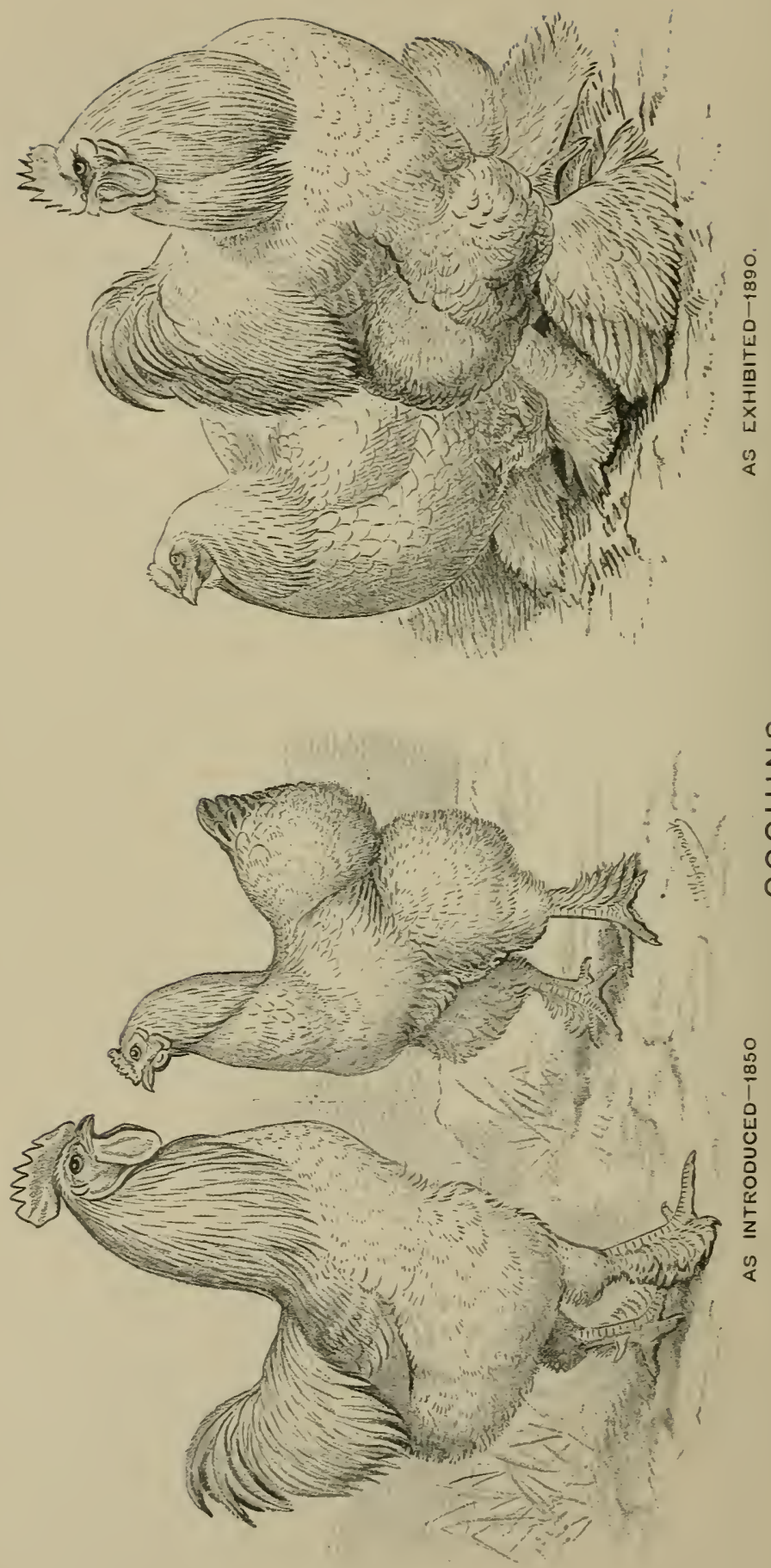


\section{CHAPTER IV.}

\section{COCHINS.}

The introduction of Cochins into England may be regarded as having given the first strong impulse to the now prevalent pursuit of poultry keeping. Previous to that time fowls were kept mainly for profit; but when the Cochins, the first specimens of which were exhibited about the year 1850, were first imported from Shanghai, their singular form attracted the taste of the public, and a veritable "Cochin mania" was the result.

The birds as first introduced differed from the previously known breeds of poultry in several characteristics. The feathers of the wings and tails were short, and the birds hardly capable of flight, being readily confined by a $3 \mathrm{ft}$. or $4 \mathrm{ft}$. fence. The feathers of the thighs and those on the lower part of the back were more abundant and fluffy than in any of the breeds known. The crow of the cock was much deeper in tone than that of the male of the ordinary rarieties. There were certain peculiarities of structure, such as a deep groove in the frontal bone, which leads me to suspect that these fowls might not have had the same origin as our ordinary breeds. The eggs were all a deep buff colour, and the hens were the most prolific of any varieties that were prone to incubate; in fact, when first introduced, they were absurdly credited with the power of laying two or even three eggs per day. I have now lying before me the record of the laying of four young Cochin hens, bred from the best of the imported birds; these in 1855 laid $570 \mathrm{eggs}$, and another set of four kept during the following year, 1856, under the same most favourable circumstances, laid $599 \mathrm{eggs}$, showing an average of 146 eggs per annum for each fowl. As each of these hens was allowed to rear one brood, and as one half of the eggs were produced during the six winter months, the result must be regarded as much more satisfactory than any obtained from show Cochins at the present time, whose food is employed in the production of useless feathering. 
As useful forrs, the strong points of Cochins on their first introduction were the early laying of the pullets, which produced their eggs in winter irrespective of temperature; the hardihood of the chickens; the ease with which ther could be kept within bounds; and their rapid growth to a large size. These adrantages led to their value being greatly orer-estimated. A great amount of nonsense was written about them, and it was eren stated by one well-known writer that a Cochin hen would be as valuable to a cottager as an ewe lamb. But the drawbacks to the atrantages ther possess are most decided. Their small wings and incapacity for flight are accompanied by a rery slight derelopment of the pectoral muscles; consequently there is little meat upon the breast, and when dressed the lieel of the bone is prominent and ugly. It is true ther make up, in the amount of flesh on the legs, what is wanting on the breast; but it is no recommendation to a table fowl to develop largely the inferior portions to the detriment of the finer parts. In the improved breeds of cattle the best joints are dereloped and the inferior lessened in size; there is small bone and very little offal. The same charicteristics should distinguish a table fowl-it should he as nearly as jossible all breast, with short limbs and fine bones. Again, the coarseness and yellowness of the shin and fat is a serious drawliack to the saleable value of Cochins, and unfortunately they accumulate large quantities of fat internall where it is useless, and scarcely fatten on the breast at all.

Nerertheless, from their large size, hardihood, and prolificacy many persons were induced, when they were first introduced, to tum Cochin cocks into their poultry yards with a riew to the improvement of the ordinary furmrard stock. Nerer was there a more fallacious idea; half breeds between the Cochin and the common barndoor fowl are about the least useful variety of poultr? that can be imagined-ther are gaunt. weedr, big-boned, angular, rellow-legged birds, as accurately represented br Braquemond on jage 6 ; and it is only requisite to ast the opinion of the poultry salesmen, and of the higglers who collect and fatten the fowls for them from the countre, to know the estimation in which such birds are held. At the present time the ralue of Cochins chiefly depends upon the hens being good sitters. Whatever merit thes possessed as profitable larers at the period of their introduction has been entirel bred out by those who hare reared them for the poultry shows. Cochins are now perhaps the worst layers of any incubating rariety. As inhabitants of a furmpard, the present race of show 
Cochins is utterly useless. The alteritions that have been effected in the breed mas be inferred from the illustration, which shows the birds as they were when first introduced as contrasted with the prize winners at the present time.

I stated in the introrluctory ehapter that Cochins, as at present exhibited, are a mass of useless feathers. Feathers consist of dry animal matter, having rery closely the same constituents as the dry animal matter of flesh. Flesh, on the other hand, is animal or nitrogenous matter mited with three times its weight of water. As far as feeding is concerned, it costs, therefore, as much in corn to produce $11 \mathrm{~b}$. of feathers ats $4 \mathrm{lb}$. of meat, and if the plumage of a Cochin weighs $\frac{1}{4} l b$. more than is necessary, or in excess of the weight of the plumage of other rarieties, the materials that would have made 1lb. of flesh have been wasted. And this waste is repeated at every annual moult. Is it surprising that poultry keepers who do not breed for the show pen complain of the enormous appetite of Cochins, the small amount of flesh, and the small numbers and size of eggs that there are to show for the food ther consume?

A writer in the Feathered World, May 15, 1891, published a long critique on an article on "Farm Poultre," written by me and published in the journal of the Royal Agricultural Societr. In this letter the Cochin is thus describerl: "The Cochin, a great, lumbering, elumsy bird, is about the worst stamp of a bird a farmer or cottager could have about the place, as far as profit goes. As table fowls when and where did they ever leat in a table-fow class the cross-bred birds of the present day, specially reared for the table? As soon as they have laid ahout a dozen or a dozen and a half of eggs, do they not show signs of becoming broody? As brooders they are certainly safe sitters, and as safe to squash the chicks as they hatch out. And what of their eating propensities? I am sure they will give any other Fariety of fowl a long start for the small comparative returns they give in eggs."

It is equally amusing and instructive to notice the energy with which each fancier denounces the uselessness of those breeds that are not to his liking. The "black sheep " of this writer are Cochins and Spanish, " neither of which varieties," he truls sars, "are good all round fowls for general purposes, riz.. ecro producers and fit for table." 


\section{CHAPTER V.}

\section{BRAHIIAS.}

As regards practical purposes, Brahmas may be regarded as identical with Cochins, from which they differ only in slight fancy characteristics, chiefly those of colour and marking. The breed was manufactured in America, there is no evidence whaterer that ther came from the banks of the river from whence they derived their name, no such hirds being known in the locality. The qualities of the Brahma as a profitable fowl, whether for the purpose of producing food, eggs, or for crossing with other breeds, are identical with those of the Cochin. Like the latter breed, it has since the time of its first introduction been largely influenced by being reared as a fancy fowl. Exactness of colour and marking has been secured, abundant fluffy plumage has been obtained, and this in conjunction with greatly increased size. My friend the late Richard Teebas, well and farourably lnown as a judge of poultry, had a Brahma cock in his yossession that was brought over from the United States, where the breed originated, in an egg, which was afterwards hatched in this country; this bird attained the remarkable weight of upwards of 17 lb.

As a market fowl, the Brabma cannot be recommended. It is deficient of meat on the breast, has large, coarse legs, and is not of high quality. The public are beginning to tire of these large and comparatively useless breeds, and in the poultry journals of the day there are loud lamentations orer "The decadence of the large breeds." In these letters, however, there is no assertion of any value that they possess as useful poultry, they are mourned over only as fancy fowl; bred for the purpose of obtaining prizes. One of the largest breeders, writing of them, laments that they will be less and less shown until larger prizes are offered and corresponding higher entry fees resorted to.

The alteration which has been effected in this breed since its first introduction in 1850, is shown in the engraving. From the 

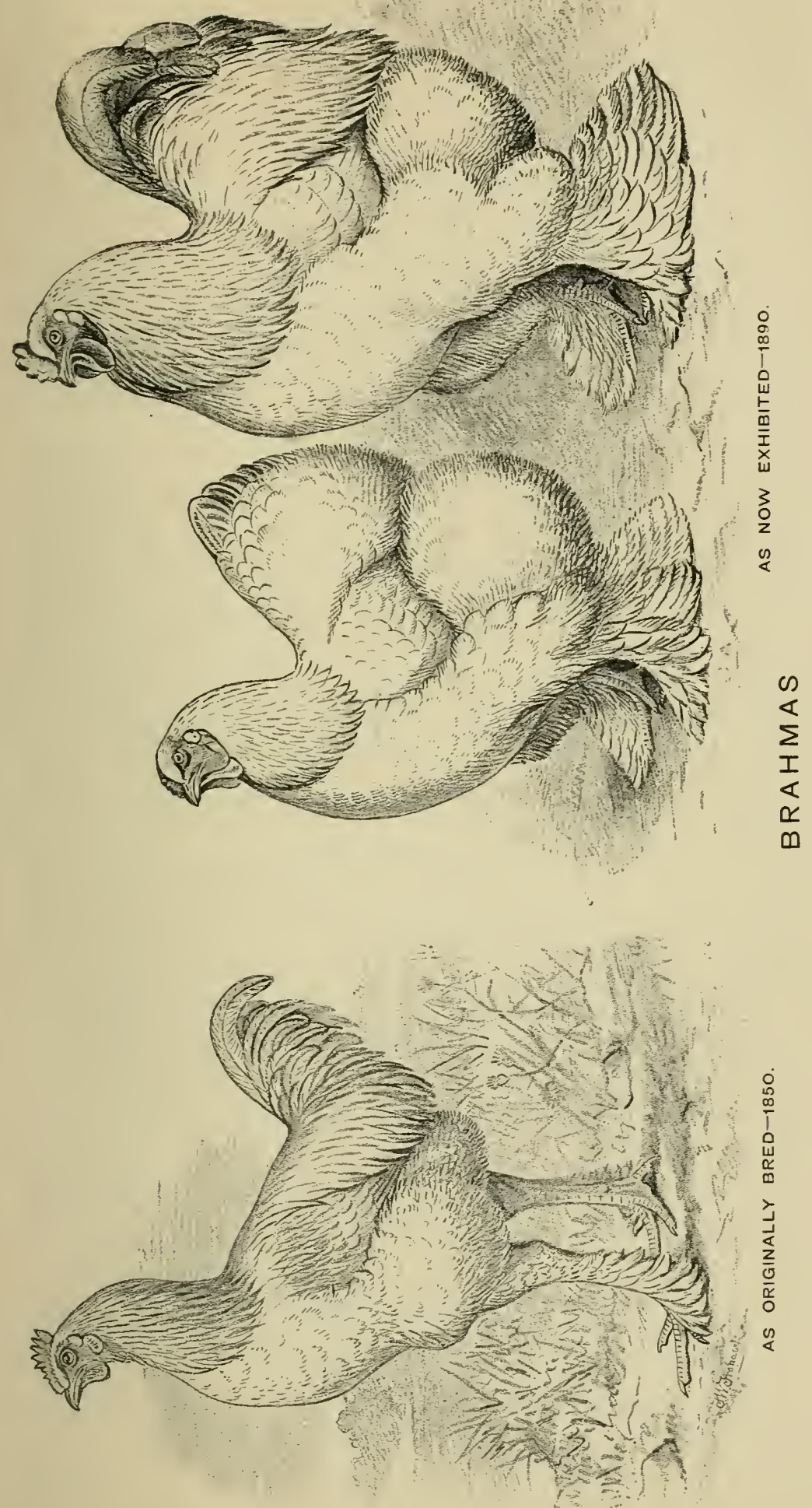

original fowl of the Cochin trpe, slightly modified by crossing with an American variety, the birds have been altered into the form shown in the other two figures. The effect that lias been produced has been most disastrous as far as regards any practical merits that the birds ever possessed. Mr. Norris-Ely, one of the strongest adrocates of this breed, writing in The Feathered World of July 3rd, 1891, speaks of the alteration of the birds as being most effective in the show pen as far as appearance is concerned, but adds that this has been produced by sacrificing the laying power and fertility of the strain, and the Stockiceper, in some articles on this variety, states as follows:

"The Brahma used to be considered the farmer's fowl, because of its immense size and goed laying properties in the winter months, when eggs are scarce, but now under altered conditions it is 110 longer regarded as such. A few years ago $141 \mathrm{lb}$. to $16 \mathrm{lb}$. was no uncommon weight for a Brahma cock, but now 12lb. is very rarely attained, and is the exception rather than the rule; one other craze has tended to detract from the useful properties of the Brahma for farm purposes, and that is the quantity of feather on its legs and feet. The present requirements of these two characteristics in the show pen, viz., colour and feather, have transformed the Brahma from the farmer's into the gentleman's fowl, making it now chiefly to be regarded as purely a fancy bird."

Another point which renders the Brahmas aud several other show varieties utterly unfitted for practical use is the fact that in order to breed birds that are successful at shows two distinct breeding studs are required, one for the purpose of providing show cockerels and the other for breeding pullets. Of course this point is not generally known to the public at large. Amateurs think that like will alwars produce like, and that chickens will resemble their parents. Thes go to a show, buy prize or commended cocks and hens, mate them together, and are surprised that they can neither lreed show cockerels nor show pullets from the pair, being ignorant of the fact that separate studs are required to produce birds of different sexes in order to win. In confirmation of this statement I would quote again from the Stock Keeper, the editor of which, in writing on Brahmas, says:

"Another point that has perhaps had some influence on the seeming decrease of the popularity of the breed is, that separate pens are required for the breeding of show cocks and hens, which refers more especially to the dark variety, where it may be said 
there are two distinct sections, and need to be kept as distinct as even darks and lights themselres. It is here that the anateur is at sea. He naturally thinks that by mating the hest exhibition cock with the best exhibition hen be is likely to get offspring of the best kind. Suffice it to say this is an entirely erroneous impression. The proper mate for the best exhibition cock is never seen in the show pen. Her modest garb and cloudy markinss would not grace the wire cage of the show bench; nor would, on the other hand, the proper mate of the best exbibition hen satisfy the judges in their requirements for a typical show cock."

The uselessness of such hreeds for practical prurposes need not be insisted upon.

Unfortunately this inutility is not confined to Brahmas, but extends to nearly every rariety lired for the show pen. That this is recognised by all intelligent fanciers may be regarded as proved hy the following quotation from the treatise on "The Leghom Fowl," by Mr. L. C. Verrey, Honorary Secretary of the Leghorn, Plymouth Rock, and Andalusian Club. In this the author states that

"It would be tolerably easy to mate a pen for breeding purposes if it were possible to get cockerels and pullets of equal quality from the same parents, but it is the same with Leghorns as with all other hinds of fancy poultry where colour and marlings are the luimary points. It is necessary to have two pens, one for breeding males and the other for females." 


\section{CHAP'TER VI.}

\section{L.NGSHANS, PLYMOUTII ROCKS, AND WYANDOTTES.}

\section{Langshans.}

The Langshans are another recently introduced Asiatic breed. These, when first imported, were so closely similar as to be almost identical with black Cochins, with which they were generally confounded. The latter were not unfrequently exhibited in the classes for Langshans, and won prizes. The breeders of the latter variety, however, maintained their distinction and bred for different points, selecting their stock for hardness and brilliancy of plumage, and claiming for the birds the possession of useful qualities as table fowl. The result has been that the birds have considerably altered in type since the time of their first introduction, and may now be regarded as the most profitable fowls of any of the recently introduced Asiatic breeds. They have larger wings, and consequently require larger breast muscles to move them, than either Brahmas or Cochins, and, not having been bred for superabundant and fluffy feather, they are better layers; but with all these advantages they fail to be a first-class market fowl, and, in the numerous opportunities I have had of contrasting the birds at shows of dead poultry, I have never seen Langshans exhibited that could be regarded as of high quality as market or table fowl, although I have had to give prizes to some in classes where the competition was limited. The qualities in which the Langshan excels the Cochin have, in the opinion of some of its admirers, been produced lyy crossing with the Game. Miss Croad, writing in Poultry, April 3, 1891, states that the best proof we have of this is the account $\mathbf{M r}$ Housman gives of the strain he favours as a judge. He says, "I find as a rule that those birds that are tall and tight-feathered have a much better breast of full solid meat than those that are short and fluffy; the flesh of the latter is much more spongy in character, and the tight-feathered birds I always find are much more hardy 
and healthy than the soft-feathered ones." Ans more satisfactory opinion of the inutilitr of hearil r-feathered fluffr fowls for table or market purposes could hardly be required.

Some of the birds shown as Langshans are quite destitute of feather on the shanks; these hare been exhibited, both before and after haring been crossed with other varieties, under the name of Orpingtons.

\section{Plimouth Rocks.}

The tendency of the present srstem of exhibiting poultry is to lead to the production of new lreeds, ol,tained br crossing the older rarieties. When these have been so far established as to breed tolerably true to the desired form and colour, which may be accomplished in the course of three or four generations, they are exhibited, and, if well puffed, command high prices as fancy stock, are lauded far berond their merits, and become for a time the rage. The introduction of the breed called Plymouth Rocks is a good example of this method of procedure. The present Plymouth Rock is a cross between some of the Asiatic rarieties and the cuckoocoloured fowls which are common in America, and are known as Dominiques. Like all breeds that have been recentls produced by crossing, the Plrmouth Rock is hardy and a good larer for a sitting rariety. Its recent origin is shown by the fact that a large portion of the chickens do not breed true to colour, but come black in place of being cuckoo-coloured. As a prolific bird for rough household purposes the Plymouth Rock is not without its use; but as a fowl for the market it is onlr necessary to ask the opinion of the Surrey fatteners to learn its real ralue. I have only seen at the shows of dead poultry one first-class couple of Plymouth Rock chickens, and as their legs were white in place of being yellowthe normal colour of the breed-their purity was doubtful. One great characteristic of the Plrmouth Rock is the brilliant yellow colour of its skin. This is regarded as objectionable in a market fowl in this country. In America, where the breed originated, fowls are much more frequentls used as "broilers" (riz., chickens spl]it down the back and grilled) thin in this country, and the colour of the skin is not regurded as objectionable. It is singular that the fashion should have set in so strongly in farour of this breed, when a far superior rariety, with the sane markings, but with white skin and legs and better breasts-namelr, the Scotch Grey-was already known in this country, and is a bird much 
superior as a table fowl. The Plymouth Rock cannot be recommended to those who breed for the market.

\section{WyaNDOTTES.}

At present another recently manufactured variety is coming rapidly to the front, which, like the Plymouth Rock, has its very distinctive markings to recommend it. This breed is known as the Wyandotte, which has been made by crossing the Brahma with some of the varieties of fowls that possess what is called the laced plumage - that is to say, having the feathers margined by a black band, like a mourning envelope. As a table fowl, the Wyandotte prossesses the characteristies of the Brahma, but as an egg producer it is superior to that breed in consequence of the rigour imparted by the recent cross; hut statements that have been reeently circulated as to its extreme prolificacy are such as no practical poultry keeper can aecept. It is doubtful whether any experienced breeder for the table or the market would attempt to utilise such a strain; but it is only fair to state that the Wyandotte fanciers are strenmously endeavouring to hreed good birds for the market, and are offering prizes for the best deal Wyandottes; but why thes should hamper themselves with breeding for feather if ther desire to raise market fowl it is diffieult to perceive.

In a letter which appeared in the Field of October 24th, 1891, respecting this effort, I stated that:

"By dint of careful selection for the last few years, Wyandottes have been bred very closely up to the required standard of feather; and, having done this, it is much to the credit of the fanciers who constitute the North of England Wyandotte Association, that they have turned their attention to improving the breed as a table fowl. They resolved that classes for table fowl should be provided at their next show; and in their report they have recognised the truth of the remarks that I have made about fancy poultry, as hitherto exhibited, and establish these classes for the purpose of doing, as they say, good service to the breed.

"'The Countess of Bective, the rresident, supports the Wrandotte as an all-round fowl, and considers that if the useful qualities of the breed are not eultivated, and too much attention is paid solely to fancy points, its popularity will soon be on the decline; hence the establishment of these table-fowl classes, for Wyandottes only. 
"I was much gratified at the fact that the hom. secretary, Mr. W. H. Midgley, wrote to me requesting to be allowed to reprint an article of mine for circulation amongst the members, so that all those intending to compete might be placed on an equality as to the instructions for preparing and killing their fowls. I shall be greatly interested in the result, as the ohject of the society is not to adrance the Wyardotte as a show bird onl useful properties which they believe it to possess.

"I believe this to lee listinctly a step in the right direction with regard to fancy fowls, and it is a source of gratification to me that even one class of fanciers has recognised the value of the views I have adrocated for so many years."

This meritorions attemp, on the part of the Conmittee of the Association only resulted in showing how difficult it is to unite the aims of the fancier, who breeds for show points, with those of the rearer for the table and the market. The classes of Wyandottes shown as dead table fowl did not receive the support anticipated. The members said that all their time was occupied in the preparation of their live birds for the show, and that they had no time to derote to the production of birds for the table. Consequently out of 237 entries in the Wrandotte classes at York, only seren entries were made in the table class for cockerels, and the class for pullets was cancelled, there being onl two entries. As I have said before, Wyandottes are evidently becoming exceedingly popular amougst the breeders of fancy fowls, but whether the breeding for laced feathers is compatible with rearing good table birds, is a point on which I entertain much doubt, although I camnot deny the Association great praise for endea vouring to combine the qualities of table and fancry fowls. 


\section{CHAPTER VII. \\ MALALS, INDIAN GLIIE, AND ISEELS.}

MALAYS.

BEFore the introduction of the Cochins and the Bralmas, the Nalay breed had long been known in this country. Birds were frequently brought home by the ships arriving from Further India, and sold to the dealers in the neighbourhood of the docks of both Liverpool and London. Although not remarkable as prolific layers, Malays were not without their use in increasing the size of some of our breeds. I have already spoken of the introduction of a grey Malay or Kulm cock strain into onr modern breed of colourecl Dorkings; but this size wis accompanied with a considerably increased length of leg aud coarseness of bone, which can only be regarded as objectionalble in fowls bred for the table.

Unfortunately for the practical value of the Malay breed, the fanciers demanded long-legged birds, and instead of the extreme length of leg being diminished, it was exaggerated br the influence of poultry shows, the points aimed at being a long, closely, feathered snake-like neck, and extremely elongated legs, with rery scants, hard plumage, which rendered these attributes more evident.

\section{Indian Gane.}

In the south-west counties of England another rery useful breed allied to the Malay has long been known. It was formerly termed the Pheasant Malar, but is now lnown as the Indian Game, which is an unfortunate name, as the lind is not a Game cock, nor even the fighting cock of India; but it has been largels exhibited under this title, which is not now likely to be aitered.

The Indian Game mar be described as a short-legged Malay, rery plump and meaty on the hreast, with close, hard plumage, an absence of any offal in the shape of comb or superfluous feather, and altogether a most valuable table fowl, wanting, however, the 
white skin of the Surrey fowl, which is so highly esteemed in the best table poultry. Its fault is a tendeney to length of leg and neck, which is rendered more evident by the closeness of its plumage. I hare adrocated for sereral rears the crossing of this breed with the Dorking and the Surrey fowl to produce hirds for table purposes. It has recently come into fashion as an exhibition fowl, and in consequence has become better known; but the circumstance has not been witbout its most serious drawhacks.

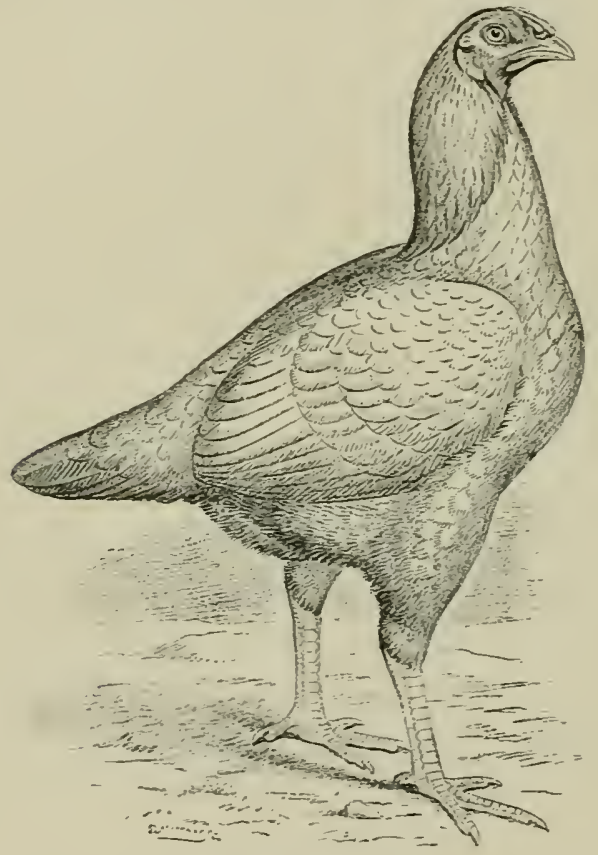

Ixdiax Gane Hex.

Indian Game as now exhibited are judged, not from their economic value, their short legs, plump breasts with abundant meat, but from their markings. To win prizes at competitive shows, the hens must have laced or margined feathers, like those alluded to in speaking of the Wrandotte. The result of this attention to fancy points is that the show Indian Game are now bred for their laced feathers, their plumpress and valuable table qualities leing ignored, but good Indian Game not bred for this particular marking of feather 
are rery generally distribnted in Devonshire and Cornwall, and may be obtained of many of the small farmers and cottagers in those counties. In selecting Indian Game for crossing laced feathers should be ignored, and birds with tight, hard plumage and very plump, broad, meaty breasts should alone be chosen.

The engraving shows an Indian Game hen of very good form, liaving the scants plumage and prominent breast characteristic of the variety. As an indication of the effect of competitive shows on the breeds of poultry, I may state that on showing this engraving to one of the best known of our poultry judges (the late Mr. Nichols), he remarked that it was one of the best representations of an Indian Game hen that he had ever seen, but that the fanciers would object to it as being too prominent in the breast and not sufficiently feathered in the neck, these points being those that are indicative of its merits as a table fowl. The outline of the bird was copied from one by Mr. Ludlow, which was published in the Feathereal World.

\section{A SEEL.}

The true Indian fighting cocks, known as Aseel, have been for some vears introduced into this country, and have been carefully bred by a few amatemrs. They differ considerably from what are termed the Indian Game, being smaller in size, and eren more prominent in breast. In proportion to their apparent bulk, thes are the heaviest forls I hare ever handled; the amount of meat upon the breast exceeds that of any other breed. But as profitible poultry they have important irawbacks. The hens lay very few eggs before they desire to sit, and the cocks are more combative than any other known rariety. Their courage and obstinacy in fighting know no bounds. The young cocks will fight while little chicken, and when they can no longer stand will lie upon the ground and peck at one another. These qualities greatly interfere with their value as profitable poultry; but an Aseel cock crossed with Surrey or Dorking hens produces chickens, the quality of which as table fowls cannot be surpassed, although in size they do not equal the cross-bred Indian Game and Dorking. 


\section{C'HAP'TER VIII.}

\section{THE FRENCH TABLE BREEDS.}

\section{Houdans, Crèvececrs, and La Flèche.}

Ix France much greater attention is paid to the ralue of poultry as furnishing a supply of chickens and eggs for the table than is done in this country. The more recent Asiatic breeds are not in demand. The favourite French races are the Hondan, the Crèreceur, and the La Flèche. These are all characterised by good quality of flesh, plumpness of breast, and absence of offal. The Houdans and Crèvecœurs have been rather extensively cultivated in England, while the $\mathrm{L}_{\mathrm{a}}$ Fleche, which furnishes the finest table prullets that are seen at the shows of dead poultre in Paris, has been nuch more rarely kept in this country, where it is regarded as somewhat delicate.

\section{Hotdaxs.}

The Houdan, since its introduction into England, has been largely exhibited, classes for it heing found at most poultry shows, and it has become to a greater or less extent a fancy fowl, being bred for size of crest and regularity of marking. The original French Houlan would at the present time have no chance whatever in a show of fancy poultry in this country. To win prizes in England the feathered crests must be larger than in the French birds, and the plumage more regularly spangled.

The engraring shows the original Houdan figured twentyfive rears since by the celebrated painter Jacque, an experienced poultry leeper, and the author of "Le Poulailler," as a full chested, moderately close-feathered, useful fowl for the talle and market, in contrast with the full crested, loose feathered English show lirds that are almost unable to see to feed. Haring been bred for some rears solely for fancy points, the size and good qualities of the Houdan have been greatly lessened, and it is not now in the favour in which it used to 


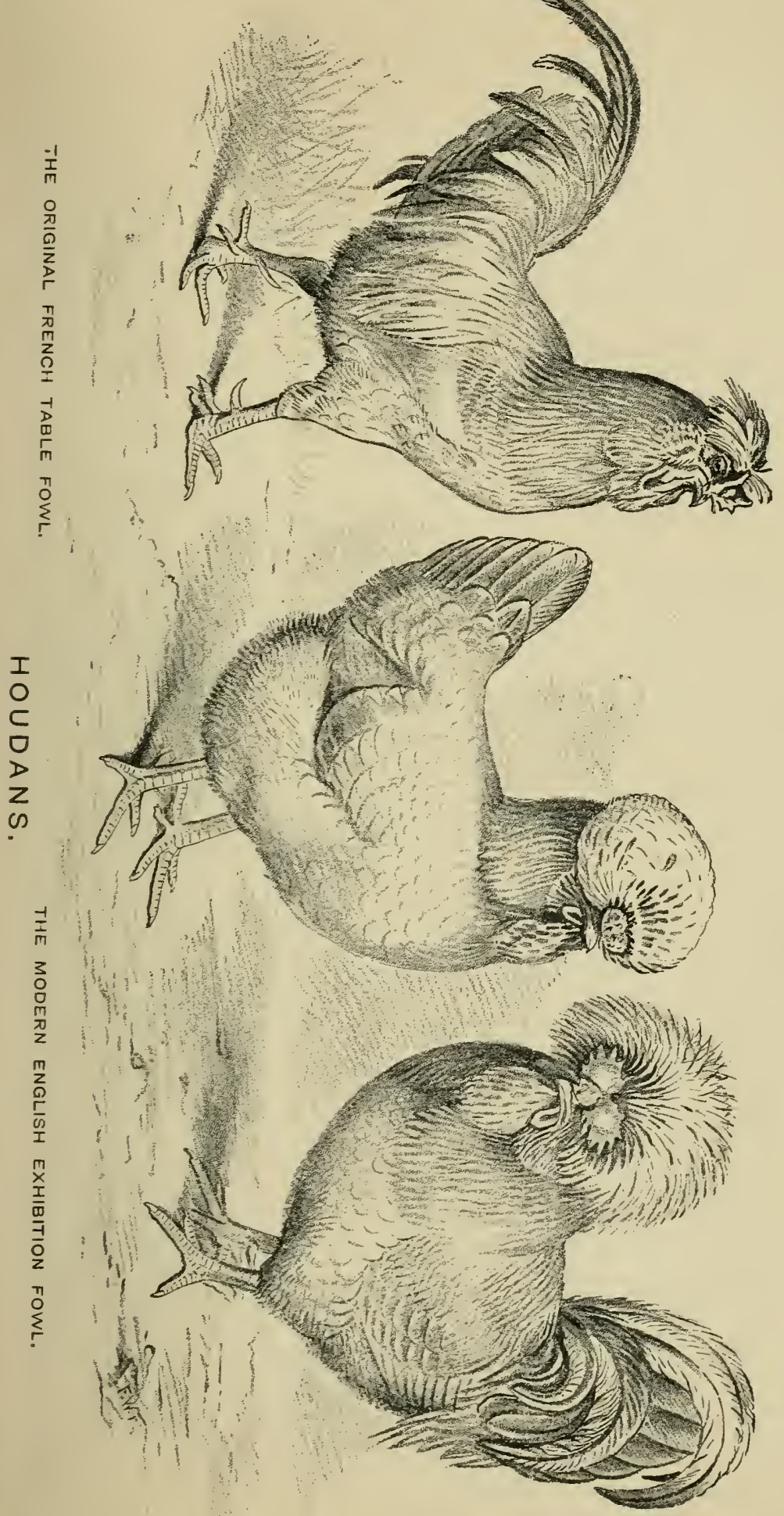



be held in this country. As a farmyard forl, the modern Houdan, with its huge crest, is useless. In addition to being grood table fowls, the Houdans in France are regarded as good lasers of large white eggs; like the Dorking, it has an additional toe, which is not of the slightest recommendation to it from a practical or economic point of riew.

\section{Crìteceurs.}

Closely allied to the Houdan, but entirely black in plumage, and of somewhat larger size, is the Crèrecour, which is regarded as furnishing some of the best table fowls that appear in the markets of France. The Crèrecoeur is said br M. Jacque to be the best race in France for the delicacy of flesh, rapidity of fattening, and early maturity. The injurious effect on useful varieties, that is the result of breeding for points which are appreciated in the show pen, is adinirally instanced in the following statement by the late Mr. Nichols, the editor of the Stock: Keeper, well known as a most practical and reliable authority. Writing in that journal for July 10, 1891, he states: "We have often felt that Crères are hard!y as appreciated as they should be. Many years ago, at the breal up of the National Poultry Company at Bromley, several specimens of this variety fell into our possession, and we found them very excellent and free lavers of large eggs, but these specimeus, we should sar, were not very hearily crested, and as soon as we bred them for larger and more globular crests, we lost much of the laying virtue. The other day at the farm of the Ayleslury Dairy Company, Horsham, we saw a large flock of these handsome fowls, which, although possessing good heads, had nothing vut of the way in the fashion of 'top-knots.' As this company goes in for profit only, we should sulpose that the managers have also experienced the same results that we did, and we should be glad to see the breed more largels cultivated for its profitable merits apart from its exhibition points."

I do not desire any stronger confirmation of the correctness of the riews I have long maintained regarding the influence of breeding for the show pen than is in this rery important quotation.

Those who are acquainted with the value of the Crivecours as table fowls in France, may possibly have been surprised at their want of appreciation in this country. Had they been bred, bowever, as useful poultry, they would not have been so slightly appreciated; but the object of the English fancier who breeds for 
the show pen has not been the supply of large plump-chested table fowls, which are also layers of exceedingly large eggs, but the production of large globular crests perfectly free from white feathers, and to this crest has been sacrificed the useful qualities that on the other side of the Channel characterise this valuable breed, which has been described by M. Jacque as being the best race in France for delicacy of Hesh, for rapidity of fattening, and early maturity.

About thirtp-five rears since, when I was first experimenting

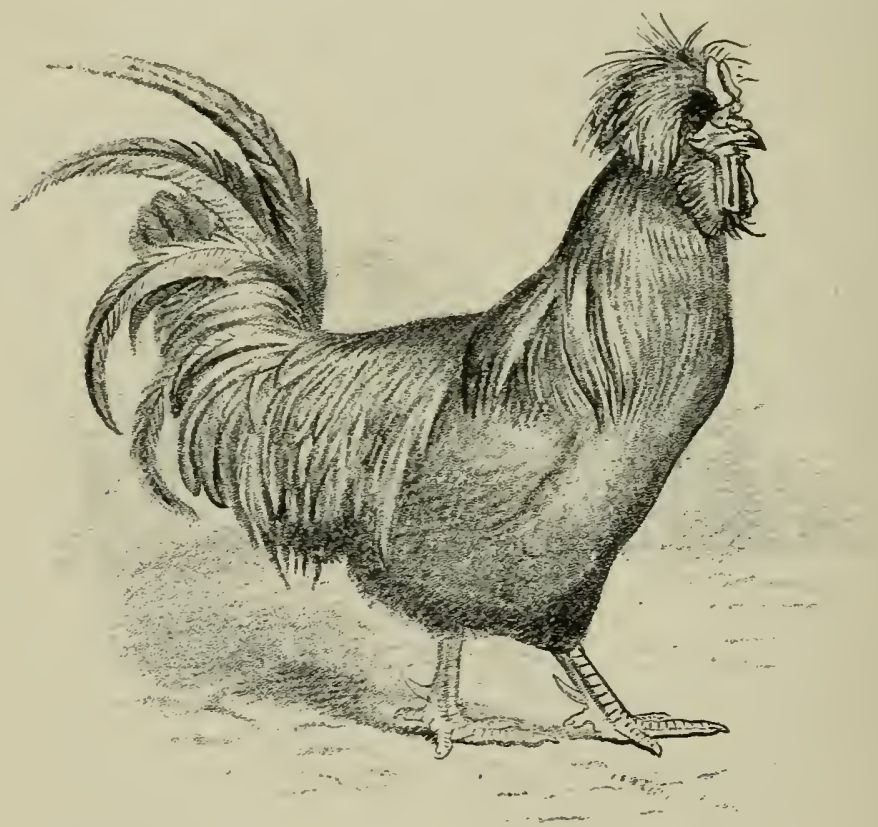

The Original Frexch Crèvecteur, after M. Jacqee.

with cross-bred table fowl, I entered some cross-bred Crèvecœurs in the variety class at the original Crystal Palace Show, when Messrs Baily and Andrews were the judges, in the vain and delusive hope that their size, plumpness, and good qualities as table poultry might commend then to the notice of the adjudicators. It was, I think, the first intimation I received in the lesson $I$ hare since learned so perfectly, namely, that the usefu] and edilile qualities of fowls are altogether ignored at poultry shors. 


\section{La Flìche.}

The La Flèche differs from the two previous breeds in having but few crest feathers on the head, and eren these are frequently alssent. The comb consists of two pointed horns, which should be but small. In the La Flèche bred in this country, exhibitors have ignorantly tried to increase the size of the combs, apparently not being aware that large combs, although they show that the birds possessing them are good layers, also indicate that they are not

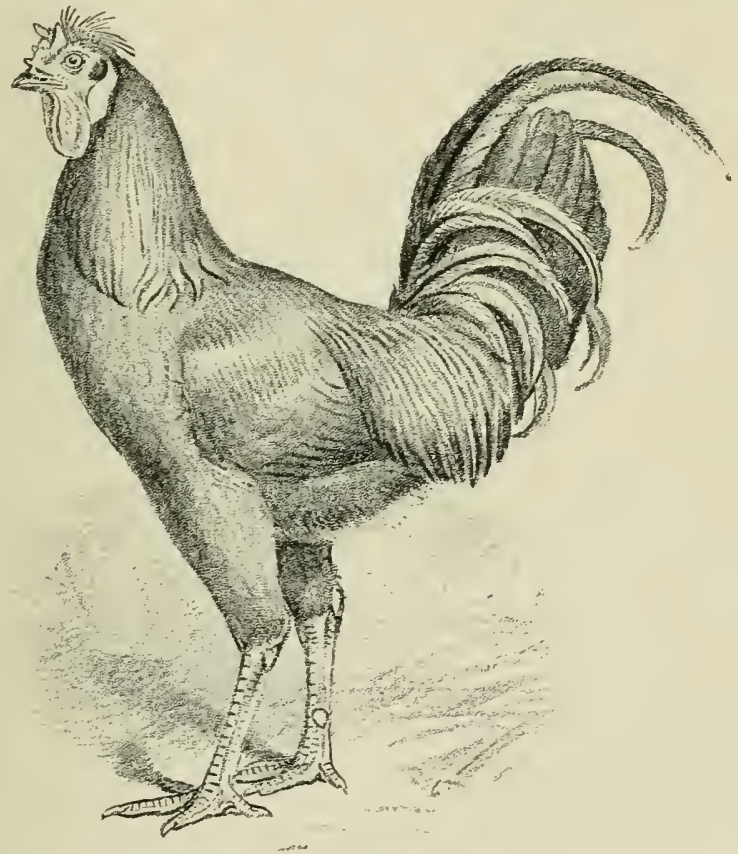

LA Flèche Cock, after MI. Jacque.

readily fattened. In this country the La Fliche are generally regarded as being difficult to rear, and, although repeatedly introduced, the breed has not maintained its ground. In France, on the contrary, the pullets of this breed generally take the highest Irizes at the annual show of dead poultry at Paris, and when fatted on buckwheat meal and milk they are of the highest possible excellence. 
The form of the La Fliche, as will be seen by the engraviugs, which are accurately copied from those of M. Jacque, differs considerably from that of the Hondan or Crèrecœur. The fowls are larger, much closer in plumage, and conserquently appear longer on their legs. When dressed the skin is exceedingly white and of fine quality, and the breasts are rery plump and meaty. From the experiments I made in cross-breeding with Crèvecours, to which I liave referred in the former part of this chapter, I am inclined to attribute the origin of the La Fliche to a cross between

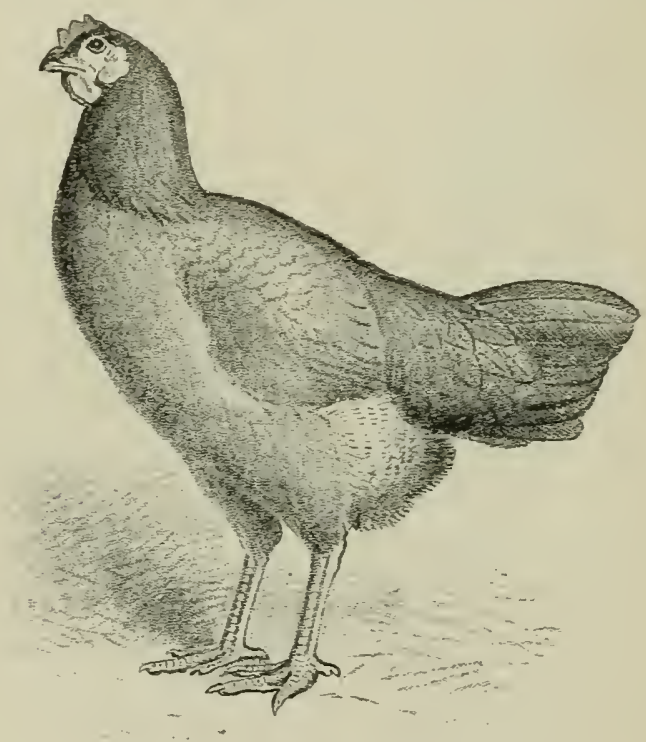

LA FLÈCHE Hex, AF'TER M. JaCQUE.

some of the older feather-crested breeds and a Malar. The peculiar structure of the nasal bones and the two-horned comb showing the crested parentage, and the plumage and general form the Malas blood. And I feel assured that there would be no difficulty in producing a most valuable and hards table fowl on the same lines by crossing Indian Game or Malay with a good useful French Crèrecœur, and carefully selecting the chicken for a few years, taking care not to interbreed. 


\section{CHAPTER IX. NON-SITTING VARIETIES.}

Spanish, Minorca, Andalusian, and Leghorn.

In those situations where the production of eggs is more remunerative than the rearing of table chickens, it will be found advantageous to keep varieties that are non-incubating, as in these the continuous production of eggs is not interfered with by the hens becoming broody, and losing time in sitting, or in the desire to do so. The most profitable non-incubating varieties of fowls are unquestionably those that have been introduced into this country from the shores of the Mediterranean. They are known under the names of Minorcas, Leghorns, Andalusians, and Spanish, and are all birds of one well-marked type, though varying much in colour and minor peculiarities. They are characterised by large, flat, indented single combs, which are upright in the cocks, but, from their thinness, fold over to one side in the hens. They are all apt to be somewhat long on the leg, and very deficient of flesh on the breast, hence they are not of high excellence as table fowl. They are distinguished by the presence of white fleshy lobes of slin under the ears (the ear-lobes as they are called by fanciers). In the Spanish, the oldest of the races known in this country, this white extends up to the comb over the whole face, which in the wher breeds is red.

\section{SPANISH.}

The Spranish fowl is a remarkable example of the effect of competitive shows, on what was formerly a most useful breed of poultry. For many years the fanciers have bred this variety for perfection of face, which, in the exhibition birds, must be purely white, without the smallest speck of redness visible on its surface. The white ear-lobe has also been enormously developed so as to become $3 \mathrm{in}$. or 4in. in length, and capable of being extended 
laterally almost to the same width. The comb is of preter. natural size, deeply indented with litrge serrations, perfectly upright on the head in the cocks; whilst in the hens it is correspondingly enlarged, but folds over one side of the face, hiding the eye. In order to obtain these results the lirds are most artificially treated. They are not allowed to gro into the sunshine, lest it spoil the whiteness of the face. They are kept in a high temperature in order to develop the facial appendages to the greatest possible degree, and to prevent the combs being frostbitten. The result has been, as far as regards the useful properties of the bird, that it has become stilted, small in size, weakly in con-
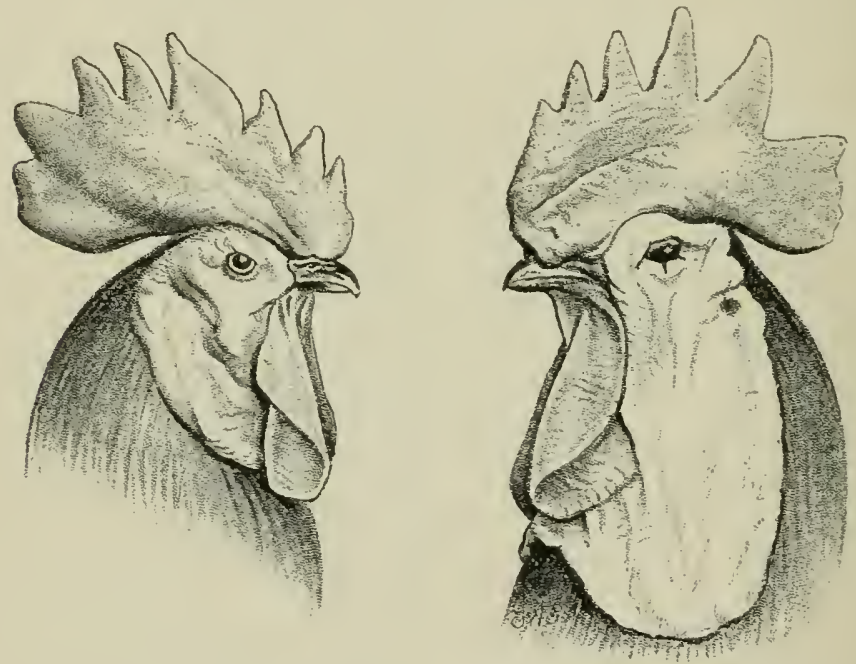

SPANISH COCK, AFTER M. JACQUE.

Spaxish Fowl as now Exhibited.

stitution, and almost useless as a layer. The most prolific black Spanish, that were formerly to be found in many farm and stable yards, are things of the past. The show birds are so useless that no one but fanciers will keep them, and as profitable poultry the breed has passed out of existence; in fiat, so few are now kept that in many of the ponltry shows no classes are inserted for them in the schedules. The extraordinary development of this breed in fancy characteristics, combined with its extinction as a useful fowl, is the natural outcome of the present system of competitive shows for fancy poultry. This opinion of mine regardiug the influence of 
shows on the Spanish as useful forls is one that I have long maintained. Writing in the year $1869 \mathrm{I}$ stated "Whatever competitive shows may have done for other breeds, they have certainly materially lessened the value of Spanish as useful fowls. In the place of the large, prolific, hardy breed which was formerly known under that name, we have a smaller race, very leggy, and feathering with such slowness that chickens are often seen in prize pens that have not produced their tail feathers. In fact, the useful qualities of the race have been neglected in breeding for face and ear-lobe."

In commenting upon my remarks on this breed in my introductory chapter, the late $\mathrm{Mr}$ Nichols, a trustworthy authority, writing in the Stockikeper, maintained that I harl overstated the case against the present race of Spanish fowls, that the prize winner that I had described as being absolutely sterile had really laid one egg, and that the lreed was not as delicate as I alleged, as he had kept high class show birds in an open shed during the past winter, the cock haring suffered no further injury than the loss of part of his comb and the ends of his toes. I expressed my thanks to the writer for his correction of my statements; but whether a hen lays one egg or none, is not of great impertance as regards profitable poultry. Nor can I regard the hardihood of a breed as demonstrated by the fact that a cock only loses part of his comb and the ends of his toes during the winter.

\section{Minorcas.}

In the south-west of England, particularly in the counties of Cornwall and Devonshire, a black fowl related to the Spanish is very frequently to be seen in the farmyards and around the homesteads. This is the Minorcat, a larger and more profitable fowl than its more aristocratic relative. The Minorca, as it existed a few years ago, was a larger, more compact, shorter legged bird than the Spanish, infinitely more robust and hardy. The face, unlike that of the last-named breed, was red, the ear-lobe only being white. The Minorca is a non-incubating variety, laying an abundance of large white eggs. The hens rarely, if ever, sit; and the pullets, if hatched early and well fed during the winter months, can be depended upon for a supply of eggs during the cold weather. As egg producers, as distinguished from table birds (for as market 
fowls they have slight value, though, of course, useful for home consumption), it is doubtful whether any breed would excel the old farmyard Minorca. At the present time it has, unfortunately for its economic value, got into the hands of the poultry fanciers, and at the shows classes for Minorcas are large and well filled. It is needless to say that the egg-producing qualities cannot be recognised in the show pen. What is bred for is, first and foremost, an unnaturally large, regularly toothed, and upright comb, which is 3in. or 4in. high in the cocks, and immaculate white enrlobes in both sezes. The eleration of the Minorea into the digrity of an exhibition breed is, in the interests of profitable poultry keeping, much to be regretted, for in the course of a few years the will probably have rivalled the Spanish in their sterility and uselessness, and we may hear of Minorca hens like those of the Syanish breed, taking first prizes that have never laid more than a single egg. The effect of the show srstem on this most useful breed was rery plainly set forth at a recent meeting of the Exeter Poultry Society, when Mr. J. Physick gave his experience of eighteen years with the Minorcas, and showed how ther had been changed from short-legged, square-bodied useful birds, into others which possessed, to use his own words, "the long shanky legs of the modern show game fowl," with large ear-lobes and enormous combs.

\section{Andalusians.}

Auother breed of the Mediterranean type, differing mainly in colour from the Minorea, is that known as the Andalusian. It was formerly of a slater-grey, blueish tint; but as now exhibited it is required to be shown with a dark lacing or edging round each of the breast and body feathers. Allowed a free range, and bred from parents that have not been reared in close confinement, as is the case with large numbers of show fowls, Andalusians are most profitable layers of large white eggs, rivalling the Minorca in this respect. The pullets when hatched early are good winter layers, and had as much troulle been taken in breeding from the most prolific instead of from the best-feathered hens, it is doubtful if any breed would have been more advantageous as egg-producing fowl. 
1) 2 


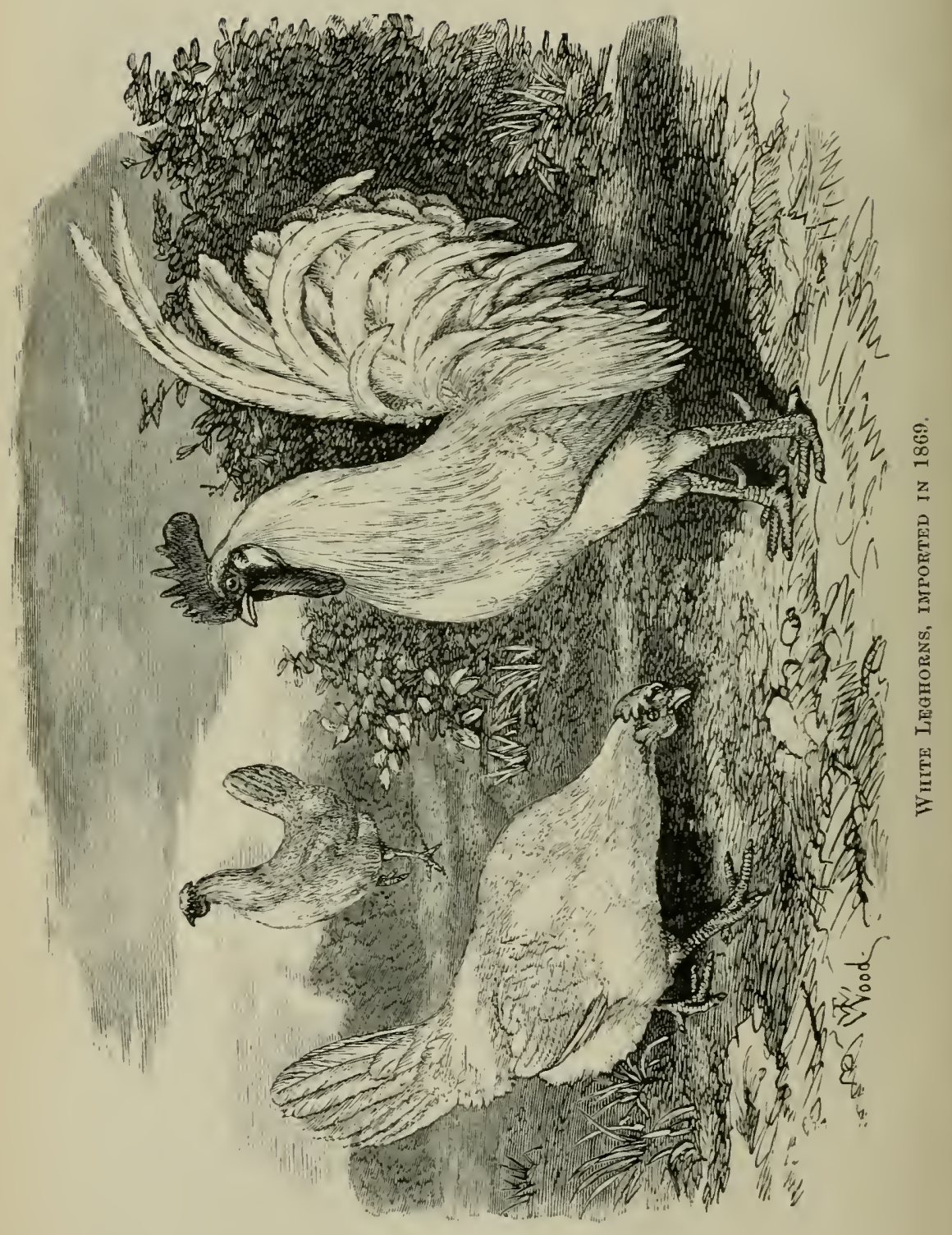




\section{LEGHORNS.}

Another breed, which obviously originated on the shores of the Mediterranean, is the Leghorn, which was first known as a yellowlegged, white-plumaged variety. The birds shown in the engraving were those first introduced into this country by myself from America in the year 1869. The Leghorn is also a non-sitter, and a most prolific layer of white eggs. It has lately come into greater fashion as a show fowl, and various colours have been dereloped in the plumage. The so-called brown Leghorns have been made by crossing with black-red game, and recently a breed, with much white in its composition, called Pile Leghorns, and other colours, such as Black, Buff, and Cuckoo, have been produced. Leghorns are generally smaller than the Minorcas or Andalusians.

The engraving is a very accurate representation of the first trio of White Leghorns which were imported to this country by myself in 1869. Not having been bred for show points, they were most prolific, and promised to become a very useful addition to our egg-producing breeds; but, having been raised to the dignity of an exhibition fowl, more attention has been paid to their white ear lobes and serrated combs than to their prolificacy. 


\section{CHAPTER X. \\ NON-SITTING AND OTHER VARIETIES.}

\section{HanBurgs.}

UNDER the general name of Hamburgs, several distinct, though allied, varieties of fowls are now exhibited. They are called the gold and silver pencilled, the gold and silver spangled, and the black Hamburgs. The so-called pencilled birds were originally imported in considerable numbers from Holland, and were called pencilled Dutch, or Dutch every-das layers; they were also formerly known as Chitteprats, and lọ rarious other local names. In this breed each feather is marked by several transverse bars of black on a lighter ground, which is white in the silver and bas in the golden pencilled breed. The pencilled Hamburgs are small fowls, and, when roung, the hens lay so well as to merit their title of "every-day layers." Nevertheless, they are hardly adapted for use as profitable poultrr, inasmuch as their eggs are too sinall to have good market value, and the birds, though plump, are not large enough to furnish first-rute market poultry. Both breeds are delicate, and subject to colds and roup, which delicacy has been greatly increased by close inter-breeding for exhibition purposes.

The birds now termed spangled Hamburgs were formerly known in the North of England under two distinct names-Lancashire Moonies, from the large moon-slaped marks on the ends of the feathers of the hens, and Pheasant Fowl, from their supposed derivation from a cross with the pheasant-a theory which has no foundation in fact, the hybrid between the pheasant and the forl being sterile. Spangled Hamburgs were formerly extensivels kept in Lancashire and Yorkshire; they are larger and hardier than the pencilled varieties, and much less subject to roup. They used to be regarded as possessing great merit as egg-producers, although their eggs are not as large as those of the Mediterranean breeds; but for many years they have been exhibited solely for accuracy of marking in the plumage and correctness of form in the comb; 
in the exhibition birds no account has been taken of their eggproducing properties, which have consequently greatly deteriorated. Beautiful as the breeds unquestionably are, it is doubtful whether they equal the best of the Mediterranean varieties as profitable fowls. The breed which is termed the black Hamburg has probably been made by crossing with the Minorca or Spanish; it is now an established exhibition variety, and is bred for fancy points. It is, however, larger, more hardy, and a producer of larger eggs than the spangled varieties.

\section{Polish.}

The title of Polish as applied to fowls is another misnomerat least, if it is used in a geographical sense-as no such birds are known in Poland. The birds which are so designated are distinguished by large tufts of feathers on the head, the presence of which is always accompanied by a remarkable alteration in the structure of the skull, and a deficiency of the bones of the nose. These so-called Polish are old breeds, the ancestors of which may be seen in the paintings of the older Dutch animal painters, such as Hondoketer and others. Doubtless the frugal Duteh selected the most prolific egg-producers for stock; but when the Polish became exhibition fowls in England, the selection of the largest-crested birds for brood stock, those that would be most successful in the show pen, was always followed. Hence the size, stamina, and egg-producing properties of these breeds have been very greatly deteriorated. The black Polish with white crests are now so delicate as to be absolutely worthless, and the large spangled varieties have lost for the most part their size and prolificacy, As farmers' fowls the Polish have never been regarded as of high value, their feathered crests interfering with their sight, and rendering them liable to run under the heels of horses and cattle, and fall into danger of all kinds. Moreover, from the deficiency of the bones of the skull, the slightest blow on the top of the head is fatal. One advantage certainly the Polish possessed, that of exceeding plumpness; and there is no doubt that the best French table breeds, viz., Houdans, Crèrecour, and La Flèche, owe their good qualities in great part to their having been derived from the old crested breeds that so often figured in the paintings of the old Dutch artists, and then to being bred by the frugal French housewives for their market value alone. In this country, where 
the show Polish have been bred solely for fancy points, they have become utterly worthless as farm poultry.

\section{Other Varieties.}

There remain several varieties of fowls known to the fancier, and more or less frequently exhibited at our shows, which hardly call for any detailed notice in a work devoted exclusively to market and egg-producing poultry. Such are the black-skinned, blackboned Silky fowls, characterised by a white downy plumage, which contrasts strongly with the black combs and skin. These birds are not without their value, as furnishing the best of all possible mothers for rearing pheasants and other small game birds; but as farmers' fowls they are infinitely worse than useless, as the introduction of a single bird into a farmyard will lead to the production of cross-breeds, which, although perhaps neither black in the skin nor silky in the plumage, have black bones and layers of black tissue between the muscles, rendering them unsaleable as table poultry. It is true that these birds are exceedingly good eating; but if a purchaser nnexpectedly finds a sireak of black in the meat on the breast, and black bones in the bird he is carving, he is apt to attribute it to disease, and to send away the fowl untasted.

Frizzled fowls, in which the feather's curl away from the body, constitute a most unprofitable breed, inasmuch as the rain, instead of running off the plumage, passes down to the skin; and the birds thus exposed to the influence of the weather are bad layers and exceedingly delicate.

Rumpless or tailless fowls are curious varieties, which are not valuable as market kirds, and which have a disposition to lay unfertilized eggs.

Red-Caps may be regarded as Spangled Hamburgs in which the combs bave been developed to an enormous size, so that they do not balance on the skull, but fall orer to one side. This development of comb can only be secured by the expenditure of a certain amount of nourishment; and as combs are not valued as food in England, the production of so much animal matter, which is not appreciated, is a useless waste.

Bautams of all hinds are so purely fancy fowls that they may be dismissed without further notice.

Some few remarks should be made on the exceedingly mixed 
assemblage of birds which are called barndoor fowls. In many parts of the country these were formerly characterised by a strong infusion of game blood, arising from the general habit of breeding Game cocks, and the fact that in many of the old leases that were drawn up, when cock fighting was rot an illegal amusement, a clause was inserted that each tenant should "walk" a cock for the proprietor of the soil.

In the south-western counties of England, the common fowls show the effect of the introduction of birds trom the Mediterranean, and others from India, which were introduced by the ships from those countries touching at the seaports, or being wrecked upon the shore. Before the era of poultry shows, farmyard birds were generally selected for their profitable characteristics. The figure of the domestic cock in the "British Birds" of the inimitable Bewick, which is reproduced on page 4, shows what these birds were before they were deteriorated by crossing with fancy varieties. In some instances the introduction of good breeds, such as Dorkings and Indian Game, amongst the small farmers and cottagers, by the landed proprietors, has resulted in the farmyard birds being greatly improved. In other cases much injury has been done by the introduction of fancy rarieties; and it is difficult to imagine a proceeding more ridiculous, or which has proved a greater failure, than the collection of show breeds for the improvement of the poultry of the Irish peasanis that was lately carried into effect by one of the Irish newspapers. 


\section{CHAPTER XI. \\ IMPROTING FARU POULTRT.}

In our farmyards and homesteads may be seen, not unfrequentls, a ver considerable number of ordinary forls of no particular breed, that hare neither been selected as prolific egg layers nor carefully bred as poultry for the market. They are of all ages and sizes, having been not unfrequently seriously deteriorated by the introduction of two or three lantams, which hare beeu kept for the amusemen of the mistress or children. It is needless to say that these poultry do not pay, and, even if ther have the waste food of the farmsard, are hardly to be regarded as remunerative. The question which presents itself is whether this stock is capable of improrement without going to the expense and trouble of clearing off all the birds and begiming afresh.

A short time since I had the following letter sent me, which expresses the requirements of many besides the writer. Speaking on behalf of himself and others, he sars: "We want to know how to improve our poultrs without being obliged to clear out, and we wish to know whether pure or cross-bred are the bestall-round fowls for heary land farms? The birds we require must lay well, kill well, be rery hardy, and range well, be good mothers, and sit well, as we want them to hatch ducks and guinea fowls as well as chickens. What cockerels had better be turned down with serenty to eighty hens, which originally were Brahma-Dorlings, but for the last few sears hare been bred in and in, and before then crossed twice with Dorkings - as feathered legs wou't do on cold wet clay land. We want good winter layers, not rery early chickens."

To improve the stock of an ordinary farmyard, where the fowls have deteriorated from in and in breeding often carried on for some years in succession, a rery remorseless sacrifice of the waste birds must be made. In the first place, all the male birds, young and old-more especially the latter-must be got rid of, sold, eaten, or even giren away, for not one of the males should be 
allowed to remain. The hens should then be all caught, carefully sorted, and only those hatched in the last season and the season before being retained, as they are the only prolific layers. It is all rery well for those who are breeding for feather or fancy points to keep, for stock purposes, old hens in which these qualities are well marked, but for farmers and others who breed for eggs and chicken for the market to do so is unadvisable. In addition to the old birds, any small hens that were hatched either very late or very early in the season should be remorselessly killed and eaten, as they are never good layers, nor will they produce rigorous chicken. In this way all the cocks and the worst of the hens should be weeded out. Now comes the question as to the breed of the new cocks that are to be introduced. Generally speaking, a short-legged, square-bodied Dorking will be found to answer the purpose very well, but in some cases-as that of the correspoudent whose letter appears aloove-Dorking blood chiefly prevails, and then it would be desirable to cross with a totally different strain. Let me cantion all farmers to aroid introducing either Cochins or Brahmas. It is true a large increase in size will result, but coarseness of bone, and scarcity of meat on the breast, will be ineritable. A good close-feathered Indian Game, or an old-fashioned short-legged fighting Game, furnishes a very good cross, or a good Surrey or Sussex cockert, such as are reared for the higglers, would be most useful.

Three or four cockerels would be amply sufficient for seventy or eighty hens; but in such a case it would be better, if it could be conveniently managed, to place in a large separate grass run some half dozen or dozen of the best short-legged, fine-boned, closefeathered hens with one of the cocks, and hatch all their eggs, thus ensuring breeding from the best. Great care must be taken that the birds are all in the most vigorous condition. The crossbreeds will be hardy, good layers, good sitters and mothersqualities possessed loy most cross-l,reeds, but certainly ljy those bred from Indiau game and farmyard fowls. To utilise these birds in the best manner, all the cockerels should be killed off when ready for the table, not one being left; and the old cocks should also l,e got rid of, sold, or exchanged-which they may be if there are any other farmers in the neighbourhood who rear their fowls un common-sense principles.

If the old cochs are retained they must necessarily breed with their own pullets, and loss of size and strength is the result. 
It may be said that this changing of stock birds is a troulule. Granted; but I do not know any good results in any pursuit that are to be obtained without trouble.

It may be asked, are not the young cross-bred cockerels worth breeding from? They most certaiuly are, but not with their own sisters and mothers. If it is wanted to breed from the cross-breds, there must be an exchange with another farmer, or two distinct lots must be kept on different parts of the same farm.

I fully believe in the desirability of setting aside a cock and eight or ten of the best hens to lav eggs for hatching, either in a large inclosed grass run or at a neighbouring cottage. I also think it desirable to vary the breed of the stock birds year after year, as the continual crossing has the effect of giring not only increased size, but great rigour and fertility.

The utility of this plan is recognised by all practical breeders for the markets, and I liave much pleasure in quoting from the last rolume of the "Agricultural Book of Scotland," in which the editor controverts the suggestion of one of his contributors, who recommended the introduction of fancy stock into farmyards, and writes: "Brahmas and Cochins are miserable birds for the table, and a cock of either breed will spoil a whole farmyard-coarse legs, coarse bone, coarse skin, and, in proportion to the large coarse legs, shallow breasts. But great improvement in the stock of birds ordinarily found in homesteads may be effected by turning down every year a full-chested, meaty cock, which may be a Surrey fowl, Dorking, Indian Game, or the old-fashioned English breed; but the young half-bred cockerels should all be killed, and a fresh old bird introduced every year, the breed being altered from that of the last season." 


\section{CHAPTER III.}

\section{HOUSING.}

The first consideration in keeping poultry is the accommodation that has to be afforded them. Where ther are bred for market it is obvious that expensire poultry-houses, fitted with the requirements of the fancier for keeping his birds distinct, are inapplicable. What is really required in a poultry-house is a sufficient space for the perches and the nests. As poultrr-houses are usually constructed, the perches rum from side to side, each one being higher than the preceding, the back one reaching nearly to the roof. The perches are put in this pasition because persons have observed that the fowls always prefer ascending to the highest level-a habit which is obviously derived from the instinct which leads them to ascend to the higher branches of the trees, so as to escape their natural enemies, such as foxes, jackals, and other terrestrial beasts of pres. A fowl roosting a considerable height in a tree descends by flying down in a very oblique line, su as to alight at some considerable distance, consequently its fall is not rapid, and it does not strike the ground with violence; but when it roosts on a high perch in a house, it cannot fly down, hut has to drop nearly perpendicularly, and consequently comes with great riolence to the ground, not unfrequently, in heary specimens, breaking the keel of the breast bone, and inducing disease of the feet by the force with which they strike the earth. These are not the only evils that arise from this absurd, though exceedingly common, arrangement of the perches. All the fowls wish to go to the top perch, and fight for the possession of it, the weaker being knoked off and often injured. These evils may be entirely avoided by placing all the perches on one height, which should not be more than $4 \mathrm{ft}$. from the ground. The fowls can then descend without injurs; and any individual one that may be required is easily captured at night, after they have gone to roost.

When low perches are used, care must be taken that there are no beams or rafters above, on to which the fowls can fly, or they will invariably try to do so. In case these exist and cannot be got 
rid of, access to them must be prevented by the use of coarse wire work or lathing.

In small narrow poultry-houses it is customary to make the perches reach from side to side, so that it is difficult to gain access to those at the back. If they are all placed on one level, a much better arrangement is to leave a broad passage up one side, the ends of the perches next to it resting on a horizontal bar, which is supported by one upright in front and by the back of the house behind. This leares a path up one side, along which the layingboxes or nests can be placed npon the ground, in a position that does not expose them to be soiled by the birds that are perching abore.

When fowls are weakly bred they often become crooked in the breast. Most persons imagine this to arise from the use of small perches; no idea can be more fallacious. If fowls are allorred to roost in the trees like pheasants, they will always be observed to select the smaller branches on which to rest. These they can grasp securely by the toes, and are not in danger of being blomn off by the wind. In fact, as a fowl sinks down upon its breast bone to roost, the toes close around the branch, which is thus beld securely-an action which anyone may imitate by extending the legs of a dead fowl, placing the toes around the finger, and then pressing it towards the bodr, when they will be found to close around and grasp the finger. Roosting in this way, the fowls rest upon the feet quite as much as upou the breast bone; but placed on a broad, flat perch, such as is frequently employed, this is prevented. The whole weight of the bird comes upon the keel of the breast bone, which, if the fowl is weakly, is apt to be rendered crooked by the pressure.

In manc farmyards and homesteads it will be found much more adrantageous to allow the biris to roost where they like, in cartsheds, umused barns, trees, \&c., if in these places they are safe from pilferers. Roosting out in the open air gives them much finer health and condition than when shut up in the close, stifling, fotid atmosphere of an ill-rentilated, dirty poultry house. But, as these conditions are not alwars arailable, it is necessary in the majority of cases to form a house of some lind or other; an unused stall in a stable makes a very good house for a small number of fomls. A shelf formed of loose tlat boards may be placed orer the manger, and the perches put a few inches abore them. The manger itself may be divided into two or three nesting places, being filled with moist earth, covered with a little short, soft straw; the boards 
above receive the droppings from the perching fowls, and these can be removed daily with a small short-handled hoe.

If fowls are to be kept in health, they must have sweet, wholesome places to roost in. Eggs hatch very badly in a fotid atmosphere; and those which are hatched in a house do not, on the average, produce so large a number of chickens as those under hens that nest out in the open air, nor are the chickens so vigorous.

Cleanliness-without which there can be no purity of the airis an absolute necessity in a well-managed poultry house. The surface beneath the perches should le covered with some material that can be removed at least twice a week ; dry monld will answer the purpose very well, or ashes from the house. Some of the most successful poultry keepers have adopted the use of peat moss litter. Whatever is employed, the manure should be removed frequently, so as to keep the house perfectly sweet and wholesome. For this purpose also openings for ventilation should be made; but care should be taken that a direct draught does not blow upon the birds. They can stand the cold and wind in winter, when roosting in the open air, as well as pheasants and peacocks; but they are amenable to the Spanish proverb, which says:

If the wind reach you through a hole,

Go make your will, and mind your soul.

A poultry house, to keep it clean from vermin, should be limewhitened, once or twice a year, with wash made with freshly slaked lime--to which it is desirable to add earbolic acid, which will be found most destructive to the insects. This lime wash should not merely be spread on the external surface, but directed, as far as possible, into the cracks and joints of the perches, nest boxes, \&c.

Unless there is ample provision for the fowls to dust themselves under some dry shed, a dusting bath may be placed in the house, although it is preferable outside; but wherever it is put it should be kept dry. Any shallow box open at the top answers the purpose very well, and it should be filled with fine ashes from the house. The fowls will not be slow to avail themselves of the advantages it offers to throw dust in between their feathers to get rid of the vermin which naturally infest them; although it is only badly fed, badly managed fowls that live in dirty houses, where the fleas and lice breed in myriads in the unchanged nests, that become badly infested. A fowl swarning with vermin is an indubitable proof of the bad management to which it has been subjected. 


\section{CHAPTER XIII.}

\section{FEEDING.}

THE cost of maintaining fowls that have a free run in a farmyard of mixed husbandry is very small, for they supply themselves with a considerable proportion of their food-not merely without cost, but with advantage to the owner, inasmuch as they pick up grain and seeds, which, if carried into fields with the manure, produce plants that can only be regarded as weeds. The amount of food that fowls gain in this way cannot be accurately estimated; it depends entirely on the character of the farm. If thrashing is going on continuously, rery little food is required to be giren; at other times it must be supplied with a more liberal hand. Those fowls which require to be supported entirely br hand (excepting the food that they obtain for themselves in the fields or orchards) should be fed at least twice a dar. This feeding is generally very badly managed. A measure of corn is taken out and thrown down day after day in the same spot. The forls scramble for it, the stronger drive away the weaker, the old cocks chase the young ones, and the food is picked up off ground covered with fowl dung, and is eaten in a filthy, unwholesome state. When I see fowls fed in this way, it reminds me of the mode of feeding human beings in some Oriental prisons, where the food is thrown down on the floor reeking with unutterable abominations. Jail ferer amongst the human, and disease among the feathered bipeds, are results not to be surprised at. The idea of causing fowls to eat corn defiled with their own excrement is to me repulsire in the highest degree; and it is, I know from experience, most injurious to the high condition of the birds. To feed fowls properly with grain, they should not be fed at the house door, but out in the open, and the corn scattered among the grass as widely as possible. Not a single grain will be lost; the fowls will search for it until every one has been found; and, instead of filling their crops in an unnatural mauner and to an undue fulness, they will have had exercise in collecting their food, which 
is taken gradually and in an advantageous mode, much wore in accordance with nature.

Fowls, if they are to produce eggs or to get in high condition, should be well fed. They should twice a day have nearly, but not quite, as much as they can eat. No intermediate feeding should be allowed-no throwing out of waste house scraps at uncertain times; for if this is done and the fowls are accustomed to it, they will hang about the house, and run after anyone they see emerge from the doorway, in place of wandering about the fields seeking and gaining a considerable quantity of food for themselves.

The kind of food that should be given to the stock birds in a farmyard will depend upon the grain which is cheapest at the time and most easily obtained by the proprietor. Sinall tail corn, small barley, cannot be utilised better than by giving it to the birds. Foul and musty corn, howerer, should not be used, inasmuch as it implarts a bad taste to the eggs, and to the flesh of the growing chicken. Green food should hardly ever require to be given, becanse the fowls should only be kept under such conditions that they can obtain it for themselves. Small potatoes, boiled and mixed with a certain proportion of bran, or, still better, sharps, pollard, or middlings, so as to be able to be formed into balls of a friable character, furnish very admirable food for the stock, and may advantageously form the whole of one of the everyday meals. If light oats are given to fowls they are much better relished if previously soaked in water, when the lightest are eaten. I am convinced that the practice of always giving dry hard corn is not advantageous, for neither pheasants nor fowls could obtain such food in a state of nature. The seeds that they would get would be almost always more or less moist; and the closer we can imitate the natural condition of things the better. Fowls would progress more advantageously if, instead of giving them hard, dry corn, which frequently swells in the crop, and produces "crop bound," we were to give them moist corn, and scatter it so widely that they can obtain it grain by grain.

At the present price of maize, it is often ardvantageous to use it as a portion of the food for fowls; but it contains a larger percentage of fatty matter than any other grain, and, if given abundantly, is far too fattening for laying hens. It may, however, be used partially in winter with very great advantage. It is not adapted for fattening for the table, inasmuch as it produces a soft, yellow, 
oily fat, in place of the firm, whitened flesh that is required by the first-class poulterer.

As the conditions under which fowls are kept are so variable, it is impossible to gire an accurate estimate of their cost. It mas rary from even less than half-a-crown a head yer annum in farnisards of mixed husbandry, where thrashing and horse-keeping is going on, to $5 s$. or $6 s$. a head where they are entirely hand-fed. 


\section{CHAPTER XIT.}

\section{HATCHING.}

In the majority of poultry houses the nests are made in boxes, raised from the ground in rows placed on shelves, and packed as closely as possible in tiers one ahore the other. These nest boxes are furnished with straw or hay. It is difficult to conceive a more unsatisfactory arrangement; the nests are so dry that the eggs fail to hatch. The sitting hens are packed so closely together that in a short time they swarm with fleas and vermin. As in all other circumstances connected with stock, the nearer we can imitate the perfect arrangements of nature the better. The nest of a hen or pheasant is naturally placer on the damp ground, where the eggs are exposed to the changes of the weather previous to the hen sitting upon them; ret, unless inundated by water arising from the rainfall, they rarely fail to hatcls. The frosts of early spring, the showers of April, the alternations of temperature in day and night have no eril effect upon them. They hatch much more successfully and produce much more rigorous chickens than the eggs of the poultry-fancier that are carefully packed away in drawers filled with bran, and kept at an even temperature until placed under the ben. The closer we follow nature the better. Our nests, like hers, should be upon moist ground. If the hen is not liable to be disturbed, and we want early and vigorous chickens, the best plan is to leave the eggs untouched in the nest, and let the hen warm them up every time she deposits a fresh one-in plain words, to leave lier alone altogether. But this, unfortunately, is not often practicable. Hens are fond of laying where others have laid before, and consequently we are compelled to alter the natural mode of procedure. Our artificial nests, however, should always be made on the damp ground. A bushel of ordinary mould thrown into a corner or against the wall, and surrounded with a few bricks to keep it in position, or placed in a shallow box or half-sieve market basket, forms the best foundation for a nest for poultry. A handful of 
short straw can then be taken, and with it the mould rubled round into a slight hole, which, with the straw, constitutes an admirable nest.

If many hens are set in the same house, some contrivance is necessary for the purpose of preventing their being intruded upon when sitting; for a strange hen trying to force her way into the nest of a sitting hen is almost certain to result in the breaking of the eggs, and consequent loss of chickens.

When it is ascertained that a hen has become decidedly broody, the eggs can be giren to her at night, each one being marked with a ring made round it, or by crosses on the opposite sides, so that if, by auy accident, another egg is laid in the nest, it may at once be seen and removed. If the hens are confined in the nests by coops or wirework, they should be taken off at a regular hour every das, abundantly supplied with food and water, and watched until the return to the nests-a proceeding which it is necessary to do to aroid two hens going on one nest, and breaking the eggs. Most poultry rearers have the erroneous idea that the chickens will be killed if the hens are absent so long a time that the eggs become cold, and are rery fidgety as to the return of the hens on to the nest after a short period. This anxiety is entirely misplaced, as the eggrs may be allowed to become cold without injury to the vitality of the chickens. This is especially the case in the early stages of incubation.

The fresher the eggs that are used for hatcbing the better. None should have been laid more than ten days, or a fortnight at the outside. The number of eggs placed under a hen usually varies from ten to fifteen. In cold reather it is exceedingly desirable not to put so large a number under the hen that the outer are merely covered with the feathers. When only a proper number are given they are actually in contact with the naked skin of the breast of the hen, and not with the feathers alone. This fact may readily be ascertained by putting the hand on the eggs under a quiet hen, when the warm skin of the breast will be found in contact with them.

Should the hen on coming off the nest not be allowed to go out into the open and dust herself, a box filled with dry ashes should be provided in the hatching house.

On the serenth day after setting the hen, the eggs should be tested, and those that do not contain chickens remored. The most simple egg-tester is made out of a piece of cardboard; the corer of 
an old book answers very well. An oval hole should be cut in it, not quite large enough to allow an egg to pass through, and if the cardboard is white, one side should be inked or painted black. The eggs are more conreniently remored from the hen at night, or if in das they should be taken into a room from which daylight is excluded. A single lamp only should be used. The cardboard, with the darkened side towards the observer, should be held near the chimney of the lamp, and the eggs one after another, should be held against the hole. Those that contain chickens will be observed to be quite dark and opaque, except at the Jarger end, where the air-space exists. These should be replaced under the hen. Those

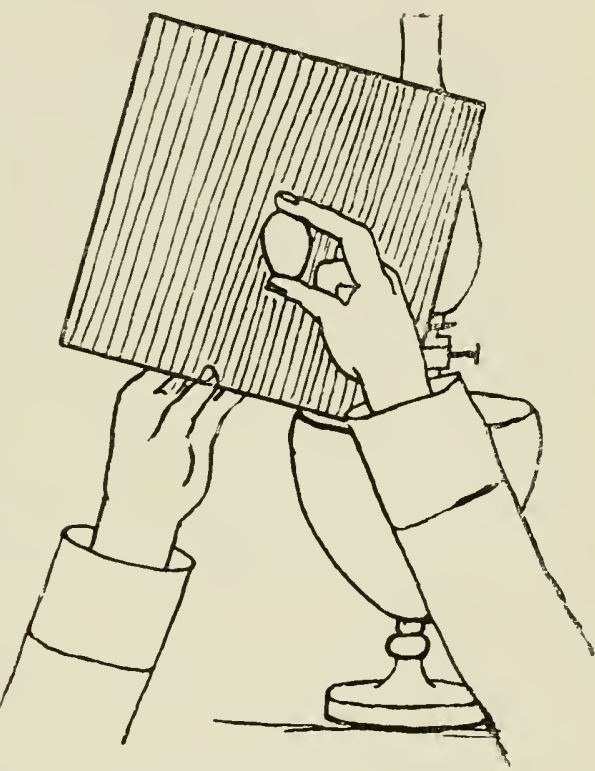

Method of Testing Eggs. that have not beeu fertilised, and are consequently sterile, are sufficiently transparent to allow the light to pass through, and look as fresh eggs would if examioed on the same manner. Such eggs are usually termed "clear." T'hese clear eggs are perfectly good to eat; but it is preferable to sare them for the food of the chickens when hatched. Throwing them away is a wasteful proceeding.

If two or three hens are set upon the same day, and all the eggs examined at the end of a week, it will be found advantageous, if many are clear, to give all the fertile eggs to one or two of the hens, when a fresh batch of new-laid engs may be placed under the other. It is a most uneconomical mode of proceeding to set a single hen in the early spring, when perhaps a considerable number of the eggs will be clear, and allow her efforts at hatching to be rewarded with one or two chickens, when by setting several together full clutches may always be ensured. 
In placing eggs under hens, rery foolish mistakes are often made as to their selection. The eggs taken should be of the arerage size, neither too large nor too small The largest eggs otten contain two yolks, and rarely hateh, or. when they do so, produce deformed chickens, or birds with extra wings or legs; and the smaller esgs show that the ritalits of the hen is lessened during the time they are being formed. Eggs with thin shells-which can often be detected by their extermal appearance-should never be placed under a hen; thes are certain to be broken and soil the others. Those with any irregularity of shell should invariab!y be rejected. I do not think in all my experience that I hare erer known an egg with an irregnlar shell-such as a ridge round the centre, or any other irregularity-to hatch; although I confess to having tried the experiment many times when breeding from hirds that were valuable.

Under ordinary circumstances, the eggs hatch on the same day three weeks as ther were placed under the hen. No interference with them during the period of hatching is desirable. Ponltry keepers, especially breeders of ralnable fancy birds, are rery apt to be meddlesome with the eggs at hatching time; they cannot resist the temptation of taking them out from under the hen, seeing how they are hatching, remoring the empty egg shells, enlarging the openings which the chick makes for itself, when they generally wound some of the blood ressels of the skin, which are not ret closed, and do far more harm than good. I am firmly convinced that the lives of many chickens are sacrificed by undue interference for erers one that is sared bs any aid that is giren. The chicken has on the tip of its bill a little hardened point, $\mathrm{ly}$ which it cuts off the top of the shell by blows from the inside, and thus liberates itself. If it is too weakly to do this, it is not likely to be of much ralue, or erer to derelop into a good bird. When hens and pheasants hatch out in the open, it is rare, as I have said before, that they do not bring off a full strong clutch, without any interference on the part of their owners.

At the present time many persons are in the habit of employing inculators in the place of broody hens. There is no doubt that good incubators are raluable additions to a poultry yard where many chickens are raised. I have used them myself with very great success and adrantage. In a well-constructed incubator fully as many chickens can be hatched from a giren number of eggs as under the best sitting hens; but it must be one in which the 
natural conditions of hatching are fully observed. These are-a lower temperature below than above, as the ground on which the nest of a hen is naturally made is colder than the breast of the bird; a moist atmosphere, similar to that arising from the damp, ground; pure air, such as the hen is surrounded with when hatching in the open; and a well regulated heat above, which never under any circumstances exceeds the requisite temperature. I have only seen one incubator that fulfils all these conditions, and that is the one known as Hearson's. I bave carefully tested it for some years in work, and have found it perfectly successful. It is so ingeniously constructed, that a rise of temperature over the amount at which it is set cannot possibly occur, however high the flame of the gas or lamp may be turned. Its reliability may be inferred from the fact that a modification of it is used in the maternity hospitals for delicate newly born infants, and another in pathological laboratories for developing bacteria and microbes.

Incubators in which the hot air from the lamp, charged with carbonic acid, and the deleterious products of combustion, is allowed to pass over the eggs, are necessarily injurious. In these the impurity of the atmosphere is most detrimental to the young unhatched chick, which breathes through the pores of the shell. In otber contrivances the heat is supplied intermittently by means of boiling water, added twice or thrice every twenty-four hours. In these the temperature varies so greatly as to be fatal to success.

A very interesting description of the system pursued in France, of hatching ordinary fowls by hen turkeys, was given a few years ago by Mr. C. L. Sutherland in his report to the Royal Commission on Agriculture. In this he says: "At Houdan, in the Seine-et-Oise, which I visited on the 26th of March, 1880, the poultry-breeding industry may be seen in full force. Houdan fowls alone are kept, and it is calculated that the pullets, when well fed, will commence to lay at five months old. The majority of breeders adopt the plan of placing twenty-five fowl's eggs under a young turkey hen. When it is desired that the turkey hen shall commence to sit, be it in January or June, she is placed in a suitable box almost entirely covered by a board, and some dummy eggs are put uncier her. She is generally kept in the dark. She soon takes to the dummy eggs, which are then removed, and twenty-five fowls' eggs are placed beneath her. She is taken off the eggs once a day to feed, and carefully replaced, not on the eggs but in front of them, and she then, after the manner of turkeys, 
carefully hooks them underneath her with her beak. When the chicks are hatched they are remored from under her, to be sold or sent off at once, or to be brought up by another turkey hen, which is perhaps an indifferent sitter, and which, in lieu of sitting, has from eighty to a hundred chicks given her to bring up. Orders are kept on hand for these chicks (poussins), which, within trelre hours of being hatched, are despatched all over France in well ventilated boxes holding from twelve to twenty each, and at the following prices, viz. : One dozen, $12 s$. ; twenty-fire, $22 \mathrm{~s} .5 \mathrm{~d}$.; fifty, 44s.; one hundred, $80 s$. The hen turkey which hatches out the chicks is then prorided with twenty-five more eggs, upon which she at once sits, and this process I was assured was carried on six, seven, and eight times in succession. Young turker hens are preferred to old ones for the purpose. Such a thing as a coop is rarely to be seen. In the moruing, as soon as it is light, the doors of the sheds in which the roung chicks with their foster-mothersindifferently sitting turkes hens-have passed the night are thrown open. The inmates are driven out mostly by old women with long poles, who conduct the whole lot gently into some corert, or along the country lanes, where the chicks can find plenty of insect life, the old ladies sitting with their work and keeping careful watch over their charges."

The poultry-breeders who hare adopted the same system in this country, speak in unqualified approval thereof. Ther claim that not only can a turker hen curer twice as many eggs as an ordinary hen, and care for three times the number of chickens, but that they are more reliable both as hatchers and brooders, and that they are less affected $b y$ the weather.

In France chickens are hatched in large numbers by incubators, and also by turkes hens, for the purpose of being sold within a few hours of their hatching, as they travel very fairly in small boxes, with air holes for rentilation. When we remember that during the natural hatching months of April, May, and June a hen can take charge of a much larger number of chickens than she usually hatches, the sale of young chickens for making up the deficiency of small broods apjears a plan that could be usefully followed in this country with adrantage to both sellers and purchasers. 


\section{OHAPTER XV. \\ REARING THE CHICKENS.}

THE chickens, when hatched, should be allowed to remain undisturbed under the hen until the following day. Some persons remove them as fast as they are hatched, putting them in a flannellined basket near the fire. No plan can he more injurious. It is impossible to supply the exact temperature of the hen which is natural to the chickens, and the continued chirping of the roung birds when removed-suffering, as they do, from a temperature either too cold or too hot-mar be regarded as an indignant protest against the unnatural treatment they are receiving. When returned under the hen, they will be found to rest perfectly quiet.

They require neither food nor drink at the period of hatching, at which time the remains of the yolk are drawn into the body of the chick, and pass into the intestines, constituting the first food of the young bird; and any interference with its due digestion by putting other food into the crop is injurious. The custom formerly prevalent, of cramming a few grains of large corn, barley or wheat, down the throat of a newly-hatched chicken, is as alsurd and irrational as it is possible to conceive. On the day after the chickens are hatched they will he found to be perfectly drr, strong, and vigorous. They should then be removed from the nest with the hen, and placed in some dre, smmy, warm situation; and the contents of the nest, which is certain to contain some fleas, should be immediately remored from the hatching house and destroyed.

Cooping is generally had recourse to, and where many fowls are present it may be necessary; but, there can be no doubt that the use of coops is far from being an unmixed benefit: a cooped hen has no power of scratching for the food for her young ones, and they have to depend altogether upon what is given them by the owners; moreover, the ground under the coop becomes foul and tainted, and during the night the chickens are breathing air which 
is contaminated with the odour of the excrement of the hen and of themselves. If the coops are closely shut up, as is often the case, the atwosphere before morning becomes positively fœetid. To rear strong, healthy chickens under the circumstances is difficult, if not impossible. Then, again, the coops that are constantly to be seen in farmyards are as ill-contrived as it is possible to imagine. They are often made like the roof of a house-two ends and one side being closed, and the other with horizontal bars. It is difficult to imagine a worse prison in which a hen and chickens could be confined; it affords but little protection from the weather, is heary to move, and gives the hen no opportunity of scratching. A much better plan of cooping the hen is to place her in the first instance in a small movable rmm. Contrivances of this sort are sold by all the poultry appliance makers, but they are too expensive for the ordinary rearer. They can, however, be quickly extemporised by putting a box or coop in the middle of an unrolled coil of wirework, which can readily be moved on to fresh ground day after dar. If put out on grass, it will be found particularly desirable to imitate the practice adopted so advantageously in pheasant rearing, namely, to mow the grass for some little distance round the coop, so that the roung chickens are not wetted by the dew before it is off in the early morning. This should be done some short time previously, so that the roung leares of grass and tender clover may be growing for the use of the young birds.

It is frequently, howerer, inconvenient to use wirework in this manner, in which ease I can strongly recommend the plan of tethering the hens with chickens, as adopted in many instances by pheasant rearers. The hen should be fastened by a piece of string to a peg driven into the ground, and an open, sheltered coop should be placed near her, under which she can retreat at night and during rain. The coop should not be put so close to the peg to which the hen is attached that she can walk round it, but near the limit of her cord, so that she can pass in and out, but not round the back. There are rery few gardens where racant spots do not exist on which hens with chickens may be tethered. Not the slightest injury would arise from placing one over newly-planted potatoes which have not get come up, on spots where beds will be made for vegetable marrows, or between the gooseberry or currant bushes or raspberry canes. In fact, there is no large garden without many open spots where a hen could be pegged down from day to day without doing the slightest injury to the regetation. Under these 
circumstances she will be able to scratch the surface of the ground, and supply her young with the seeds, grubs, worms, and natural food which is so much more advantageous to them than any artificial substitute that can be given. The little chickens, even when two or three days old, will be observed scratching for themselves, and the progress that they make when reared under these conditions is out of all proportion to that made when the heu is kept cooped up, and the birds are fed on the hard, soiled, dirty ground.

But there is a right way and a wrong way of doing everything. If the hen is simply secured by a piece of string tied round ber leg, she will pull against it, and the leg or npper part of the foot may be injured. She should be secured by a proper-jess, such as is used by falconers. A piece of thin, flexible leather, about 8in. or $9 \mathrm{in}$. long by something less than lin. broad, should be taken, and three short slits cut in it, as show in the diagram, which is one-half the required size. The part between $\mathrm{A}$ and $\mathrm{B}$ should be placed rotind the leg of the hen, the slit A being brought over B, then the end $\mathrm{C}$ should be passed through both slits, care being taken that it goes through $A$ first. It shonld be pulled right through, when it will be found to make a secure loop round the leg of the hen, which she can neither undo by picking nor tighten by pulling. The cord of the requisite length is then tied to $\mathrm{C}$, and fastened to a neg driven in the ground, which, as I have said before, should be put a sufficient distance from the coop to allow

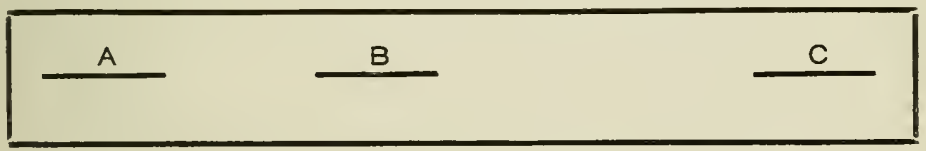

the hen to take shelter in it in case of need. A hen pegged down in this manner will become perfectly accustomed to the circnmstances, and will proceed to scratch for her chickens in a very few minutes. The advantages to the young birds from being on fresh, sweet ground and obtaining natural food cannot be orer-stated. The hen commands a sufficient space of ground to prevent it becoming soiled, and she can be shifted day after day as often as required.

When it is noticed how securely the hen is confined to the place where she is tethered, the most fastidious gardener will hardly 
object to her being temporarils located in his domain. The fact is that the hen and chickens will do much more good than harm, as the destruction of grubs, insects' eggs and larræ, far more than counterbalances any eril that the birds could possibly do.

Placing chickens under these circumstances on garden ground is far better than putting then in coops out on the grass, as, although ther get fresh air under these conditions, they are not supplied with any great amount of insect food.

The first food that is usually giren to a roung chicken is chopped hard-boiled eggs. This is a rers wasteful method of procedure. The rolk, it is true, is eaten, but the white in this hard-boiled condition is not relished, and is consequently allowed to remain exposed to the sun and air until it gets quite horny. A much better plan is to take an egg (one a dar will be found quite sufficient for each brood, unless it be a rery large one), beat it up with a wineglassful of milk, and set it into a soft custard, either by putting it into the oren or stirring it in a saucepan over the fire. This is the most advantageous artificial food that can be given to young chickens, and is certainly preferable to anr other that can be emplored. It contains all the nutritire matter of the egg, in addition to that of the milk, and is infinitely superior to curd, which is often recommended, as that does not even contain all the nutritire principles of the milk. I am confident that, br the use of custard for the first few days, a larger number of chickens can be reared than by emploring any other substance. It is easily prepared and easily given; and if the clear eggs that have been remored in testing those under the sitting hens are used it mar be said to be almost without cost.

At the experimental farm at Ottawa, in the Dominion of Canada, poultry are reared and made the subject of close observation; in the report for 1889 we are informed that experiments were made as to two methods of feeding the roung chickens-one with dry food composed of hard-boiled egg and breadcrumbs, the other with bread put into milk and squeezed nearly dry before being used. This latter, as might be expected, was found by far the better of the two; but I doubt whether it supplies sufficient animal food for the rery roung birds, and should add to it an egg beaten up with an equal quantity of milk, and stirred till set orer the fire, or cooked in the oren. The clear eggs remored from the nests answer well for this purpose.

In situations where ants' eggs can be obtained in quantity, the 
may be used, and will be found most advantageous. Gentles, or flesh maggots, are not unfrequently employed, but unless they have been well cleansed ther are apt to purge the young birds. The best mode of utilising the dead bodies of any animals is not to hang them up in the fowl run and allow the maggots to drop on the ground-an exceedingly offensive as well as undesirable proceeding - but to allow the animal matter to become thoroughly fly blown (which it will in two or three days in summer), and then to bury it in the ground in some situation to which the hens with their broods have access. The maggots, on arriving at maturity, endearour to reach the surface of the ground in order to change into flies; the hens discover this, and by continued scratching find a constant supply of insect food for their young.

In addition to custard, made as above described, lread and milk may be given to the roung chicks, or some of the best sweet oatmeal mixed with milk; but I am strongly in farour of using small whole seeds for the chicks in preference to, or at all events in conjunction with, meal or grits. In whole seed, such as canary, millet, dari, or small wheat, the vitality remains, and the seed does not become rancid or pungeut; but, when crushed, the germ is killed, and the meal, being exposed to the air, becomes rancid, unless it is kept exceedingly dry, and in this rancid condition it does not furnish good food. All those who use that most wholesome food, oatmeal, for porridge know the difference between freshlyground meal and such as has been prepared for any length of time, eren a few weeks. Then, again, a large proportion of the most nutritive and bone-forming materials exists in the husk of the seed, which are got rid of when ground into meal. The objection is sometimes made that meal is more easily digested than the seeds; but those persons who say so overlook the fact that the young chickeu is provided with a most efficient mill, in the form of its gizzard, for grinding up its natural food, and it is more desirable that this organ should be properly exercised than that it should be inactive. Untouched grain or seeds have their contents protected from the air, and the embryo is in a fresh, living, and growing condition. If these seeds are moistened and exposed to the air, they do not become rancid like meal or grits, but commence to grow. The starch of the seed is converted into sugar, and becomes soluble and in the best possible condition to support the growth of the young plant or of the young chicken that eats it. These facts induce me to believe that the use of small seeds, such as cumary 
seeds, millet, and dari, is more advantageons than the employment of oatmeal, often pungent from age, or grits, which were possibly decorticated some months before, would he. Pheasants and fowls in a wild state are not supplied with ground seeds for food, and they are more healthy than such as are reared artificially.

Mr. Bevington, one of the most sucressful rearers of table fowl, writes to me as follows: "I gire you the greatest credit for putting me up to using canary seed for rearing ms chickens; I never had such strong healthy chicks as I had this rear. I can safely say I have not lost 3 per cent. of $m y$ chickens liatched under hens. I have only lost one young turkey, and that broke its leg."

In place of the ordinary oatmeal, which is not always fresh, Mr. Bevington prefers fresh ground oats mixed with milk, both for his young stock and for fattening.

I have tried the experiment of rearing chickens without giving them meal or ground corn at any period of their lives. They had from the first a little custard for a day or two, with canary seed, which I regard as a most valuable food; then dari, which is much relished, is equally valuable; and small wheat. The hens were allowed, as mine alwars were when practicable, a free range; and I never had a finer set of healthy, vigorous chickeus, which grew to a large size, and were most admirable table fowl.

I need not say anything about the supply of green food for the chickens, for if they are reared under circumstances such as $I$ have described, they obtain that for themselves, and I camnot conceive anyone rearing poultry for the markets who would find it desirable to do so in situations where green food could not be obtained by the birds when at large.

The keeping of poultry in confined runs may answer very well as an amusement, and may be so conducted as to furnish an advantageous supply of eggs for home consumption; but as a mode of raising fowls, even for the house, let alone for the market, the idea of chicken-rearing in a limited space is not to be entertained.

It is needless to say that the roung chickens must be well fed, and at much shorter intervals than the old birds. If chickens are allowed to run in the open, the attempt to feed them by throwing down food will attract the other fowls, and they will be trampled on if the old birds are numerous, and will get a very small share of the food. This evil may be easily obriated by making a sort of cage of wirework, or laths two or three inches apart, according to 
the age of the chicks, and throwing the food for the young chickens under this. In this way thes obtain a due supply of food without being interfered with bs the older birds. A circular wicker coop will answer the purpose, but it is not large enough. I much prefer a large wooden cage, with wirework on all sides. This should be sufficiently light to be mored on to a fresh place each dar, so as to aroid the very objectional though too common practice of making the birds pick up food off ground soiled by their own excrement.

When chickens are reared in numbers and kejt together at different ages it will be found very advantageous to assort them at feeding time, this is easily done by having two rolis of hexagonal wire netting, one of 2 in. mesh, the other of 3 in., each of these is coiled into a ring and the food for the young chickens thrown inside, the youngest only can get through the smaller meshed ring and feed undisturbed by the older fowls, whilst the half-grown can pass. through the 3in. mesh; these feeding rings can be of any required size, and can be mored on to fresh ground as often as desired. In using the two together the food for the youngest chicken should be thrown into their wire inclosure first, then that for the halfgrown birds, and the old fowls fed outside. 


\section{CHAPTER XVI. \\ BREEDING FOR THE IIARKET.-EGGS.}

Ir is doubtful whether a greater amount of nonsense has ever been written about any particular subject than that respecting the supply of eggs to the English market. The large amount of money that is paid amnually to foreign countries for the eggs consumed in England is simply a matter of ordinary supply and demand. We buy eggs from the foreigner because we can obtain them from him cheaper than we can produce them at home under existing conditions.

In countries where land is divided $u_{]}$, into small holdings, and there are hundreds and thousands of peasant proprietors and small farmers, each of whom can keep a mederate number of fowls almost without auy cost at all, eggs are produced in great quantity, and consequently are sold by the producer at a rery low price. These are bronght by the wires of the producers into the weekly markets, or are collected by the agents of the egg merchants, and are packed in chests and shipped to England at prices lower than they can be produced in this country. It is as senseless to bemoan the amount that is paid to the Russian and American for the whent which is absolutely necessary for the support of our population, as to bewail the cost of the eggs which are imported into this country.

Short-sighted persons, legarding only the cost of fresh eggs which the consumer living in large towns must pay, and not recognising the small sums paid to producers in distant localities, come to the conclusion that fortunes may be made by keeping poultry on a large scale. How fallacious such a mode of reasoning may be is proved by reading the returns of onr markets. In the Western Morning Neus of March 9, 1891, the prices of English eggs in the market at Totnes were $7 d$. to $8 d$. a dozen; at Ashburton, $8 d$. a dozen; at Kingsbridge, $9 d$. ; and at Launceston, Bodmin, and Padstow, they were stated to be twenty to twenty-two a shilling. In March, eggs are necessarily getting 
cheaper, as the fowls are daily becoming more prolific; it is therefore obvious that it could not be in the interest of the producer to keep them on hand-practicalls, therefore, thes are all new-laid. These prices in the open markets are, to say the least, worthy of the consideration of all those who think egg farms likely to be paying investments. There are certain localities, however, close to large towns, or near fashionable watering places, \&c., where the demand for fresh eggs at certain seasons exceeds the supply, and the price consequently ranges high. Under these circumstances it mar be desirable to keep hens for the supply of eggs rather than for the production of chickens. If eggs exclusirels are wanted, I can recommend no breed better than the common farmyard black Minorca, aroiding those that have been bred exclusively for fancr points. If eggs are specially wanted in winter, early hatched pullets alone cau be depended on. If they are required during the summer and autumn months, pullets hatched in May and June will answer quite well. Of course, eggs will be produced much more abundantly if the fowls have a free range and can supply themselves with grubs, worms, and a large portion of their own food.

It is singular to notice the difference in the appetite of the hen when she is producing eggs and when she is not doing so. Thus the large earthworms that come out on the grass after a mild rain are greatly sought after and devoured by laying hens, but are generally refused by them when they are not laying. Of course, hens cannot be expected to lay or produce eggs without they obtain the material out of which to form them. It is therefore very desirable to feed the laying hens well, but the food should not be too fattening. Maize, therefore, should be scantily employed, except in winter, when it may form a portion of the dietary. If the forls have a free range-which they must have if they are to be kept profitably-feeding twice a day is amply sufficient. At these times the laying hens should be well fed, the food, for the reason before stated, being scattered as widely as possible in the grass. No scraps or other food should be given at mid-day, as is often the custom, as this intermittent feeding leads them to hang about the homestead in place of seeking their own food in the open.

Under no circumstances should fowls be kept shut up in the fowlhouse till seven or eight o'clock in the day, as is often the case. On the contrary, they should be allowed out in the open at dar- 
break, when they obtain a Iarge number of worms that have not yet retreated into the ground.

When eggs alone are required it will be found much more adrantageous to keep pullets and roung hens only, as they lay much more abundantly during their first and second seasons than they do subsequently. A relas of young pullets, therefore, should always be prorided. It is much better to get rid of the older hens at $1 s$. or $1 s .6 d$. each than to keep them on as egs producers. I would recommend, therefore, that all the hens should, at the end of the second summer, before ther come into moult, he disposed of-eaten, sold, or eren giren away-rather than kept to lar eggs.

Care should be taken that the quality of the eggs produced is of a high character. Thes should be perfectly clean; and this can be ensured by providing nests of clean, sweet straw. If the material of which the nests are formed is mouldr, the eggs themselves acquire a mouldy flavour-most offensire to the consumer; and the same result also follows the feeding of the heus on mouldy corn. If the laring heus are fed upon fish refuse or fish biscuit, such as is made for dogs, the eggs will acquire a bad flavour, which will continue for some time after the food is discontinued. So easily are egrgs affected by the food that the rolks of the eggs laid by ducks that hare access to acorns are stained of a blackish colour by the tannin of the acorn acting on the iron in the yolk. With regard to the quality of the eggs as laid liy different breeds, I have never been able to detect any difference. Certain rarieties are sometimes recommended as being the layers of the most delicious eggs; but the quality of the egg does not depend so much on the breed as on the feeding. Take poultry of any breed, feed them well, under natural conditions, and the eggs will be of first-rate quality. On the other hand, give them moulds food and allow them to lay in dirty houses, where the eggs become tainted by the foul atmosphere, and the will be rery inferior in character.

To obtain eggs with good thick shells, which render them more safely coureyed from place to place, it is necessary to provide the hens with the material of which the shells are formed. For this purpose, in districts where there is but little lime or chalk in the soil, it will be found exceedingly desirable to crush up oyster shells, which will be most greedily deroured; or bones mar be giren after being crushed on a block with the back of a hatchet. These latter are much relished, and are particularly adrantageous as 
furnishing a supply of animal food and calcareous matter at the same time.

In some places far remote from towns it will be found more advantageous to preserve eggs for the use of the confectioner or other large consumer than to force them into the market. Of course, preserved eggs never command the price of those that are freshly laid; but they are of value, and realise a remunerative return at the time of the year when eggs are most scarce.

Eggs should not be preserved by greasing them, but by placing them in water made milky by stirring in some freshly slaked lime, or packing them in dry salt. To ensure a successful result it is absolutely necessary that the eggs should be put down immediately they are laid, as those sereral days old do not admit of being advantageously preserved. 


\section{CHAPTER XVII. \\ BREEDING FOR THE MARKET.-CHICKETS.}

THE best forrls that appear in the London markets are those usually termed Surrey and Sussex fowls. Ther may be characterised as being of the old-fashioned Dorking trpe, sometimes with and sometimes without the extra toe. They are not bred by the cottagers for fancy points, but for table purposes. These forls are bought by the higglers, who compete eagerly for them, often bespeaking clutches long before they are fit to take awas, and they are either fattened hy them or sold to the fattening establishments. I have long maintained that for table purposes it is more adrantageous to breed cross-bred forls than any rariety that is now known. I beliere that a good short-legged Indian game cock, or one of the old English fighting game, crossed with Dorking hens, or a Dorking cock with short-legged Indian or old English game hens, will produce plumper, hearier, and more meaty birds than the pure Dorkings of the modern exhibition strain, that are bred for size, feather, and comb, and not for plumpness of breast. I hare been asked to award the prizes at sereral of the shows of dead poultry, including those at Birmingham and the Dairy Show at the Agricultural Hall, and I bare alwars found these cross-bred birds superior to ans others that hare been exhibited. At the Islington Dairy Show of 1890 the first prize in the cross-bred classes, both for cockerels and pullets, went to birds that were so bred. As I awarded the prizes, I prefer taking the description of the forls that appeared in the Bazaar rather than giring ms own account. Speaking of the cross-bred birds, the writer says :

"The best pair were a cross between an Indian game cock and a Dorking hen. They mere rery white in the feet, rery large, plump, and full of quality. The skin was of a delicate texture and colour, and they were all round a grand pair of table fowls. . . . In the pullet class the birds were produced from an Indian game cock and a Dorking hen. Ther were superb in appearance, colour, and 
skin, quality of flesh, fineness of bone, and, if we except a slight tinge in the colour of the feet, we should consider them very near perfection. They were also admirably trussed, and even more attractive on this account."

At the Dairy Show of 1891 the prizes were awarded for weight, quality and plumpness being apparently regarded as of less value, consequently, in the cross-bred classes fowls bred between the Dorking and Langshan took the first prizes. With the co-operation of Mr Titus Barham, the president of the Dairy Fa'rmers' Association, I was enabled to make a very satisfactory examination of several of the fowls that received prizes in the classes for dead poultry. Mr Barham and I shared the two pairs of pullets which took first and second prizes in the cross-bred class. I regarded the second prize pair, though smaller than the first prize birds, as the best in the show, and far superior to the larger and coarser couple which were placed above them. The two pairs were divided between Mr Barham and myself, so that one of each should be cooked together and tested on our respective tables, in order that we might come to independent conclusions as to their merits. The cross-bred Indian game and Dorking that fell to my share weighed, as it came from the show, 4lb. 120z. $=760 \mathrm{z}$. When drawn and trussed for roasting, the weight of the bird was $61 \mathrm{oz}$; that is to sar, it had lost 15oz. of what may be termed offal--say, the feet, neck, head, and intestines. This loss, disregarding fractions, was one-fifth of its weight.

The larger pullet, that took the first prize, was bred between Indian game and Langshan ; its weight was 5lb. $60 \mathrm{z} .=860 \%$. After being drawn and trussed for cooking, it weighed $66 \mathrm{oz}$., having lost during this process $20 \mathrm{oz}$. of offal. In round numbers, it had lost one-quarter of its weight - a much larger proportion than the crossbred Dorking. When tested on the table, there conld not be the slightest doubt as to which was the superior bird in quality. The Dorking cross was better flavoured, more delicate and finer in texture, than the other-altogether a superior bird in quality and also in the quantity of flesh upon the breast. Mr Barham tested his at his own table, and his guests were all of the same opinionwhich decision they came to quite irrespective of any knowledge of the verdict that was given in $\mathrm{mr}$ establishment.

The difference in the value of the birds was further shown in the weight of the bones, which were separated and weighed one against the other after cooking. Those of the Iangshan cross were larger 
and heavier than those of the Dorking. I do not know any experiment that could have been conducted more satisfactorily. These two pairs of birds, fortunately for the comparison, belonged to the same exhibitor, Mrs Fricker. They had both been fattened and treated in precisely the same manner. They were killed (after haring been duly fasted, so that they were perfectly empty of food) by piercing the brain through the roof of the mouth, and the blood had been allowed to escape. They were well plucked and carefully trussed, so as to make good marketable forls.

The second prize pair were one of the best-looking couple of pullets, as to quality and plumpness, that I have ever seen at an English show, and, had anything but weight been cousidered, should have receired the medal for the best pen exhibited.

Since testing the merits of these pullets I have tested practically another Langshan half-breed, also from the Dairy Show. Its loss in being prepared for cooking was one fourth of its weight. The bird being older, the quality of the flesh was not equal to that of the first one examined, and the breast bone had a narrow keel, so that it could not carry a large amount of flesh.

The Langshan cross may give size, and make large, hardy, useful chickens for the family, but I do not think that it will erer produce a first-class table fowl for the market.

In the official report on the dead poultry exhibited for competition at the show of the Dairy Farmers' Association, 1892, it is stated: "The judge (Mr. John Baily) is conrinced that there is no forl equal to the Dorking pure." The value of this remark mar be inferred from the fact that the medal for the best entry of dead poultry exhibited in the show was ararded by the same judge to Miss Gubbins, of Cork, for eross-bred fowls between the Indian game and Dorking, bred in the manner I have adrocated for so many years. The success of this lady is not exceptional With the same strain of birds she has always maintained the very highest position wherever her fowls have been exhibited.

The cross of the Cochin or the Brahma with the Dorking, though often giving inereased size, neither improves the quality nor the amount of flesh upon the breast. The result is a coarser bird, well adapted for home cousumption, and possibly for some markets, but it is never so fine in the bone or so plump in the breast as the cross with the Old English or Indian game.

Mr. Bevington tells me that he thought he had improved on the laying qualities and hardihood of the birds as famern's stock, by 
breeding from these cross-bred Brahma-Dorking hens with Indian game cocks, as he had many of their chickens doing well in January, and he regarded them as hardier and faster growing than those bred from Indian game and pure Dorking, but he adds :

"Alas, the Brabma cross will come out, and all the birds I hare exhibited this rear have lost first honours by reason of the coarseness which arises from the Brahma. . . . I am very interested in the improvement of table poultry in this neighbourhood, and, indeed, everywhere. I think I have tried almost every known breed and cross, and I have now settled down to the firm conviction that the very best table poultry are produced by crossing large, heavy, short-legged Indian game two-year-old hens with active short-legged, plump-breasted Dorking cocks.

"For improving the poultry of the district, the plan I go upronand I find it answers well-is to give out settings of eggs to any farmers or cottagers who may want them; and they give me back one chicken out of every brood when four wonths old. Br this means thes are put to no immediate ontlay-to which they strongly object; they gradually improre their stock, and get birds worth sending to market, instead of the miserable things that are a reproach and a byword to the county of Essex."

I have seen very good results from crossing the ordinary Malay with the Dorking, and have hard occasion to give prizes to such birds, but the Malay is too long on the leg to breed a very first-class table fowl, and is certainly not to be preferred to the Indian game for this purpose.

The Azeel, or true Indian fighting cock, is, perhaps, the most plump and meaty bird that exists. Its drawbacks, from its combativeness and want of fertility, I have already spoken of, but the excellence of its cross with the Dorking cannot be denied. Where it is employed, an Azeel cock should always be run with Dorking hens, the size heing in all cases dependent on that of the female parent.

Many of the recently introduced breeds are vaunted by their owners as possessing first-class qualities as table fowl, but it is remarkable that they rarely put in an appearance at the competitions of dead poultry that are held, and, when ther do, they are usually relegated to a very inferior position. The best of the Asiatic breeds as a table bird is undoubtedly the Langshan, but a farmer would be very ill-advised who would breed it for market 
purposes. The same mar be said of the recently manufactured breeds, the Wyandottes, Orpingtons, Plymouth Rocks, and others. The latter, though useful all-round birds for family purposes, are not sufficiently plump, and too brilliantly yellow in the skin, to make good table fowl; consequently they are not esteemed by the fatteners.

The preparation for the market varies considerably, according to the circumstances under which the fowls are reared. Some persons may find it more advantageous to sell their birds privately, others to the higglers who buy for the fatteners; and in some instances it will be more profitable for the rearer to fatten his own birds.

It is needless to remark that chickens intended for the table must be kept in good condition during the whole of their lives. No subsequent treatment can make the poorly fed chickens, which are brought over in large numbers in crates from Ireland for the use of the fatteners in England, into table-fowl at all equal in merit to those which are reared $b r$ the peasants and small farmers in Sussex and Surrey, and are bought at a much higher price by the fatteners. The latter are generalls good table breeds, which cannot be said of the Irish birds; but, setting that advantage aside, there is a great superiority in the chickens that have been well fed and dereloped during every period of their lives, over the half-starred, tough, and skinny birds which hare been treated differently.

The determination of the age at which chickens should be shut up in order to be fattened for the table is a point of very great importance, if first-rate results are required. The general rule is. to shut up the cockerels "as soon as their tails begin to turn"that is, as soon as the two long central tail-feathers uvertop the straight feathers of the tail-and the pullets before they have laid.

The object of these directions is erident; as soon as the young birds begin to exercise their reproductive functions, they cease to be first-class table poultry. It is quite true they are edible, but. they are not birds that one would wish to place before a gourmet; nor will they command the highest price in a good market; and, what is still more to the point, not only is the quality lessened, but the quantity, in proportion to the amount of food consumed, is seriously interfered with, for the birds cease to grow or fatten at the rate they did previously.

It is not geverally known that br keeping each sex not only apart, but absolutel out of sight of the other, both the cockerels 
and pullets may be grown to a much greater size than usual without the quality of the flesh being deteriorated. If the young cocks are separated as soon as their sex can be distinguished, and removed out of the sight of the hens, they do not become hard and coarse, but grow to a larger size than they otherwise would. I am not recommending that they should be shut up in small runs or pens, but that they should be kept quite apart, and even out of hearing of the other sex. If this is done, the severe and painful operation of caponising is quite unnecessary; in fact, it is not generally performed, even on the finest birds exhibited at the fat poultry shows held in France.

Keeping the sexual proclivities in abeyance by separation is sometimes practised with regard to Gold or Amherst Pheasants. These birds, as ever rearer of them is aware, are most pugnacious, the males killing not only one another, but also the females. Nevertheless, a score of Gold cocks in full plumage may be kept in one inclosure, affording one of the most gorgeous sights in the animal kingdom, provided only that the whole of the males were put together whilst chicken, and had never been allowed to associate with the hens. Under these circumstances they live peaceably, but the introduction of a single hen would be the signal for the commencement of a "battle roval," from which it is probable not a single bird would emerge alive.

If a corresponding plan is adopted with poultry, the roung cocks can be kept until late in the season, or even far into the new year, without deterioration, but, on the other hand, with great improvement as regards size.

The same remarks are true, mutatis mutandis, with regard to the hens. A fowl that has laid an egg is herself edible, but cannot for a moment be compared to a pullet that has not laid; the quality, tenderuess, and sapidity of the flesh of the latter are greatly superior. Hence those pullets that are intended to be fattened for the table should not be allowed to run promiscuously with the other birds in the poultry yard; if first-class poulards are required, they should be separated.

It may be said that this separation of the sexes in poultry is too much trouble to be generally followed. This may be true, but in many places where large numbers of poultry are reared for home consumption or the market, it could be done without any great increase of trouble, and the improvement in the birds would amply repay that which was necessary. 
To those who rear for their own tables, and hare facilities for carrying these suggestions into effect, I can strongly recommend them; but they must take the strictest precautions that the birds are separated before they have manifested any sexual proclivities.

This adrice has leen confirmed by the experience of breeders who hare eridently raised Game fowls for the table or for other practical purposes. Mr. J. S. Turner, writing on the subject in the Stockireper, says :

"I noticed Mr. Tegetmeier's article, and it struck me some of your readers might be interested in our experience of the subject. My father has bept black-red Game for years-the oldfashioned short-legged sort. Thes are splendid table fowls, much meat and little bone, and when lilled and hung in their feathers for a reek or two equal pheasants. We do not care to begin killing them till November, by which time the roung cockerels would probably have saved us the trouble by killing earh other if left with the hens. We don't wait for their tails to turn in, but as soon as we can distinguish cockerels from pullets, the former are all sent to an off farmstead, where there is not another chicken within a mile of them. We had ahout sixty this year. A few of the best we generally sell for breeding, the rest we kill as wanted, and hang from a fortnight to six weeks. We began killing this year the beginning of November, and they were as tender as spring chickens up till the end of March. For any man who has an off place for cockerels there is no hetter loreed than the old Game as table fowls."

No stronger confirmation of the utility of separating the sexes could be required. With regard to Game fowl, which are so admirable as table fowls for home use, though rather small for the market, the great objection has been their tendency to fight; this, however, is entirely obviated when the cockerels are kept away from the hens. In contrast with the good quality of the separated same cockerels, Mr. Turner stated that a number of Andalusian cockerels running with the hens, though younger than any of the Game, "were as tough as leather" when brought to table. This would not have been the case had they also been separated, as they would have been tender, although far inferior in plumpness and flavour to the Game.

An interesting experiment was tried after the Islington Dairy Show held in 1890. After the awarding of the prizes, Mr Tim. Bevington, one of the successful competitors, secured no less than 
eight of the prize birds, in order to test their merits on the table. These birds were carefull cooked, and constituted the pièces de résistance at a dinner which was giren at a well-known literary club. The whole of the birds may be described as rery magnificent specimens of first-class table poultry. Their size may be inferred from the fact that one of the members of the club, seeing these roast chickens on the table, inquired, "What are you six fellows doing to want eight turkeys for your diuner?" As one of the party who carefully tested the merits of these birds, to which I had previously awarded the prizes, I can testify to the fact that in quality of flesh the cockerels of Mr. Berington, that had not been put up to fatten, but that had been separated from the hens in the manner recommended, rere certainly superior in succulence and flavour. The birds were fat enough to take prizes in a very serere competition, and I certainly preferred them to others, which I had placed higher in the prize list, as I had to award the prizes to them as market as well as table poultry. It is hardly necessary to say that they were well bred, being crossed between the Dorking and Indian game.

The value of the cross between Indian Game and Dorking has been maintained for some years by Mr. C. L. Sutherland, who rears all his table fowl from these breeds; but, as the Indian Game hens are not remarkable as larers, he prefers rumning Dorking hens with Indian Game cocks, when he finds the great majority of the chicken come with white skin and legs. These cross-bred birds are close-feathered, handsome fowls, good sitters and mothers, and, like most cross breeds, very good lavers, the eggs being of a pale buff colour. 


\section{OHAPTER XVIII. FATTENING.}

ThE house in which poultry are fattened should be free from draughts of cold air, and kept at a moderately warm and uniform temperature. Quietude being especially desirable, the house should be so situated as not to be accessible to the fowls at liberty; and it should be partially darkened, if possible. It is also impor-
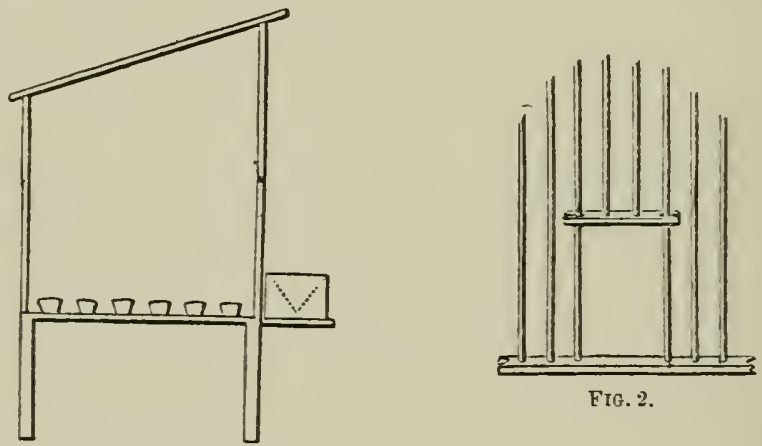

EIG. 2.

FIG. 1.

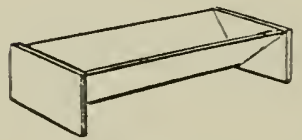

FIG. 3.

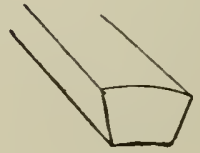

Fig. 4.

Details of Fattenisg Coop.

Fig. 1. End riew of Coop and Trough. Fig. 2. Sliding Bars in place of doors.

Fig. 3. Feeding Trough. Fig. 4. End of Bottom Bar, showing its shape.

tant, in the highest degree, that it should be perfectly dry, as it is scarcely necessary to add that a fowl suffering from cold and inflammation is not likely to fatten.

The fattening coops should be $2 \mathrm{ft}$. $6 \mathrm{in}$. or $2 \mathrm{ft}$. $8 \mathrm{in}$. high in front, and about $2 \mathrm{ft}$. deev, with a boarded roof sloping backwards; the 
back and ends should be closed, and the bottom made of flat bars with rounded edges, $2 \mathrm{in}$. wide at the top and narrower beneath, so as to prevent the droppings sticking to the sides. These bars should run from end to end of the coop (not from back to front), and they should be $2 \mathrm{in}$. apart on the upper sides. The front of the coop should consist of rounded bars $3 \mathrm{in}$. apart, and two rods connected together below, and sliding through holes made in the roof, will be found more secnre than a door. Before the front should run a ledge to support the feeding troughs, which are best made by joining two pieces of wood at a right augle and securing the ends by letting them into grooves in stout end pieces.

The fattening coops should stand on legs to raise them a convenient height from the ground, so that the droppings may fall on a loose board and be removed daily; or each may have a shallow drawer underneath, which is daily filled with fresh earth. In cold weather the front should be corered up with matting or some other warm material at night.

The length of the coop must depend on the number of fowls that it is required to contain, but it is never advisable to place more than ten or a dozen together, and if strange fowls are put up, care must be taken that they agree, as otherwise the constant excitement would prevent their fattening.

It occasionally happens that fowls are infested with lice to such a degree that they become irritable and refuse to fatten; in these cases, a little of the flowers of brimstone dusted under the feathers before cooping them, immediately expels the vermin.

The fowls when first cooped had better be left some hours without food. By this time they will have become very hungry, and will eat with avidity; whereas, if food is placed before them on their first imprisonment, they often refuse it for some time. The best food for them is coarse oatmeal or ground oats mixed with scalding milk; barley meal is good, but not equal in its fattening properties to oatmeal; this is evident from the fact that the latter contains $6 \mathrm{lb}$. of fat in every hundred, barley meal only 2lb. Maize meal is not advantageous, for it produces an abundance of yellow, oily fat not desirable in a market fowl. The birds should be fed at regular intervals. The first meal should be given very early-at five o'clock in the summer, at darbreak in winter; the second at noon, the last just before dusk. Discretion should be exereised in the quantity given. It should be fully as much as the fowls can 
eat, and no more. Should any be left from one meal to another, it should be thrown out to the other fowls, the troughs scalded out, and fresh food given. Great care should be taken to prevent the troughs, becoming sour. In order to do this they should frequently be scalded and dried in the sum.

If it is considered desirable to use any animal fat, the hard trimmings of loins of mutton will be found most advantageous. They should be chopped up and mixed with the meal before the scalding liquor is poured on; or, still better, may be boiled in the liquor before it is poured orer the meal. A supply of clean water and some coarse sand or fine gravel are necessary. Many persons omit the latter; but, as the due grinding action of the gizzard cannot go on without it, it is most conducive to the proper digestion of the food. In places where the millers prepare the finest flour, usually known as "pastry whites," they have a very superior kind of fine middlings or thirds. This is frequently sold, in London at least, under the name of " coarse country flour." It is cheaper than the best oatmeal, and may be in part advantageously substituted for it. The most conrenient mode of using it is to bake it until it becomes quite hot, when, if cold water is poured on it, it becomes a crumbly mass. The common sharps or coarser middlings will not answer, as they contain too small a portion of nutriment, and purge the forls.

If it be thought fit to follow the practice of cramming, the oatmeal should be mised rather stiff, and then rolled into crams about 2in. long, and as thick as a man's little finger. Six or seven of these are then taken, dipped in milk or water, and placed in the back of the mouth of the fowl, which is held in the lap, the mouth being openedffwith the aid of the left hand. In this manner the birds should be fed three times a dar, care being always taken to ascertain that the last meal has completely passed out of the crop before the next is given. Sometimes, in cramming, the food will become hardened in the erop. In this case, no further food should be given, but some lukewarm water should be poured down the throat, and the mass loosened by gentle pressure with the fingers.

At the present time, when the process of cramming is followed, especially on a large scale, it is usually done with the aid of some machine, semi-liquid in the place of solid food being used. Several machines have been devised for this purpose. The most recent, and that which seems to combine all the advantages, is that made 
by Hearson. It consists of a reserroir for the food, with a small pump below, which is worked by the foot of the crammer. The apparatus is so constructed that the exact amount of food given to the fowls can be regulated by a stop, so that over-filling the crop, is aroided. The birds that are to be fatted are generally fed in coops, as previously described, for ten days or a fortnight before being crammed. When in use the cramming machine is filled witb.

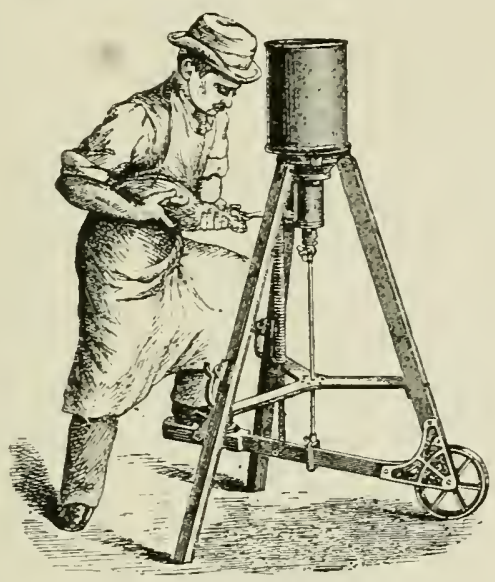

Hearson's Cramilug Machine.

semi-liquid food, wheeled in front of the fattening coop, and the fowls are taken ont successirely and held under one arm; the bird's bill is opened and a soft flexible indiarubber tube passed about six inches down the gullet, and as much soft food is discharged into the crop as is sufficient. The bird is then returned to the cage and others dealt with in the same manner. So expert do the crammers become, that several hundred birds an hour can be fed in this way by one man. Mr. Berington informs me that he has had the most successful results from using this machine with ground oats (not oatmeal), mixed thin with scalded skimmed milk.

In place of cooping the fowls, another plan is frequently adopted on the Continent, in which each fowl is tethered by both legs in a separate compartment. These compartments are open below at the back, so that the excrement of the fowl falls out of the cage on to the floor. The fowl should be tethered br 
a brail on each leg, as before described for securing the hens with chicken.

Unless there is a demand for very fat fowls, it will not be found necessary to cram them, as usually, after a fortnight to three weeks' feeding, those that are allowed to pick up their own food will become sufficiently fat for all useful purposes. The chicken that are to be put np to fatten should be from twelve to fourteen weeks old in the summer, and rather older in the winter, when they do not grow so rapidly. If they are required to be kept still longer, it is absolutely necessary, to prevent them becoining tough and hard, that the sexes should be separated at an early age.

The mode of killing the fowls when they are required varies in different parts. Abroad, the bird is generally killed by either thrusting a sharp knife backwards into the brain through the roof of the mouth, or by cutting the large vessels of the throat; but in Fugland the almost universal practice is to dislocate the head of the birds required for food. The bird is taken by the hocks with the left hand, and the head held in the right, the back of the bird being upwards. In order to dislocate the head from the neck, it is suddenly bent backwards, the neck of the fowl being forcibly stretched at the same time. To do this more effectually, the left hand should be held against the left thigh, and the right hand with the head against the right thigh, almost close to the knee. In this position both hands are steadied, and by widening the distance between the knees, whilst the head is bent back, it slips instantly out of the socket. The act is instantaneous, and there is no pain to the bird, inasmuch as the spinal cord and all the large nerves are divided, as well as the arteries and veins ; in fact, after the operation, the head is only connected with the body by the skin of the neck. Practically it has been beheaded, and all sensation is instantly at an end. It is quite true that muscular contraction exists for several minutes, consequently, if the fowl is put down it flutters about and gives persons the idea that it is still alive, so much so, that some very unsatisfactory prosecutions have taken place for the punishment of persons plucking forls alive, for as the feathers come out with much greater facility immediately after the fowl is killed, the pluckers, having killed the bird, immediately proceed to denude it of its feathers, and this may be done before muscular contraction ceases, although the head of the bird is separated from the body. 
There is no doubt that this is the most humane manner of killing fowls, as it is instantaneous, which is not the case if they are killed by bleeding.

When carefully plucked the wings should be twisted behind the back, the hocks placed together, and the bird placed on its back with the head and neck hanging down, so that as much blood as possible may drain into the neck.

If thought desirable, the fowls may be placed in such a manner that a board may be put on the top of them, and the breast pressed flat, but plump fowls do not require this, and are not improved by the operation. Under no circumstances should the breast bone be broken, as the value of the fowl is much deteriorated. Should the legs be dirty, they should be washed before the fowl is placed in position.

A fowl killed for the market should not be hung up and allowed to stiffen into a shape that cannot be readily put into marketable form afterwards.

Before killing, it is absolutely necessary to fast the fowls from fourteen to sixteen hours. It is therefore better that they should be killed early in the morning after a night fast, than in the evening, when they have been feasting all day. Fowls, therefore, that are intended to be killed early in the morning, should have both food and water taken away from them not later than four or five o'clock the evening before; the intestines will then be free of food, and the birds will keep a much longer time than if the crops and bowels are full. 


\section{CHAPTER XIX.}

\section{SHOWING AND TRUSSING DEAD POULTRT.}

At our agricultural shows, the utility of the birds is, in almost all cases, entirely ignored. Prizes are giren, not to poultry as animals useful for food, but as fancy stock; feathers, combs, and markings being estimated in preference to qualities which are appreciated in the poultry market or on the table. When prizes are offered for dead birds, regulations as to the manner in which they should be exhibited are seldom issued. Thes are allowed to be trussed in such a mode that their bad qualities may be, as far as possible, concealed, and their good ones exaggerated. In the French mode of trussing the choicest forls, the back is usually exhibited in place of the breast, the hocks being tied together orer the centre of the breast, and three or four of the quill feathers of the wings, which are left in the pinions, are pulled between them. This method, howerer, is hardly likely to come into fashion in this country.

At English shows the fowls are generally exhibited undrawn, but trussed and skewered. The toes are tightly drawn in by the sides of the breast, and are pulled together by strings which are passed through the body or across the back. This is done with the object of forcing up the flesh on the breast, so as to make the fowl look much plumper than it naturally is. By this contricance a poor fowl may, to an inexperienced person, be made to look much better than one that is really superior to it. No such trussing should be allowed at a show of dead poultry. The hocks should be merely tied together, and the forls shown without the breast-bone heing broken, as seen in the engraring. The prizes should be awarded for the gooduess of the fowls, and not for the skill of the exhibitor.

All fowls should be shown in precisely the same manner, and the regulations should state that they should be exhibited "plucked," but not drawn or trussed. Thes should be displayed 
on a raised shelf, with the head hanging down in the position represented. It may be said that the fowls would look much more attractive if dressed for the table; but if so exhibited the

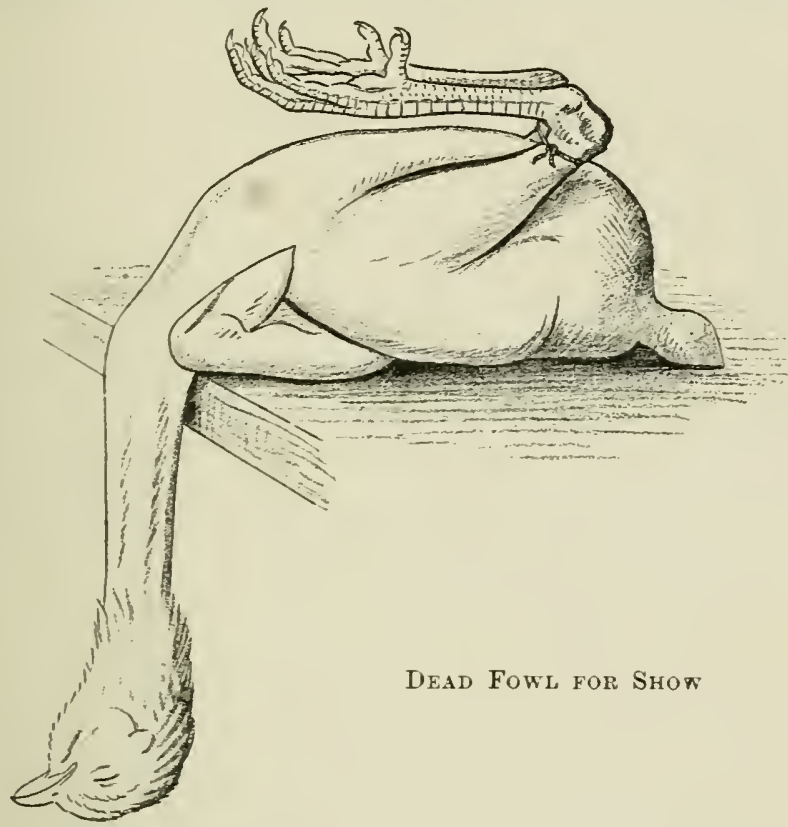

prize would be awarded for the skill of the trusser rather than for the goodness of the fowl.

The second engraving represents a fowl as trussed for roasting

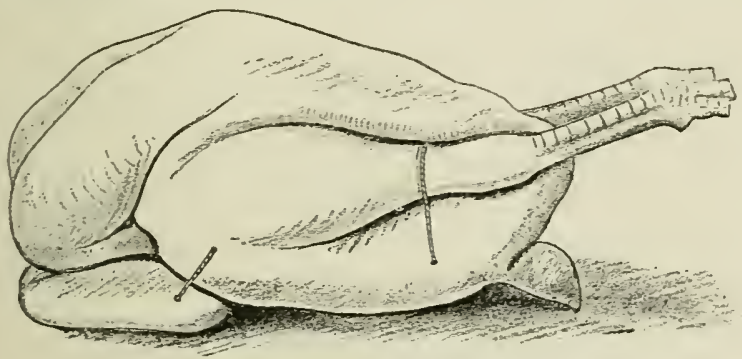

Fowl Tressed for Roasting.

according to the plan pursued for the table of the highest lady in the land. The manner in which this is done is so superior to that 
ordinarily adopted that it is worth a detailed description, the mode of operating being that which is followed by Messrs. Bellamy, of Jermyn-street. The dresser takes the dead fowl, and cuts across the skin at the back of the neck, about $2 \frac{1}{2}$ inches from the body. The knife is then passed under the skin, down towards the junction of the neck with the body, making a flap out of the skin of the back of the neck. This exposes at once the bones of the neck, which are then cut across where they join the body. The crop can then be readily extracted, and the skin of the front of the neck quite cut across, when the head and neck are at once removed.

What may be regarded as a great improvement in the preparation of a fowl for the table is then generally followed by Messrs. Bellamy. This improvement consists in the removal of the merrythought, which is done almost with a touch, the point of the knife passing between it and the flesh of the breast, when it may be taken away without even the smallest quantity of meat being attached to it. The object gained in the removal of this bone is to allow the flesh of the breast to be cut away more conveniently, and in longer slices, in carving.

After the removal of the head and neck, the finger is passed into the interior of the body, and all the structures that can be reached by it are loosened, the finger being passed round the interior as far as possible; this should be throughly done. The fowl is then rested on the table, tail upwards, and a somewhat deep and large incision is made straight across the body, between the tail and vent. This cut enables the finger of the trusser to be placed round the bowel, a loop of which is pulled out, and the knife, being placed under the loop, cuts out the vent without the slightest difficulty, leaving an opening sufficiently large to enable the fingers to be passed into the interior to seize hold of the gizzard, when, if the loosening in the front has been properly accomplished, the whole of the interior of the fowl, including the intestines, liver, and heart, are drawn away in one mass. This method of operating is much more expeditious, more cleanly, and infinitely more workmanlike than that usually followed. Should the fowl have been one of extreme fatness, a little rolling of the body under the hand before beginning to draw it suffices to loosen the gizzard from the large mass of abdominal fat which is occasionally present in the interior.

To complete the trussing of the fowl in the manner shown in the figure, a trissing needle 8 inches long, threaded with thin strong 
string, is requisite. The legs being brought into the position shown in the drawing, the needle is passed through the leg, close up to the joint, then through the body and the leg on the other side, and pulled out; the fowl is then turned over, and the needle, still carrying the string, is passed through the joint and the pinion of each wing, when it comes out close to where it was first put into the fowl, and the two ends of the string are tied tightly together, keeping the legs and the wings in position. To secure the ends of the legs, the needle, with the string attached, is passed through the body close to the backbone, over the leg, and back through the body under the end of the breast-bone. It is then tied, and the fowl presents the appearance shown in our figure, the knots in the two strings not being shown by the draughtsman. The ends of the toes are cut off, and it is customary with the best poulterers to remove the extreme point of the pinion and the small fold of loose skin which is attached to it before trussing, in order to prevent these becoming scorched in cooking.

It is needless to speak of the superiority of this mode of trussing over that usually adopted. No skewers, which have to be remored before it can be served on the table, are left in the fowl, nor are any large incisions made in the flesh, letting out the goodness of the meat. The strings that are used are cut and drawn away without trouble, and do not interfere with the carving of the fowl. It is needless to say that the breast-bone should never be broken, as it is impossible to carve a bird satisfactorily when that has been done.

The ease and rapidity with which a fowl may be prepared for roasting in this manner is remarkable, and its neat and attractive appearance not the least adrantage.

The preparation of a fowl for boiling is usually performed in a somewhat more intricate manner. The method adopted is somewhat different, and is represented in the following engraving.

I am also indebted to the very skilled operator at Messrs. Bellamy's for a careful demonstration of the wethod pursued, which may be described as follows: The fowl, when taken in hand after having been plucked, is, in the first instance, treated as one required for roasting. The extreme tip of the wing and the thumb pinion are cut away, as well as the loose strip of shin along the under side of the wing, which is left after the removal of the quill feathers. The proper mode of removing the neck, crop, and merrythought, and drawing the fowl, is the same in trussing for 
boiling as for roasting, but the subsequent proceedings are very different.

The fowl having been drawn, the fingers are passed from behind under the skin at the side of the breast, which is separated and loosened from the flesh round the joints of the leg, right down to the hock. This is done on both sides, and so effectually that by laying hold of the shank the fleshy part of the leg can readily be pushed up under the skin, but before this is done, a cross cut is made at the back of the leg lin. above the hock, and another about $1 \frac{1}{2} \mathrm{in}$. below the hock, but this is made in the front. These cuts are for the purpose of dividing the sinews and enabling the foot to be twisted right round, so as to come at the back of the fowl.

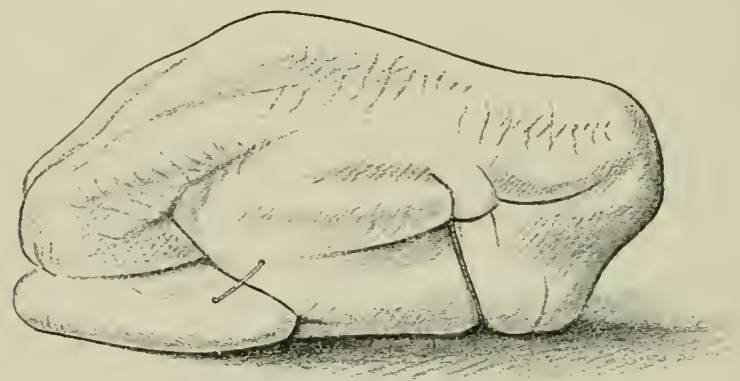

Fowl Trussed for BoIling.

Then, holding the foot in the hand, the hock is pushed through the first cut made in the skin, which is drawn down over it, and it disappears altogether from view. The shank is then cut across where it projects beyond the skin, and the foot is in this way removed, and, the hock being under the skin, no portion of the leg is visible. The fowl is then turned over, and it is customary to crack the shoulders by striking them between the wings and the spine with the back of the knife. This enables the wings to be brought closer to the body when the trussing is completed.

The long trussing needle, which is threaded with fine string, is then passed through the leg at the back of the knee from one side, and through the correspnnding part of the leg on the other, and through the pinion and joint of each wing. This brings the string to the same side where the needle was first passed through the leg, and the two ends are tied tightly together, thus securing the lugs and the wings firmly to the body with one tie, as is shown in the 
left hand side of the figure. In order to secure the ends of the legs which are thrust under the skin a second string is passed through the body above the hock (which must be felt for, as it cannot be seen), then under the breast-bone to the hock on the opposite side, and brought round behind the back and securely tied. The tail is then, as it were, pushed into the interior of the body, and the fowl, ready for boiling, appears as is shown in the figure.

The description may appear to include numerous details, but it is not difficult to follow the steps with a fowl in hand, and once learned it is not easily forgotten. 


\section{CHAPTER XX. \\ TURKEYS AND GUINEA FOWLS.}

IN suitable situations, where there is a good range and a dry soil, turkers may be kept with great advantage. It is useless, howerer, for anyone to think of keeping them unless the conditions are favourable. A free range is absolutely indispensable to their being kept to profit, and a clayey damp soil is fatal to success.

The best breed of turkers to employ is that known as the Cambridge, which has been crossed with the recently imported American. This fresh blood has induced not only increased size, but much greater hardihood of constitution. Many breeders have failed eutirely in profitable turkey rearing through breeding in-andin from the same stock year after year.

In selecting a stock bird for breeding for the market, a turkey cock of extreme size should not be chosen. The large birds bred and fatted for exhibition purposes are often unfertile, and apt to injure the hens. A dozen hens may be allowed to run with one cock turkey. The hens, if joung and well fed, will commence laying very early in the year, when the first eggs may be set under large broody hens, such as Cochins, Brahmas, or Dorkings. The nests are often concealed in hedges and other places where it is difficult to discover them; but it is not always desirable to let the hel sit where she makes her nest. On the eighth or tenth day the eggs should be tested as directed for those of fowls, and only those that are fertile replaced. The chickens are hatched at the end of the fourth week, on the trenty-eighth das. The nest, of course, should be made upon the ground, with the same precautions as those recommended for fowls. It is always adrantageous to sit two, or, still better, three hens at the same time, so that, should several of the eggs prove barren, those that are fertile can be given to one or two of the hens, and fresh eggs supplied to the other. If turkey hens are employed to sit on the eggs in preference to fowls, it is exceedingly important to see that they leave the nest every day, as 
they are apt to remain on their eggs too long and starve themselves. It is not desirable to sit the hens after the end of June, as late-hatched chicks rarely do well. In France, where a much larger number of turkeys are reared than in this country, the eggs produced late in the season are utilised for food, numbers of them being sent over to England. At the time of hatching, no interference whatever with the chickens is desirable. They should be left alone until the next day. No attempt at feeding them should be made, as during the first twenty-four or thirty hours they are digesting the yolk, which is drawn into the intestines at the period of hatching. On the following day atter they bave been hatehed they may, if the weather is fine, be placed out of doors in a sheltered situation, such as an open shed-the ground, if not perfectly dry, being covered with ashes or chaff.

For the first food of the young chickens, egg-and-milk (custard) will be found to be much better than chopped egg, which is generally given to them; and it may be mixed with bread dipped in milk and then squeezed dry. They require at first to be fed about erery two hours, beginning with daylight in the morning and finishing the last thing at night. The egg-and-milk should be continued for two or three weeks without being stinted, unless ants' eggs can be obtained in abundance, which will be found a valuable addition. In addition to egg-and-milk, fresh meal-andmilk can be given.

Turkeys at all periods of their lives eat a much larger amount of green food than fowls. They are especially fond of milky plants, such as dandelion and lettuces; and it will always be found most advantageous to grow a number of lettuces and let them rum to seed, using them in the milky condition for the food of the young turkeys; or chop'ped dandelions may be given. If well fed on natural food, and bred from strong, healthy parents that are not related, young turkeys are not so delicate as is generally imagined. If the weather necessitates keeping them indoors, they are subject to cramp; and therefore it will be found better to keep the hen, if she is cooped, under a large dry open shed or on a lawn or meadow, with the grass closely mown for some considerable distance around, as bas been adopted in pheasant rearing, and also for fowls.

With turkeys, as is the ease with pheasants, it is most desirable to use fresh ground for rearing every year. If the birds are infested with gapes one year, it is almost useless to try and rear others on the same ground the following season. When the 
weather is dry, it will be found very advantageons, although it is contrary to the usual custom, to allow the ben a free range during the warmer parts of the day. If she is well f fi1, she will not drag the young turkey chicks about until they become tired; and the scratch that she gets for them is of immense ardvautage. Unless extremely well fed and nourished, reared on dry soil, and bred from bealthy parents, turkeys are subject to cold $i$ " the head, which rapidly derelops into roup, in which state it is exceedingly infectious. They are said also to be rery delicate a little under three months old, when they begin to show the red heads which distinguish the cocks from the hens; hut, if well fed, they will not be found to suffer at this period. When they are fullv fledger, turkeys become very hardy. They will roos, in trees during the latter part of the sear without injury. When kept in a house, it will be found very desirable to separate them from the rommon fowls. The perches should not be more than $3 \mathrm{ft}$. or $4 \mathrm{ft}$. from the ground, otherwise there will be, as with fowls, the continual fighting for the highest plar:s, and bumble fert from leaping down on t" the hard ground The building should be rentilated, and kept scrupulonsly clean, but the birds should not be subjected to a draught. The stock birds must be well fed in winter with two nr three feeds a day. Ground oats or barles meal, with boiled potatoes, will be found much more advantageous than feeding them exclusively on whole corn.

In France, after the harrest is gathered, flocks of young turkeys are driven on to the stubbles, usually in charge of a girl, who, with a long, light pole, drives them out in the morning and returns with them at night. Here they feed on the grsen regetables to which they are so much addicted, and on the corn which would otherwise be wasted, and for some weeks obtain as much food as they can eat, without cost, and with advantage to the farmer.

Turkeys may be so fed as to be always ready for the market. To be fatted, they should be kept in a shed where sereral can be together, as a single bird will not fatten. Here they should be supplied with plenty of green stuff, a fair amount of grit, and oat, barley, or buckwheat meal mixed with milk. The food should he varied, so as to keep up the appetite. Maize meal is sometimes used; hut it always produces fat of a yellow colour and soft, oily consistence, instead of the white, firm character which is so much esteemed in the market.

In suitable situations, where there is sufficient amount of space, 
and where due attention can be given to the rearing of the young birds during the first few weeks of their lives, there is no breed of poultry that pays better than turkeys; but they must be carefully attended to from the first, and well fed during the whole of their lives. If in good condition, they realise about Christmas time a much larger sum per pound tban forls; and they also have this adrantage, that they can easily he sold privately or without being sunt to market, and so the profit on the sale does not go into the hands of the middleman.

Guinea fowls may be kept with advantage in many situations, especially where the soil is dry, the aspect warm and sunny, and there are trees or dense bushes in which the birds can ronst. They realise very fair prices in the markets in the spring, when ordinary game is going out of season, and chickens are not to be obrained. They are, however, not general favourites with farmers, some ol,jecting to the continuous cry of the hens, "come back," "come back," others to the fact of their almost always laying away in concealed nests, and to their not hatching until late in the season. when their chickens are too delicate to withstand the cold. Their noise cannot be obviated, but by taking away the eggs as they are laid, on being always left in the nest, a very large supply may be ohtained, as the hens generally lay on until Jul! or August hefore desiring to sit.

If young Guinea fowls are required, the eggs should be placed under some small broody hens in April or May. The chicks, when tirst hatched, are exceedingly elegant, being covered with striped down, which is set off by th" red colour of the legs and beaks, and they are rendered still more attractive by their extreme activity. In rearing young Guinea fowls, great care should be taken to feed them at very brief intervals of time, as they suffer much from eren a short deprivation of food. No diet will be found more advan. tageous than the egg and milk prepared in the form of custard. This should form a part of every meal for the first month, along with oatmeal mixed with milk and grits, and canary seed; and as the young broods grow up small tail-wheat, boiled vegetables, and potatoes may be added to their dietary. If ants' eggs can be obtained, it will be found very advantageous to employ them. Guinea fowls do well in dry coverts, but they are not desirable where pheasants are preserved, as they drive the latter away. 


\section{CHAPTER XXI. DUCKS.}

As usually kept, it is very doubtful whether ducks can be regarded as profitable to the farmer or small producer. There is, however, no doubt that, as ther are reared for the London market in the neighbourhood of Aylesbury, they can be produced most profitably.

The rearing of ducks in that district has been dereloped intu a systematic industry, the rules of which are well understood and carefully followed. The ducks are bred in the early season, raised under most favourable conditions to ensure their rapid growth, killed when the nourishment that has been bestowed on them has produced the best results, and before it is employed in the production of new feathers, and forwarded to the London markets at the season wheu the demand is greatest, and the prices consequently are highest.

The objections to duck keeping, as ordinarily followed, are many. In the first place, inferior lreeds of ducks are frequently kept-small coloured varieties, which do not arrive early at maturity, and which, when plucked, from the dark colour of the down, are not as attractive in the market as the white Aylesburys, which alone are reared by the experienced duckers. The superiority of this breed is rers convincingly demonstrated by Mr. Henry Digby in his very practical treatise. Writing of the Aylesiury, he states:

"The great size to which the attain at an early age, and the excellent flavour of their flesh, is unequalled by any other breed. It is rerr prolific, hardy, and a thorough forager; it thrires in almost any climate or on any soil, and, being of a pure white, it has adrantages orer those varieties which have ulany colours. For where colour and markings are a consideration, size, constitution, and laying propensities hare been sacrificed for these characteristics, thereby causing degeneration."

As MIr. Digby is a most successful rearer of various breeds of 
ducks for exhibition, his testimony as to the effect of breeding for colour may be taken as fully substantiating the statements I have made as to the result of breeding for the poultry shows in place of rearing useful stock for the table and market.

Farmyard ducks are often allowed to remain on the water at night, when the greater number of their eggs-those that are produced before the ducks become broody-are dropped in the water, when they sink, and their presence is not known until some months afterwards, when, having become rotten, they rise to the surface. The young ducks in most farmyards are allowed to go on the water when they do not grow rapidly, and they are not killed until they are far advanced in their moult, the nourishment that they have taken for the last few weeks having been devoted chiefly to the production of new feathers. The breeder of ducks for the market should act on the knowledge that the birds can be made to weigh as much at eight or ten weeks as they do at four or five months, and that they should be killed and sent to market when they command the highest prices.

To rear ducks successfully, the large white Aylesbury should be the breed selected. It may be not unprofitably crossed with the Pekin, if eggs are chiefly required. The store ducks should be well fed (which is most conveniently done by putting their oats or other corn in a tub of water) during the winter months, so as to induce laying at the earliest possible season. It is much better to allow the stock birds access to water and a free range, so that they provide themselves with a large amount of animal food in the form of grubs, worms, \&c. ; but they must be carefully shut up at night, or the eggs will be laid in the water and lost. Any old sheltered pigstye will answer for the purpose of keeping the drake and half a dozen ducks that will be found profitable to the small holder. It may be littered with short straw, dead leaves, or any other refuse of the sort. It is needless to say that it must be kept clean. No nests are necessary, as the eggs will be laid at random about the pen; but if the ducks are in good health and have a free range, the shells will be found so firm that they are not broken. These eggs should then be set under hens; in the duck-rearing districts large broody hens are exceedingly valuable in the early season, as there is a great demand for them for the purpose of hatching ducks' eggs.

The system pursued in the neighbourhood of Aylesbury has been so well described by Mr. J. K. Fowler, a very practical 
breeder, that I cannot do better than quote his words on the subject. Speaking of the Aylesburys, Mr. Fowler first describes the enormous quantities that are sent to London in the spring, a ton weight of ducklings, from six to eight weeks old, being not unfrequently taken in one night from the Aylesbury district by railway to the metropolis, where ther realise rery high prices. $\mathrm{He}$ theu goes ou to say that the duckers-as the breeders are calledare mostly provident labourers, who do not grudge giving their time and attention to their young broods as long as there is a good demand. The system by which this industry is carried on is rery simple. Almost erery cottager maintains a set of ducks, usually four or fire and a drake. These they keep in an outbuilding attached to their dwelling, and in some cases eren in the cottage itself. From them the duckers collect the eggs in the early part of the season, when they command a rery high price. In December, $\mathrm{Ml}$. Fowler says, as much as $12 \mathrm{~s}$. a dozen will be giren for the eggs of good ducks, the purchaser taking the chance of their being fertile. The ducks are mostly allowed access to the river which runs through the town, being distinguished by marks of paint of different colours. At night ther are driven into their respective homes, well fed and comfortably housed, and the eggs which are laid before the moruing are set as soon as possible under large hens. The ducks themselves are never allowed to sit. The hens are usually set in small hampers, or, what is still better, round cheese boxes, placed ou the ground. The nest is often made of ashes; but mould which is lept slightly damp during the whole sitting is better. Feeping the nest damp is far preferable to sprinkling the eggs with luke-warm water. The period of incubation is twenty-eight dars.

When hatched, the roung should be left under the hen until they are well dried, and quite strong enough to stand. Many scores of ducklings are lost from being remored too early from the mest. In a few days, three or four broods may be put together under one hen, who is quite able to take care of them.

For market purposes, Mrr. Fowler informs us that the treatment of the roung ducks is as follows:

"Thes are not allowed to go into any water, but are kept in horels or the rooms of cottages, each lot of thirty or fortr separated by low boards. It is no uncommon thing to see 2000 to 3000 all in one establishment. The are kept rery clean and dry on barley straw; their food consists of hard-boiled eggs chopped fine and 
mixed with boiled rice and bullock's lirer cut up small. This is giren to them several times in the day for about a fortuight or more. When they are capable of consuming more, they are fed on barley meal and tallow greaves, mixed together with the water in which the greares hare previously been boiled. My poultryman also uses horseflesh to mix with their other food."

The abore constitutes all that is necessary to procuce early ducklings for the table. It is needless to say that these birds are never allowed to go out of their pens, but are fed many times a day with as much as they can possibly eat; and they always have a trough of water br them, with some gravel or sand at the bottom, which is necessary to the proper digestion of the food. The great object of the ducker is to get his birds on as rapidly as he can, so that they attain the greatest possible weight before they begin to moult - this they do from about ten to twelve weeks old-when the nourishment taken is emplosed in the production of feathers; consequently, if a duckling is kept orer that age, it does not gain in weight, and decreases in quality. The profit on ducks can only be made by sending them to market at the proper time, namelr, when from eight to ten weeks old; for, if they are kept till they are seven or eight months old, they are inferior for table purposes, cost more to produce, and yield less to the producer. It is no wonder that, managed in this way, most farmers say, "Ducks do not par."

The ducks sent to the London markets are either killed by cutting the large ressels of the neck, or by thrusting a knife through the roof of the mouth into the brain-both of which methods allow of the escape of a large quantity of blood from the body, and render the flesh whiter than it otherwise would be. $\mathrm{Mr}$. Digby gires it as his opinion that ducks should not be bled to death, as from the loss of the blood the flesh becomes too dry. $\mathrm{He}$ recommends dislocating the neck, as practised with fowls, as the quickest method and the most merciful.

It is not necessary for me to say anything about the coloured breeds, as they cannot be plucked so as to look as attractive as the Aylesbury, and it is doubtful whether they mature with as great a degree of rapidity.

For home consumption many persons prefer ducks that hare more flavour and are tirmer in flesh than those which are killed before moulting; in which case the ducklings should be allowed to go into the water to obtain a large proportion of their own food (which consists of worms, spawn, young fish, tadpoles, \&c.) and not 
killed until they are well through their moult. In these cases, where the wild flavour is required in the ducks, the Aylesbury is surpassed by the smaller breeds, such as the black (so called) East Indian, the wild duck, or cross between them and auy other variety.

The difference in the customs of the French and English in the matter of ducklings is most marked. The French appreciate fullflavoured ducks in the spring, these they term Caneton de Rouen. These birds do not in the sligbtest degree correspond with the Rouen ducks of our poultry shows, being small in size, with a certain proportion of white in the plumage; they appear identical with the birds which have been exhibited in England under the name of Duclair ducks. When sent to market the skin is darkcoloured and most unattractive looking. The difference, in appearance, between the English Aylesbury and the French Caneton de Rouen depends not only on age, but greatly on the method of killing. The Caneton de Rouen is killed by suffocation, the mouth and nostrils being closed. The result is that no blood escapes from the body, the skin becomes dark and discoloured, but the flavour of the bird is retained to a much greater extent than is the case with our Aylesbury breed; in fact, the Caneton de Ronen eats like a large and tender wild duck. I have never seen these birds exhibited for sale in England, although they are imported for the use of the large hotels celebrated for their Continental cookery; but, should there be any large demand for them in the London market, there should be no difficulty whatever in their supply from English sources.

In buying stock ducks, good size should be looked for; but I most especially cantion anyone who wishes to breed for market purposes against the purchase either of old specimens or of large exhibition birds, whose bellies trail on the ground; such birds are ruptured from over-fatness, and both ducks and drakes are perfectly useless for stock purposes. Even Mr. Digby, an enthusiastic exhibitor, writes:

"For the market I should never think of breeding from largeframed parents, but would select my breeding stock from a good prolific strain, and about-or a little under-5lb. weight when in store condition; for from such stock it is casy enough to get ducklings to weigh $4 \mathrm{lb}$. to $5 \mathrm{lb}$. each at ten weeks old."

Advantageous as breeding ducklings for the market may be when conducted on a proper system, it is obvious that it can only be so to those who lay themselves specially out for the pursuit. 


\section{CHAPTER XXII.}

GEESE.

Is situations adapted for geese there is no doubt that they are profitable, but to do well they require access to water and a good grass range. They should have an outhouse to themselves, plentifully supplied with straw with which to make nests on the floor. These should be partitioned off from one another. A goose generally lays about a dozen eggs before wanting to sit. The house should be so arranged that the birds have free entrance at all times of the day; and the sitting geese may have food, such as oats, put for them in a deep pan of water. This has the double advantage of preventing the food being soiled by the dirt and droppings on the ground and from being devoured by sparrows.

The period of incubation is about thirty days if the goose sits closely, but it may extend over that period. The sitting goose generally leaves home once a das, when she should be well fed, if food is not always kept near her; and it is desirable also that she should have access to water at this time.

Nany practical breeders of geese prefer to hatch their eggs under large hens, giving four or five eggs to each-the nests being always made on damp soil.

It is not desirable to interfere with the bird at the period of hatching. The goslings should remain in the nest for at least twenty-four hours before being disturbed or fed. The next day they can be remored and supplied with cut grass or green turf, and oatmeal made into a paste with milk or water. It will be found very desirable not to allow the young birds to depend on the supply of food they get for themselves, but to give them oats, which are best given in water, night and morning. If they are kept short of food during the period of growth, it cannot be expected that they should make fine birds. Mr. Digby, a very successful rearer 
of large geese, is in farour of more stimulating feeding; he writes as follows:

"My first feed consists of hard-boiled egg, a bit of suet, and a few breadcrumbs chopped up together. Of course, there is, or ought to be, moderation in the supply of such highly nutritious food. Eggs and bread are only necessary for the first three or four days; a liberal supply of fine sharp grit and green food of some kind is absolutely necessary from the first. Sufficient clean water to drink during the first week or ten days will be all they require. After that time a swim will do them good, but do not drive them into the water; let them take to it of their own accord. When the goslings are three or four days old, diminish the quantity of eggs or discontinue their use altogether. I prefer giving for six or eight days. A bit of good sound wheat, a few groats, or a bit of tip-top barley once or twice daily affords a healthy change. Now, as size is a great consideration, it will be beneficial to gire goslings that kind of food containing a large percentage of bone-making material. Fine sharps-or middlings, as it is often called-should be used along with the biscuit meal. The adrantages of this method of feeding are many, especially if such a method is supplemented by good pasture. It is a mistake to suppose that goslings will thrive as well on poor, coarse land as they will on rich, wellcultivated soil."

When large enough the young geese may be fattened, which is usually done by shutting up a number of them together in a clean, dry, warm place, with an unlimited supply of oats in water for about three weeks. It has been suggested by a very practical writer to turn them on to the pond the day previous to killing, for the purpose of allowing them to wash their feathers; but if they are kept on clean straw this will be hardly necessary. All food and water should be taken away from them for at least twelve hours before they are killed.

Where there is good convenience for keeping geese, and they can obtain a large proportion of their own food on the pasture land and stubble, there is no doubt that they can be made to pay well, and the whole stock can be kept in a productive condition much longer than is the case with any other poultry; in fact, geese of ten or even twenty years appear to be quite as prolific as those that are younger.

In purchasing geese for farmyard stock it is not desirable to buy over-large exhibition specimens; they are, undoubtedly, not 
as productive or profitable for market birds as those of fair average size; in fact, many of the large show birds are useless for stock.

The Toulouse or grey geese may be advantageously used to cross with the white Embden, or with the common saddle-backs, as giving increased size and prolificacy.

The vignette at the end cf this chapter shows a useful form of portable poultry house, designed by Boulton and Paul, well adapted for housing fowls on the stubble after harvest, when they can obtain their own food for some weeks; but it is obvious that such houses could not be employed in all localities.

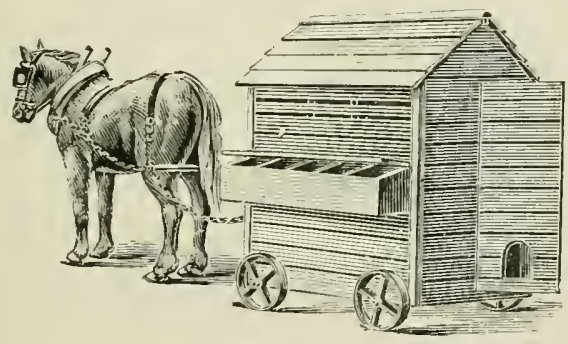




\section{CHAPTER XXIII. DISEASES OF POULTRY.}

IN a work devoted to the profitable rearing of poultry for the market, it might be expected that something should be written respecting the diseases to which these birds are subjected. Although I may be considered as somewhat prejudiced in farour of treating diseases remedially, inasmuch as my original pursuit was the medical profession, I am free to confess that I clo not think that the small farmer, or poultry rearer, need trouble himself greatly about the treatment of fowls when ill. If the healthiest and most vigorous only are bred from-if they are reared under natural conditions, kept clean, fed on wholesome food, not overcrowded, and given free and unlimited ranges-there will be very little, if any, disease amongst them; and if any does appear, it will be found much more satisfactory immediately to remove, kill, and bury, or, still better, burn, the sick birds, than to attempt to treat the disease remedially.

The ohject of the poultry breeder for the market should be to rear the healthiest and most vigorous birds, capable of growing rapidly into profitable fowls. This can nerer be accomplished if invalid birds, that have been cured by remedial agents, are kept. Nevertheless, a few words respecting the prevention of the more common diseases may be expected from me.

Roup, in many places a rery fatal disease, arises from exposure to cold and wet, and spreads rapidly in overcrowded and dirty poultry bouses. In advauced cases there is no cure. The birds, whether male or female, having been once affected, are useless for stock, and had better be got rid of instantly, as the disease is undoubtedly coutagious.

GAPES, which arises in chickens from the presence of small, - parasitical worms in the wind pipe, appears to infect the ground. There is little doubt that the eggs or germs of the parasite are present in the small worms, mollusks, or insects that the chickens 
and young turkeys eat. There is only one practical mode of preventing this destructive disease, and that is rearing the birds on fresh, uncontaminated ground.

CRAMP, which seriously affects birds bred from weakly stock at unnatural seasons of the year, and in damp situations, can be rarely cured when it appears, but can always be prevented by attending to the sanitary conditions.

Fowl Cholera is a disease fortunately little known in this country. It is one of a most contagious character, and, where it occurs, by far the cheapest and most effectual remedy is the destruction of all the affected birds, and the complete purification of houses, nest places, coops, sitting-boxes, \&c., by washing with lime wash, strongly scented with carbolic acid.

Dr. E. Klein, in his most valuable work on the diseases affecting birds, * gives a description of this disease as occurring in France and Germany, where it produces great devastation. I am not aware that the fowl cholera has ever been prevalent in England, but I reproduce the symptoms from Dr. Klein's mork, as it is quite possible that it way be introduced from the continent.

Fowl cholera occurs rapidly, within a day or a day and a half after infection, the srmptoms being purging of thin greenish mucoid evacuations, great unwillingness to move on the part of the bird, and quietness. The fowls affected refuse food, become drowsy, and die in one, or at most two days. On examination after death, the internal organs are found to be congested with blood, which is crowded with bacilli or the germs of the disease. These bacilli also exist in the evacuations of the fowls, and thus contaminate food thrown upon the ground. Rabbits and pigeons, as well as fowls, are liable to this disease, which can be produced in them by inoculation with the blood of an infected animal.

The Pourtry Farm Disease (the Orpington disease, or Fowl Enteritis of Dr. Klein). In the same volume Dr. Klein published an account of his researches respecting an exceedingly fatal and destructive disease prevalent at a Poultry Farm in Kent. The account is so instructive, it demonstrates so perfectly the folly of keeping large numbers of fowls on the same ground, and shows the excessively deleterions effect of feeding the birds on ground soiled by their own excrement, that it is exceedingly desirable that the

* "The Grouse Disease, Fowl Enteritis, and Some Other Diseases Affecting Birds." By Dr. E. Klein, M.D., F.R.S., Lecturer on Anatomy and Physiology at St. Bartholomew's Hospital. London: Macmillan and Co. 1892. 7 s. 
main facts should be brought before poultry keepers. Dr. Klein informs us that, in 1888, Mr. W. Cook had on his ponltry farm, then at Orpington, in Kent, on about two acres of land, a fatal epidemic, by which he lost between March, 1888, and March, 1889, over 400 birds. Nearly 200 died during March and April, occasionally six per day. Until twenty-four to thirty-sis hours before death the fowls appeared perfectly healthy. The first indication of the disease was diarrhca of thin, yellow, frequently fluid evacuations; the birds were quiet, but nerer sleepr, as in fowl cholera. On the next morning, or, latest, the day following, the animals were found dead. Post-mortem examination showed

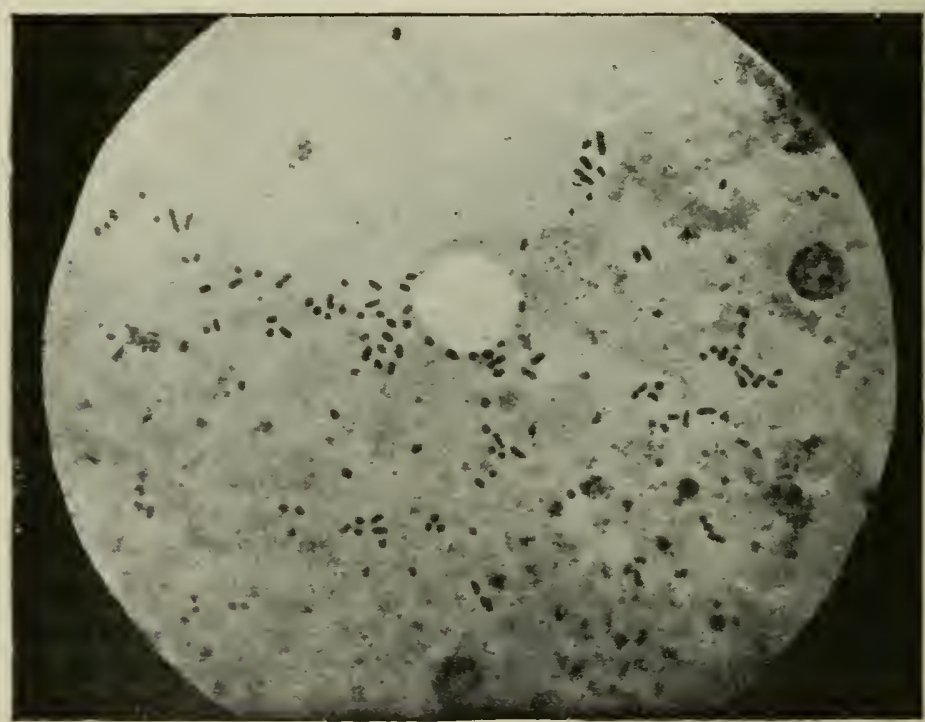

Bacilli in a drop of mucus, from the intestines of a fowl with Poultry Farm Disease. Magnitied 1160 times. From Dr. Klein's photograph.

the heart filled with clotted blood, the liver enlarged, soft, and brittle; the spleen constantly enlarged twice or more, soft, and flaccid. The serous corering of the intestines, and particularly the mucous membrane lining the cæcal appendages, were highly charged with blood. The lower bowels contained yellow fluid fæcal matter; in the cæcal appendages there was much mucus. 
The blood contained a species of bacillus, which may be cultirated on nutritive gelatine. A tiny droplet of the heart's blood rubbed over the surface of gelatine, and kept for two to three days in a warm temperatare, produced from fifty to two hundred colonies of bacilli.

Inoculations with the blood of a fowl that had died of the disease were made under the skin of healthy fowls, pigeons, and rabbits. The pigeons and rabbits remained well, the fowls all died. After fire days, severe purging of yellow, thin eracuations set in, and on the seventh day the inoculated birds were found dead.

In the contents of the bowels the same bacilli were present in very large numbers, as shown in the engraving. It was further proved by experiment that fowls to whose food the bowel discharges of a diseased fowl were added became smitten with the disease. In Dr. Klein's own words, "Under natural conditions, the fowls, just as in fowl cholera, contract infection most probably by picking up food from a soil tainted by the eracuations of birds affected by the disease." From this it follows, that once let a diseased foul appear in a poultry yard, the disease would rapidly spread to the healthy fouls, these latter picking up their jood from a soil tainted with the contagium voided in the evacuations by the diseased foul; the smaller the area of the poultry yard, the more rapidly would the disease spread. In the epidemic at Mr. W. Cook's. that was the subject of $\mathrm{Dl}$. Klein's inquiry, about 400 to 500 fowls were kept on about two acres of ground. It is clear that this area would in the course of a few months become strongly tainted with the contagium, and there was erery chance given for the new comers to contract infection. In such a case, nuthing short of energetic measures would stop the spread of the disease. When once it has made its appearance, every diseased bird ought to be immediately removed, killed, and burnt, and the healthy birds shifted into an altogether new ground. The ground on which the diseased birds had been kept ought to be railed off, well dug up, and thoroughly disinfected with quicklime. The animals ought to be carefully watched, and on the first sign of disease destroyed, and the ground again treated as above. Only by attention to the separation of the bealthy from the diseased birds, the inmediate removal and destruction of the latter, and the thorough disinfection of the land, can the spread of the disorder be checked.

It is exceedingly satisfactory to know that the disease is not 
spread through the air, for Dr. Krein experimented on two lots of fowls separated only 18 inches by wire netting. One lot was inoculated by the Orpington disease, all became ill on the fifth day, two-thirds died, as did two other fowls that got access to them; whilst the other set, which were not inoculated, were not affected, though only 18 inches apart.

There can be no doubt that the poultry keepers of the kingdom are deeply indebted to Dr. Klein for the demonstration of the cause of death in these overcrowded fowls, who infected each other by eating food soiled with excrement, containing millions of bacilli, one of which is capable of producing the disease in the healthiest fowl. In the following chapter I have entered at length into the subject of poultry farming; but whether the weak enthusiasts will be converted from the error of their ways, even by Dr. Klein's demonstration that the excrement of one fowl will infect and destroy a flock of 500 birds on two acres, is doubtful. Such poultry establishments are started either by enthusiasts who will neither listen to reason or experience, or by adventurers, who see in the gullibility of their dupes a means of making a livelihood.

The Orpington disease has unfortunately been prevalent in Ireland, having been introduced by the fancy fowls sent into the congested districts. In the report of the Congested Districts Board for 1893, it is stated:

" Upon the appearance of a widely-spread fatal disease among poultry in the congested districts, and, as some of the newlyimported cockerels died, the Board requested Mr. Tegetmeier, a celebrated authority on poultry, to visit the localities to which the cockerels had been sent. He reported that the disease was "Fowl Enteritis,' and that it was practically incurable, while he at the same time indicated how the spread of the disease might be checked. Many of the cockerels, however, in his opinion, died of 'hardship', the districts being ill adapted to support pure-bred fowl, such as had been supplied. He strongly recommended that in future only farm-bred birds should be purchased, and not those bred by poultry fanciers for show purposes."

ScuRfy Legs.-The occurrence of scurfy legs in fowls, more especially in the feather legged rarieties, is well known to all poultry fanciers. They depend on the presence of minute parasites (Sarcoptes mutans), which live under the seales of the legs and upper part of the toes, where they set up an irritation, causing the formation of a white, powdery matter, that raises the scales and 
forms rough crusts, which sometines become very large. When these crusts are broken off and examined with a microscope, or even a good hand lens, they will be found to be filled with the female parasites, generally distended with eggs. The crust itself may be compared to the crumb of dry bread; but the parasites are to be found only in those parts which are kept moist by the skin. 'They appear to cause great irritation to the bird.

This disease is propagated by infection. It is seen in fancier's' yards where the poultry are closely confined together. The disease has been found affecting turlieys, pheasants, partridges, and even small birds in aviaries.

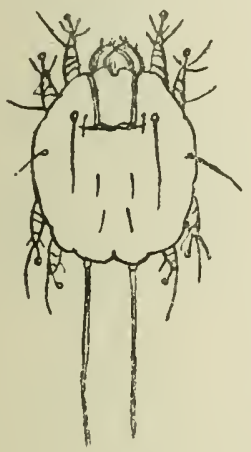

Male.
Scurfy Leg Parasite

(Sarcoptes mutans).

Magnifled 100 diameters.

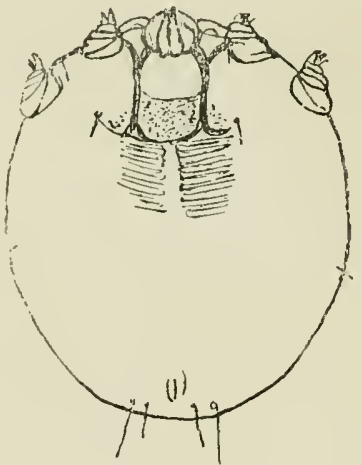

Female, distended with eggs.

The treatment in fowls is very simple. The legs may be soaked in warm water, and the crusts removed, and the legs washed with carbolic soft soap, as made for dogs; and the coops, nesting places, perches, all cleansed with lime wash, scented with carbolic acid. Great care should be taken not to employ as mothers any hens affected with the disease. If a Cochin or other hen in the slightest degree affected with scabies is employed, it is obvious that, as young birds are covered by her, the parasites can readily pass from her to the chicken, and the disease becomes disseminated. 


\section{CHAPTER XNIT.}

\section{FALLACIES OF POULTRY FARIING.}

There is no one subject connected with poultry rearing on which so great an amount of misconception exists as that of poultry farming. The general belief that prevails is that the vast number of eggs, amounting to many millions annually, which we receire from abroad are mostly produced in poultry farms. It is difficult to account for this belief; it is utterly baseless; there are no poultry farms, properly so called, in any part of the Continent. But rast numbers of small peasant proprietors and small farmers keep poultry, and the eggs are collected br the agents of the merchants or sold by the wives of the peasants themselves in the rillage markets which exist in most parts of France. If any confirmation were wanted of this fact, I might quote from the report of Mr. C. L. Sutherland, one of the assistant commissioners appointed under the Agricultural Interest Commission. In his report, which was presented to both Houses of Parliament, he states as follows:

"It is a commonly receired idea in England that there exist in France huge poultry farms, where fowls are kept by several hundreds: and it has been orer and orer again urged on English farmers to adopt this poultry farming on a gigantic scale, as some sort of means of alleriating the present depression, and enabling them to make money. A long acquaintance with the chief French poultry breeding districts, as well as answers to inquiries I have from time to time made on the subject, enable me positively to dens the existence of such establishments. The greatest number of heads of poultry that can be kept profitably on a single farm varies from 200 to 300 . If a greater number than this is kejt the ground becomes poisoned, and it is found impossible to rear chickens. Whenever Jarge poultry tarms have been started in England-as, for instance, at Bromley, in Kent-they have failed, and chiefly owing to the above reason; a reason perfectly well 
known to and understood by all practical poultry keepers. The manner in which so many fowls are reared and eggs produced in France is as follows, independently, of course, of climatic influences, which must be held to be of some little account. Every peasant proprietor, every bordier, with perhaps two or three acres of land, keeps forrls, the produce from which is collected by dealers, who scour the country. In this way a very large number of fowls in the aggregate is kept, but they are scattered about all orer the country."

Some years since attention was directed to pou try-keeping in France by the publication in this countrs of an account of a poultry establishment near Paris, in which the birds were fed on horseflesh. This ridiculous hoax would not hare been worth notice bad it not heen reproduced and commented upon in many of our public papers. The account was reprinted in many periodicals, such as the Gardener's Chronicle, the IIar Lane Express, the rarious agricultural journals, $\&$ c. So high an authority as $\mathbf{M r}$. Cutbbert S. Johnston, F.R.S, published the following article respecting it in the Mark Lane Express. Mr Johnston stated:

"The French practical philosophers certainly know how to make the most of things Thus M. de Sora has the power of making hens lay every day in the rear by feeding them on horseflesh. The fact that hens do not lay eggs in winter as well as in summer is well known, and the simple reason appears to be that they do not get the supply of mear, which they obtain in the warm season from worms and insects.

"He soon ascertained that a certain quantity of raw mincemeat giren regularly with other food produced the desired result; and, commencing with only some 300 fowls, he found that they areraged th $\rightarrow$ first year some twenty-five dozen eggs in the 36.5 days. The past season he has wintered, thus far, about 100,000 hens, and a fair proportion of male birds, with a close approximation to the same results. The consumption of horses for this purpose by M. de Sora has been at the rate of twenty-two per day for the last twelve months. As one item alone in this immense business, it may be mentioned that in the mnnths of September, Octoher, and November last MI. de Sora sent nearly 1000 dozens of capons to the metropolis."

Mr. Johnston said these details are worthr of our serious consideration. It is difficult to imagine how such a ridiculous statement could have received any consideration whatever without 
the absurdity of the hoax being apparent; and yet it was generally credired, and persons made journers from the United States, and Australia, to learn the details of the mode of working adopted at this supposititious establishment. To any persons having even a very slight practical acquaintance with poultry matters, such a statement as that the " 300 fowls averaged the first year some twenty-five dozens, or 300 eggs in the 365 days," carries its own refutation When we take iuto consideration the fact that a certain portion of the fowls must have been cocks, and that time must have been lost during the periods at which the hens were brooding and recovering from their annual moult, it is evident that during a considerable portion of the year the hens of these numerous towls must hare laid two eggs a way each to wake up this fabulous arerage. Again, the statement that the forls were tattened for the market at, the end of the fourch : ear, is ane that coulit never have been reproduced by any person having any knowledge of the subject. A fowl of four years of age is beyond any ordinary power of mastication.

The Latin proverb which says that "trutb is great and will prevail," is familiar to all, but the vitality of a lie is equally remarkable. It is now a quarter of a century since this ridiculous De Sora hoax was fully exposed, but it is still believed and credited. In that well-conducted trade journal the Grocer, of Nor. 2, 1889, is an article on the number of imported eggs, which includes the usual recommendations of those who are ignorant of the subject as to the establishment of poultrs farms. In this article we are told of two brothers in the neighbourhood of Glasgow, who erected a large poultry farm with steam apparatus, and accumulated a handsome fortune by their enterprise. It is needless to say the exact address was not giren. We are then told of a poultry leeper near Liverpool who, by an expenditure of $30 l$, realised 70\%. a year profit. Neither the name nor address of this poultry leeper is given. It is needless to analyse the balance sheet, because it contains the usual absurdities; but the conclusion of the writer we fully agree with, namely, that it "obriously proves the gross ignorance which prevails respecting poultry keeping."

I should not hare alluded to this article, inasmuch as the false conclusions in it possess no novelty, but that the De Sora hoax is quoted as a fact. We are informed in it that in Paris, many sears ago, a gentleman named $\mathbf{M}$. de Sora enjoyed the respectable income 
of $175,000 \mathrm{fr}$. annually, derived from a huge poultry farm in the suburbs. "The suburbs" is a vague term; but it might have struck the editor of the Grocer that the locality of an institution from which an income of $7000 l$. a year was derived from poultry might have been indicated.

It might also be imagined that the demonstration of the nonexistence of the De Sora establishment for feeding poultry on horseflesh would have sufficed to prevent the proinulgation of any more of these ridiculous canards. But such has not been the case. In the early editions of the "Practical Ponltry Keeper," the concluding sections wer deroted to the reproduction of a French account of a poultry establishment at "Charny, a picturesque village near Paris." The reader was informed that 1200 laring hens, with a due proportion of cocks, were lodged in the first floor of an elaborate building, with a verandah, railway, lifting tackle, boilers, stoves, hatching room, \&c. Of this building a perspcctive view, sections, elevations, ground plans, \&c., were given in some ten or a dozen engravings, and the writer most definitely stated that the establishment was "one of the most complete and perfect of its kind in France, and which has been conducted for several years with the most eminent success." And, moreover, he did not think "its arrangements can be further improved." I need not enter into any detailed examination of the plans proposed, because a very slight acquaintance with really practical poultry keeping would have sufficed to convince anyone of the impossible nature of the arrangements. For example, each of the four hen houses into which the upper floor of the building is arranged is said to be designed for 330 fowls, the dimensions being $16 \mathrm{ft}$. by $15 \mathrm{ft}$; the nests and ascending ladders occupy the end walls, and perches consist of eight planks, each $10 \mathrm{ft}$. long-in other words, there is rather less than one foot of perch for every four fowls to be accommodated!

An example of the evil effects of the publication of such misstatements may be mentioned. A capitalist informed me that, having read this account, he was induced to expend a very considerable sum in carrying out the arrangements; that he went over to Paris expressly to visit the poultry establishment that I have described. On endeavouring to procure a conveyance to Charny, he could find no one who knew any place of the name near Paris. The Geographical Dictionary failed to give any aid. Determined not to be foiled, he gained access to the Minister of Agriculture, 
under whose authority this precious account was supposed to hare been originally published. His inquiries for the locality of Charny and of the poultry farm elicited no definite information; he ascertained, howerer, the name and address of the author of the account, whom he next risited, and on again inquiring for the locality of Charny, and the particulars of the establishment, which had been said to hare been carried on for rears with eminent success, the Englishman received the astounding answer, "Monsieur, c'est imagination."

These ridiculous accounts hare led, unfortunately for the promoters, to the attempted establishment of numerous poultry farms in England, every one of which has resulted in disastrons pecuniary failure. The rearng of poultry has been tried in this country under everr rariets of conditions. In some places extensire ranges of buildings hare been erected in accordance with various plans, but the result has always been the same. The number of defunct farms is rerr great. One of the largest of these, as far as regards the size of the building and the expenditure of capital, was at Bromley, in Kent, where many thousand pounds were lost before the attempt was given up by the promoters. This was succeeded br two others at Wimbledon, both of which passed rapidly out of existence. A third large poultry farm was established in Herefordshire, most florid and fictitious accounts of which were issued by the promoters. Another undertaking was proposed to be started at Shenley. I have before me a large number of prospectuses of poultry farms, none of which were erer worked successfully; some, of course, were obriouslr merely Stock Exchange swindles. One of these did me the honour of putting my name upon their pruspectus as one of the auditors. I need not say that it was done without my knowledge or permission.

One of the poultry farms that was established under the most farourable conditions, was that founded at Rushford, on the estate of Sir Robert Buxton, on light sandy soil, which was regarded as admirably adapted for the purpose. Sir Robert entered into the scheme with much interest, and met the promoter in a most liberal manner. The tract of land consisted of 114 acres, inclosed by wire fences. There was good cover, and in some parts a number of furze bushes, under which the fowls could shelter. An incubating house was built by Sir Robert, from the promoter's own designs, which was described as a brick structure, admirably adapted for the purposes for which it was intended. Eight incubators, each holding 
250 eggs, 2000 in all, were described as being in full work. Ample provision was made for the artificial supply of heat for the rearing of the chickeus, which were not to be overcrowded on the land, and were not to exceed from 60 to 100 per acre. The breeding birds were to he located in runs separated by wirework, and not more than from a dozen to twenty kept together. The manure was to be carefully collected and utilised. There was to be an intelligent ponItry keeper, two labourers, their wives, and a bor under him. Although the poultry was chiefly to be bred for the market, a careful selection was to be made of the best stock. When this proposal was first brought before the public in 1882, I criticised it adrersely in the Field, and said that I should like to see the balance sheet at the end of two year's. This request was regarded as an impertinent interference on $\mathrm{my}$ part with the business of a private indiridual, more particularly as I said that I had never known any poultry farm, on whatever conditions it was started, that was in esistence at the end of three rears. It is difficult to imagine a poultry farm conducted under more adrantageous conditions. The land was dry, well adapted to pheasants, and therefore to poultry; the rent was exceedingly low, the capital expended was that of the landed proprietor, who entered warmly into the scheme, and if ever a poultry farm could hare sncceeded it should have been that at Rushford. Мry opinions regarding its failure were regarded as utterly unfounded, but at the end of two years this venture, which seemed so promising to those who were not fully acquainted with the subject, was dispersed by the hammer of the auctioneer.

In the Field of January 10, 1891, I published the following comments on au article by the Hon. A. H. Catheart, on "Chicken and Poultry Farming in Germany," which appeared in the Royal Agricultural Society's Journal, recently published. Mr. Cathcart's article was descriptive of the establishment of an incubator maker, Herr Gruenhaldt, at Walmünster, Lorraine, a village of about 100 souls, situated some trenty miles from Metz. The land is described as consisting of about thirts English acres, and to be distant three and a half miles from the railway station, with which there is communication only by telephone and a postcart which passes twice daily, the owner of the poultry establishment keeping no horses. "Practically all the food is purchased, as buck wheat, Indian meal, and fish made into baked cakes." The stock on hand is said to be always from 7000 to 10,000 head of poultry, chiefly chickens, with turkeys, geese, ducks, guineafowls, 
and rabbits. The staff employed consists of the proprietor, his clerk, a manager, a foreman, three boys, and three or four men for the cows, garden, and orchard. The orchards are stated to contain 1200 fruit trees. The schloss, or château, is a broad-fronted building of two storeys, with a considerable space under the high pitched roof, which is entirely occupied by the newly-hatched chickens, and they are said to remain there for six weeks, in three tiers of cages with sanded trays. They are then put ont into the runs (which must be small and numerous, as there is said to be above six English miles of wire netting) for another six weeks. The value of the chickens sold "all over Germany" is, for the smaller, 1 mark $60 \mathrm{pf}$., equal to $1 s$. $6 d$. each; for the larger, 2 marks $60 \mathrm{pf}$., say 2s. 6d.; for a few exceptionally fatted and older, 4 marks $50 \mathrm{pf}$. The establishment is regarded as being able to suppls 30,000 chickens annually, which, at a profit of 1 s. per head, would give a profit of $1500 l$.

A very cursory examination of the details of this scheme will show that it possesses no more solid foundation than the scores of others that have been tried in England and France, and ranished after having been established one or two rears.

That tens of thousandsof chickens hatched by incubators can be reared until six weeks old in the dark cock-loft of an old château is a demand on our credulity which we cannot permit.

Numbers of chickens are said to be sent "all orer Germany," but, as the proprietor keeps no horses and the railway is three and a half miles distant, how the are sent there, by the mail cart or the telephone, it is difficult to conceire; and that chickens sold at three months old at $1 s$. $6 d$. each can yield a profit of $1 s$. each is incredible. It is needless to say that no information is giren as to the length of time this establishment had been in operation, nor of the precise number of birds sent awar, nor of the cost of food, labour, rent, or gross receipts. There was not the slightest attempt at furnishing a balance sheet. Doubtless Mr. Cathcart wrote in perfect good faith; and put down what he was told by an enthusiast, but he obriously had no personal experience of the subject he wrote about.

Nevertheless, the Royal Agricultural Society of England thought fit to publish this most unsatisfactory account, which is of no practical ralue whatever, and which could only have one effectthat of inducing persons ignorant of the subject to embark in similar undertakings. 
The above comments were followed by a visit to this establishment, which was described in the Live Stock Journal of March 20, 1891. The account is as favourable as possible, but it is only necessary to read between the lines to see that the criticisms that I made on the estaljlishment were justifiable. In his first paragraph Mr. Brown states: "Although I am bound to say that the results are scarcely so satisfactory as might have been wished, this may be due to circumstances, to be explained anon, which are his (Herr Gruenhaldt's) misfortune rather than from any other cause." Then follows the statements that there is " the possibility that the farm may be vacated ere long," that not one of the incubators was in operation, and, says the writer, "a further and considerable capital is essential in order to carry on the work." Nevertheless, we are told that the institution "paid, and paid well, during the two years it has been established." That this establishment should not be put in action at the commencenent of the third breeding season from want of capital is a thing which is easy to believe; but that it "paid, and paid well" during the two years that it has been in operation is a point on which my readers can form their own conclusions. People do not give up businesses from want of capital when they have "paid well" for the two previous seasons.

We then have a long description of Herr Gruenhaldt's particular incubators. We are next told that the chickens, twenty-four hours after they are hatched, are removed into cages in the upper rooms of the schloss, which must, according to the engraving in the original article, be in semi-darkness. Out of these cages, we are told, these chickens never go; but they are supplied with food made of maize meal and buckwheat meal and milk, and kept in an even temperature by a stove; that they are ready for killing at six weeks old (!), that all are killed when they attain the age of two months, and at this time we are informed that many weigh $31 \mathrm{lb}$. each, and the price per pound varies from $11 d$. to $1 s .3 d$. They are killed on the spot, and despatched by the German parcels post, in summer ice being used for packing.

It would be interesting to English poultry rearers to know the breed of the fowls that reach $3 \mathrm{lb}$. in weight at two months-such a variety is unknown in this country-and to learn the proportion of deaths that takes place amongst the chickens that are removed from the incubator into their eages and fattened for the table. Mr. Brown unfortunately did not see anything for himself, not even a 
single two months old chicken weighing three founds! the operations being suspended; lut that chickens varring from six weeks to two months old can be reared and sold at $18.3 d$. per pound in a district where evers peasant produces chickens for the market mould require some rery reliable eridence to render it credible.

We do not know what the arrangements of the German parcels post may be, but the ice used in summer for packing chickens must necessarily melt, to the destruction of all other packages, goods, and letters with which the water came into contact. We are told, however, that last year 9000 chickens were reared in this manner, in addition to nearly 1000 hatched by the incubator and sold alire at two or three dars old. Now, taking this statement as a basis of calculation, it is not difficult to arrire at some approximation as to the income of this poultry-rearing establishment. The gross amount arising from the sale of the 10,000 chickens, varying from two or three dars to under two months old, could not possibly be much higher thau $500 \mathrm{l}$, out of which would have to be paid the rent of the chateau and the surrounding land, the purchase of eggs for hatching, the interest on the capital expended in the construction of the inculators and all the appliances requisite, the food of the birds during the time they are growing, the cost of the labour in cleansing, killing, plucking, and that of converance to market. Ought we to feel surprised that, notwithstanding we are told on the one hand that the business has "paid, and paid well" during the two rears it has been established, it cannot now be carried on for want of capital: It must have had some capital to commence with, and, if it has paid well, that capital should have been increased.

The concluding sentence of this account informs us that, "although the establishment at Schloss Walmünster proves as yet nothing as to the pecuniary success of poultry farming, there are sereral worel features of interest noted." It appears to me, and rery probably will to most of my readers who take an interest in the matter, that, though this establishment does not prove anything as to the pecuniary success of poultry farming, it is an additional proof of the failure that always attends such efforts.

The fact cannot be too strongly insisted on, that, under all circumstances, poultry should be regarded as a bre product. Where the forls necessitate no extra pasment for land or building-where 
they get, as in a farmyard, a considerable proportion of food for nothing, and where they are fed, when the food is supplied to them, on waste products, such as tail corn, small potatoes boiled down, and other almost valueless articles of diet, and cost nothing for lalour-fowls can always be kept to profit. It is in this way really that they are liept by the small peasant proprietors in France, and by a large number of cottagers in England; and it is with the object of showing how they can be kept to the best adrantage that this work has been written.

Poultry farms, properly so called, must not be confounded with those establishments for the sale of fancy poultry at fancy prices, which the owners advertize as Poultry Farms, they being in fact nothing of the sort, but merely places where large numbers of show poultry are kept in separate runs for the purpose of sale, at prices varying from half a guinea to five or ten guineas a bird. But even these establishments are rarely successful.

The Prebendal poultry farm at Aylesbury, though conducted with the greatest amount of skill and kuowledge of exhibition poultry that could be brought to bear upon the subject, was dispersed in the usual manner, by the auctioneer's hammer, in October, 1889. Fancy poultry establishments still exist, but they change owners very frequently, the original promoters, in some instances, having to my knowledge lost thousands of pounds. But even if these establishments could always be conducted in a prosperous manner, they would furnish no argument against my contention that poultry farming does not pay, it being totally distinct from the breeding of fancy or exhibition poultry.

To produce poultry and eggs in large quantities for the market, and as part of the food supply of the country, has never yet been made to pay when carried on as a separate business, and liable to he charged with all the outgoings that are necessarily incurred. As was stated by the late Mr. Alexander Comyns:

"This is the only form of poultry farming that is worthy of the name. The poultry fancier and exhibitor may enlarge what was, perhaps, his private bobby into a business, which may be small or large; but he, after all, has only to do what poultry fanciers like most, and is in no wise concerned whether the imports of foreign eggs increase or decrease. He may often go so far as calling his establishment the - Poultry Farm, but as long as the chief part of his business is selling fancy poultry and eggs, he is not a poultry farmer." 
With all these facts hefore us it nevertheless appears impossible to eradicate the idea, that poultrs farming pure and simple cun, on a larger or smaller scale, be made to par. Not a rear passes but that some scores of prirate individuals, haring perhaps small incomes of their own, go into the country, take a house with a few acres of land, erect buildings and commence poultry keeping with a riew to supply the markets at a profit. If, as I hare said before, the poultry be a bye product of the farm, costing little or nothing in the way of rent for land or building, little in the way of labour, and obtaining a large portion of their own food, then fowls can be kept to profit; but these conditions are absent in all the so-called poultre farms, and consequently they invariably and ineritably come to grief.

I constantly receive letters asking for advice on this matter, and my reply invariably is, "Do not enter into the business until you hare studied the details of the management of some establishment where it has been carried on for two rear's with success-a thing which I have never ret been able to find."

I could enumerate, if it rere necessarr, some scores of poultry farms that have been founded, or attempted to be founded, the whole of which have withont a single exception failed in less than two years. The money that I know to hare been wasted in these efforts amounts to rerr manr thousands of pounds.

Recently a new proposal in Poultry Farming has been issued by Major Morant, in which the keeping of hens and rearing chickens in large numbers in absolute confinement is adrocated.

Accepting the well-known fact that if hens are confined in small poultry rards the invariably become diseased as the ground gets tainted, the writer suggests that, instead of permauently fencing in a patch of ground, the fowls should be kept in morable houses, each with a small wire run; and he imagines that they will be as healthy and lay as many eggs as if the had their liberty. As an example of his system, he relates that four half-bred pullets rere placed in a boarded coop, $4 \mathrm{ft}$. long bs $3 \mathrm{ft}$. broad, and $3 \mathrm{ft} .6 \mathrm{in}$. high in the centre, with a felt roof, in which was a glass window, the floor being formed of open spars of wood, and the whole sufficiently light to be lifted easily. Attached to this coop was a run $8 \mathrm{ft}$. by $4 \mathrm{ft}$., and $2 \mathrm{ft}$. high, corered with wire netting.

* How to Keep Lajing Hens, and to Rear Chickens, in large or small Numbers, in absolnte confinement, with "perfect success." By Jajor G. F. Morant. London: L. Upcott Gill, 170, Strand, W.C. 1891. 
This house and run were moved on to fresh ground daily, sometimes to the grass and sometimes on to racant garden ground, where potatoes or other crops had been remored. Under these circumstances he states that his four pullets laid 647 eggs in ten months.

Judging by the results obtiined with a single coop, Major Morant thinks that such houses, only of a somewliat larger size, each capable of holding ten pullets, might be multiplied indefinitely, and that 100 houses, holding 1000 hens, could easily stand in a six-acre field, and be kept to profit by the farmer. The heus, he says, should average from 150 to $200 \mathrm{eggs}$ a year each, and that they should be kept until they are tro years old, when he thinks they will fetch about $2 s$. each, sufficient to pay for rearing the pullets which are to replace them. That young pullets in their prime, whether for laying or killing, could be exchanged for old hens, is not within the experience of any practical breeder. It is always difficult in the country to get rid of old hens at $1 s$. or $1 s .6 d$. each.

Whilst admitting the advantages that may accrue to a small householder from keeping a few fowls in one of these confined runs, I differ in toto from Major Morant as to the possibility of keeping a large number of laying hens in confinement on this system with any profitable result. I will take his own statements, and apply them to 1000 hens. In order to keep them on this system they would require 100 houses and runs-each of which he himself estimates as costing $2 l$., the total being $200 l$. The 1000 young hens in their prime could hardly cost less than $3 \mathrm{~s}$. each $=150 \mathrm{l}$. He states that a jons and trolly wou'd be required to more these houses and runs ou to fresh ground every day. We may put the cost of this pony and trolly down at not less than $15 \mathrm{l}$. The cost of the baskets and boxes for the conveyance of eggs to market, and other incidentals cannot be put below $10 l$. Here we have a capital invested of $375 \mathrm{l}$., the interest upon which, joined to the annual depreciation and repairs of the houses, cannot be taken at less than 50l. The rent of the six acres may be put down at $15 l$. The cost of feeding the fowls, according to Major Morant's own showing, is $1 \frac{1}{2} d$. a week each, or $6 s .6 d$. per head per annum. This for 1000 hens amounts to 321l. We are not told how many labourers would be required to feed the 1000 hens and attend to and remove the 100 houses with the aid of the pony and trolls, but we can liardly put this labour at less than 50l, and the eggs would have to be packed and conveyed to market. The keep of 
the pons, rent of the stable, and other buildings required for the puultry establishment (that of the drelling-house not eren being taken into consideration) could hardly be less than 2.5l; whilst the exchange of the old worn-out hens for young pullets mar be estimated at the rery lowest as $25 l$. per annum. The total annual expense of keeping these 1000 hens would therefore amount to 486\%. Now, taking the number of eggs produced at Major Morant's own calculation, namels, 175 per hen, these in the open market, where the 175,000 eges per annum would bare to be sold, could not possibls command a larger sum than 10 s. per hen. This would give us a return of 500l, learing a profit of 147 . per annum, out of which the house rent and liring of the proprietor would hare to he paid. The expenses here are estimated at the lowest possible amount; and no account is taken of loss of ans of the hens by disease, which would ineritably occur anongst so mans, crowded together as ther would be.

It is useless to write about fresh eggs producing $2 d$. each in the shops, when ther hare to be sold wholesale. The estimate of $10 s$. for the produce of each hen. which I have allowed in this account, is far too farourable, but I am desirous of not orerstating my ase. The cost of eggs in the comtrs markets must be taken as the guide, and not the fancr prices in fashionable shops.

The following is the balance-sheet that mar fairly be deducer from the author's own statements :

Axvel Balaxce Sheet.

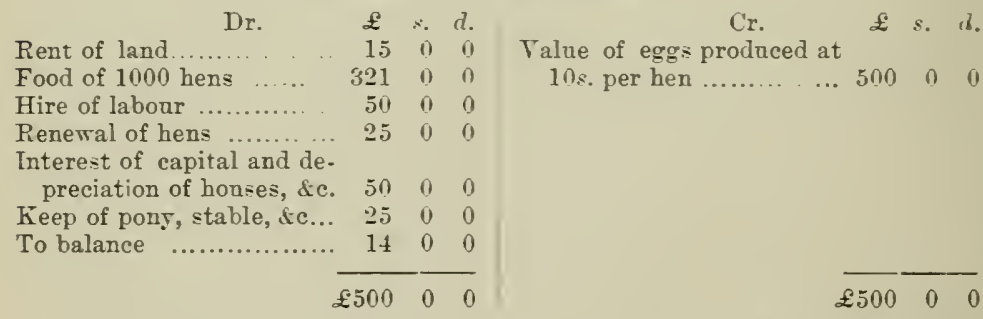

I have little doubt but that the proposals in Major Morant's pamphlet will br carried into effect by -ome enthusiasts; but, as I hare said of mans more promising schemes, I want to see the balance-sheet at the end of two sears.

The proposal of Major Morant to rear chickens for the market under similar conditions I have not entered into, as it appears to me, as a practical man, quite outside all serious consideration. 


\section{CHAPTER XXV.}

\section{FOWLS IN SMALL RUNS.}

THe great extension of the poultry fancy in England has induced many persons living in suburban and even town residences to keep fowls in small enclosed runs for the supply of eggs for the table. This has little to do with the subject of profitable market and table poultry, which is the main object of this work; but, as the practice is extensively followed, and there is a right and wrong way of doing everything, it may not be without advantage to devote a few words to the consideration of the best method of keeping fowls in confined places. I am constantly receiving such questions as "How many fowls can I keep in a run $30 \mathrm{ft}$. by 10ft., or in one of $50 \mathrm{ft}$. by $12 \mathrm{ft}$.?" \&c. My reply always is, "The smaller the number you keep in a confined area, the healthier they will remain, and consequently the more productive." When fowls are crowded together in a small space, the ground becomes saturated with thei own excrement, their food (scattered on the surface) is alwars contaminated with it; the air they breath is impure, being charged with the gases arising from the fotid ground; and the possibility of obtaining worms, grubs, or any natural insect food, and even green foor (except such as is supplied artificially) is denied them. Can it be wondered, then, that the birds become unhealthy, and that, to supply the want of natural animal diet, they take to eating each other's feathers and their own eggs: Then, again, from want of due exercise, and over feeding, especially on fat house scraps, the liens not unfrequently become enormously fat internally, and cease to be productive.

To prevent these evils as far as possible, certain precautions should be taken. The largest space available should be given to the birds. If sufficient can be afforded, and it is practicable to do so, it should be divided into two or three portions, each of which should be allowed to lie fallow for a time, being deeply dug up after it has become foul, when some fresh slaked lime should be 
added, and the ground sown with rape. This by its quick growth rapidly exhausts the manure of the soil, and furnishes an admirable supply of green food to the fowls when they are let into it. The portion of the run in which the birds are kept should be as clean as possible, and may with great advantage be covered with house ashes day by day.

In feeding the birds great care should be taken not to gire them fatty scraps from the house. Bones, which they will pick perfectly clean, may be given, but all fat meat or grease of any kind should be aroided, as the great tendency of the birds is to become unduly fat internally. For the same reason maize, the most fattening of the ordinary grains, should be aroided. The dietary should consist, as far as corn is concerned, of barley, wheat, or dari, which may be supplemented with waste potatoes and other regetables from the house. The food should in no case be thrown down on the ground, which is always more or less soiled in a confined run. Green food in abundance is absolutely necessary. Cabbages or lettuces running to seed may be utilised with adrantage, being most advantageously tied up against the side of the run, so that the fowls can eat them without dragging them about on the soiled ground; or large swede turnips may be secured by being stuck on a stake driven into the ground and the tops cut off, when they are readily eaten by the birds.

With regard to the breed that may be used, it is better under the circumstances to employ non-sitting rarieties, because they lay a large number of eggs; and the profitable rearing of chickens is perfectly impracticable under such conditions. Therefore such varieties as Minorcas, Andalusians, and Leghorns may be selected, if it is particularly desired to keep a pure breed. It will be found a much better plan to buy roung pullets ready to las, keep them until they have finished laying, and then dispose of them aud buy others. Under these circumstances there is no utility, and frequently a great annoyance to the neighbours, in keeping a male bird. If the requisite number of pullets are bought twice a year, a very fair supply of new laid eggs, which are especially raluable in the suburban districts, can thus be obtained for household purposes.

If early-hatched pullets are bought in September or October, and well fed in the manner described, without being orer fattened, they will lay well throughout the winter, before becoming broody. When this takes place in the spring they should be sold as stock 
birds, or eaten at home (they are of no value as market fowl), and their place supplied by some late-hatched pullets, which may be depended on for laying throughout the summer; these, in their turn, will be sold to make way for another batch of early spring birds. Even where this course is pursued, it will be found more advantageous, if practicable, to buy pullets of some non-sitting breed, such as Minoreas, \&c., but ordinary fowls will do well.

The adrantage of this plan over that which is sometimes adopted, of keeping the same hens year after year in confined runs, is very great. The pullets bought for laying should be strong, vigorous, country-bred birds, containing in their oraries large numbers of immature yolks, which must be developed into eggs under the circumstances in which they are placed; whereas, when hens are kept year after year in confinement they become sterile and practically cease to las. Hence many persons beginning with poultry in a confined space are very well satisfied for the first few months, but in a couple of rears, or less, get rid of both fowls and fowl runs, saying the eggs cost them about half a crown apiece-an eril which can be avoided by attending to the recommendations here made.

A letter appeared in the Times of January 6, 1892, advocating the keeping of fowls in suburban back gardens, and stating that they may be advantageously kept in an open space "however small"! The writer, whose letter is dated Dec. 31, 1891, states that:

"Alout eighteen months ago, when I removed to my present address, I found already erected a fowl-house standing in the centre of an inclosure measuring $8 \mathrm{ft}$. by $20 \mathrm{ft}$., formed ou three sides by the garden wall and in the front by a wire netting. I at once determined to try my hand at egg-producing, when a kind friend, by way of starting me in that line, presented me with five fowls-four hens and a cock. As, however, the latter proved to be an "early bird," and awoke us soon after midnight, I soon disposed of him, and resolved to act upon the zenana principle. During the autumn I purchased two pullets; so that I commenced this jear with six hens, which number has never been exceeded."

These six hens produced 44 dozen of eggs during the yearan average of eighty-eight for each fowl. It is hardly necessary to state that an average of eighty-eight eggs per year for each hen is a very poor result-indeed, and one that would have been greatly improved had all the birds been pullets, whereas four 
vere old hens. The amount of space allowed to cach fowl is $2 \frac{1}{2}$ square yards, how long such a space can be occupied without becoming absolutely foetid depends somewhat on the amount of cleansing it receives; but there is no doubt that fowls kept continuously in such a narrow space must almost of necessity swallow food tainted with their orn excrement, and that they must breathe the exhalations from the foul ground, whilst there is an absence of all fresh natural food, such as insects. worms, growing herbage, \&c. Under these conditions fowls lose their prolificacy very rapidly. If the birds of the Times correspondent are kept another year there will be a lamentable falling off in the number of eggs, eveu if feather-eating, or, still worse, the infectious bacillus of the Poultry Farm disease does not demonstrate its presence and carry off the stock.

The writer of the letter signed "O." in the Times, is merely repeating the experience of thousands of others, whose poultry in narrow runs do admirably the first year, whilst the birds are young and the ground pure, but are not so satisfactory the second season, and are got rid of as not worth their keep in the third, and this in spite of the fact that the house scraps are nearly sufficient for their entire support.

As before stated, the only method of ensuring a supply of eggs from fowls kept under these conditions is to renew the pullets as soon as they cease laying, as young birds seem constrained, if fairly fed, to develop all the ova in their ovaries into perfect eggrs. 


\section{UHAPTER XXVI.}

\section{CAPONIZING.}

THE operation of caponising is one that is not usually had recourse to even in France, and may be regarded as unnecessary in all cases where the fowls of different sexes can be separated, as recommended in Chapter XVII., at an early age.

As performed in this country, it is usually conducted in so unscientific and brutal a manner that I regard myself as justified in showing the mode in which it is accomplished in France. The American plan is, in my opinion, not as successful. Under any circumstances, the operation is one of a severe and painful character, and, in my opinion, unnecessary.

The name of capon is given to young cocks which have been deprived of the faculty of reproduction. In this state they grow to a very large size, and fatten more readily; their flesh also is more delicate.

It is desirable to submit the cocks to the operation when they are about four months old, and it is very important to choose a time when the weather is somewhat cool, rather moist than dry, and especially to avoid performing the operation during the great beats of summer.

The instrument employed in the operation should be very sharp; a surgeon's small operating knife, termed a curved pointed bistoury, is far better than an ordinary knife, as it makes a much neater wound, and so increases greatly the chances of healing; or a curved pointed penknife may be used. A stout needle and waxed thread are also requisite; a small curved surgical needle will be found much more convenient in use than a common straight one.

It is necessary that there should be two persons to perform the operation. The assistant places the bird on its right side on the knees of the person who is about to operate, and who is seated in a chair of such a height as to make his thighs horizontal. The back of the bird is turned towards the operator, and the 
right leg and thigh held firmly along the body, the left wing being drawn back torards the tail, thus exposing the left flank, where the incision has to be made. After removing the feathers the skin is raised up just behind the last rib, with the point of the needle, so as to aroid wounding the intestines, and an incision along the edge of the last rib is made into the carity of the body sufficiently large to admit of the introduction of the finger. If any portion of the bowels escape from the wound, it must be carefully returned. The forefinger is then introduced into the caritr, and directed behind the intestines towards the back, somewhat to the left side of the middle line of the bodr.

If the proper position is gained (which is somerhat difficult to an inexperieuced operator, especiallr if the cock is of full size), the finger comes into contact with the left testicle, which, in a juung bird of four months is rather larger than a full-sized horse bean. It is moreable, and apt to slip under the finger, although adhering to the spine. When felt it is to be gently pulled aray from its attachments with the finger and remored through the wound-an operation which requires considerable practice and facility to perform properly, as the testicle sometimes slips from under the finger before it is got out, and, gliding amongst the intestines, cannot be found again readily. It mar, howerer, remain in the bodr of the animal without much incourenience, altbough it is better remored, as its presence is apt to excite inflammation.

After remoring the left testicle, the finger is again introduced, and the right one sought for in a similar manner. It is readily discorered, as its situation is alongside of the former, a little to the right side of the body. Afterwards the lips of the wound are brought together and kept in contact with two or three stitches with the raxed thread. No attempt should be made to sem up the wound with a continuous seam, but each stitch should be perfectly separate, and tied distinctly from the others.

In making the stitches great care should be taken; the skin should be raised up so as to aroid wounding the intestines with the needle, or including eren the slightest portion of them in the thread-an accident that would almost inevitably be followed by the death of the animal.

After the operation the bird had better be placed under a coop in a quiet situation, and supplied with drink and soft food, such as sopped bread. After a few hours it is best to give him his liberty, if he can be turned out in some quiet place remored from the 
poultry-yard, as, if attacked by the other cocks, the healing of the wound would be enclangered.

After the operation the bird should not he permitted to roost on a perch, as the exertion of leaping up would unquestionably injure the wound; it should, therefore, at night be turned into a room where it is obliged to rest on the floor, previously covered with some clean straw. For three or four days after the operation the bird should be fed on soft food; after that time it may be set at liherty for a short period, until it has recovered entirely from the operation, when it should be put up to fatten.

In France it is customary to cut off the combs of the capons. This is regarded as a distinguishing mark of the operation having been performed, and consequently the birds do not sell so freely if ther are allowed to remain.

If the animal mopes about on the day following the operation, it is desirable to look at the wound, and, should it be inflamed, to bathe it with a little tepid water. If, however, the intestine has been rounded, there is no chance of recovering. Some persons place oil and other applications on the wound, but there is no doubt that they retard the healing process. As a general rule, it may be stated that if the operation has been skilfully performed it rarely fails of success.

The operation of making "poulardes" is much easier than the corresponding one on the cocks. The pullet is to be placed in the same position on the lap of the operator, the left leg being drawn forwards so as to expose the left flank, in which a longitudinal incision is to be made close to the side bone; this will bring to view the lower bowel, and alongside of it will be found the egg passage, or egg pipe. If this is drawn to the orifice of the wound by a small hooked wire, and cut across-or, what is perhaps better, a very short piece of it removed-the development of the ovary, or egg-producing organ, is entirely prevented, and the birds fatten rapidly, attaining also a very large size. It is most important to perform the operation before the pullets have begun to lay. I would beg to impress most strongly the desirability of practising these operations in the first instance on dead birds of the same age, so that the operator may become acquainted with the situation and appearance of the parts concerned. By this means a greater amount of success will be attained in the first instance, and much unnecessary suffering saved to the animals. 
The food used for fattening capons in France is chiefly buckwheat meal, bolted quite fine. This is kneaded up with sweet milk till it acquires the consistency of baker's dough; it is then cut up into rations about the size of two eggs, which are made up into rolls about the thickness of a woman's finger, but varring with the sizes of the fowls; these are sub-dirided by a sloping cut into "pâtons," or pellets, about two-and-a-half inches long.

A board is used for mixing the flour with the milk, which in winter should be lukewarm. It is poured into a hole made in the beap of flour, and mixed up little by little with a mooden spoon so long as it is taken up; the dough is then kneaded by the hands till it no longer adheres to them.

The food is thus administered: The attendant puts on an apron, and having the pellets at hand, with a bowl of clear water, she takes the first fowl from its cage gently and carefully, not by the wings or the legs, but with both hands; she then seats herself, with the fowl upon her knees, under her left arm, by which she supports it; the left hand then opeus its month, and the right hand takes up a pellet, dips it in the water (this is essential), shakes it on its way to the open mouth, puts it straight down, and carefully crams it with the forefinger well into the gullet; when it is so far settled down that the fowl cannot eject it, she presses it down with the thumb and forefinger into the crop, taking care not to fracture the pellet.

Other pellets follow the first, till the feeding is finished, in less time thau one would imagine. The fowl when fed is again held with both hands, and replaced in its cage without fluttering, and so on with each fowl. 


\section{INDEX.}

Acland, Mr. C. T., on the monopoly of prizes by a few Exhibitors

Audalusians.

Ant egas for chickens .........

Agrienltural Commission, Report on French poultrykeeping......................

Aylesbury ducks best for market ........................

Azeel

Azeel erosses for table

Bacillus in poultry farm disease 102

Bantams

Barham's, Mr. T., testing of "ross-bred table fowl ........

Baimdoor fowls

Bective. Lady, on Wyandottes

Bevington's, Mr. Tim., modo of rearing table fowls .........

Bewick's farm yard fowl

Brahmas, alteratious in,effected hy breeding for show .........

Brahmas as market fowl ......

Brahmas, origin of ..............

Brahmas, necessity of two pens for breeding show birds

Braquemond Farm Yard foẃl

Breeding for show, injurious effect of.

Bromley, ponltry farm at ......

Buck wheat meal, use in fattening...

Burnell, Mr., on Cuekoo Dorking

Canary seed for chickens ......

Caneton de Rouen
PAGE

3

34

60
Caponising

Charny, supposititious poultry farni at. .

Clicken-lureeding for market

Chickens, best food for ........ 60

Chicken rearing in gardens ... 59

Chitteprats ..................... 38

Cholera......................... 101

Clear eggs, use for elicken food 60

Cock-fighting, effects on fowls 8

Cochins....................... 13

Cochins, characteristics of, as when introduced ............. 13

Cochins, eross-bred, valueless as table fowls ............... 15

Cochins injurious in farm yards 14

Cooping hens with chickens... 58

Coops with ruus ............... 58

Collies useless as sheep $\operatorname{dog} \ldots$...

Comyns, Mr. A., on fictitious poultry farms ................ 115

Cramming ................... 78

Cramming machine ........... 79

Cramp ........................ 101

Cresswell, Mr. O. E., on inferiority of modern Dorking

Crèvecœurs ..................... 27

Crêvecours, the Stockleeper on show Crèvecurs ........... 27

Crooked breast, callse of ...... 46

Cross-lured elicken for table ... 74

Cross-bred chicken at Birmingham and dairy shows ........ 74

Custard for young birds........ 60

Dari for young ehickens ..... 61

De Sora poultry farm hoax ... 107

Digby, Mr. H., on Aylesbury ducks........................ 
Digby, Mr., on rearing young geese

Diseases of ponltry

Dog shows, useful qualities iguored at. .

Dorkings, effect of shors in depreciating .

Dorkings, mode in which modern breed was obtained

Douglas's, Mr. Johu, breed of Dorkings

Ducks

Ducks for stock, selection of.

Ducks, loss of eggs, laid in water.

Ducks, killing for market ......

Ducks, rearing for market......

Dust bath for fowls

Eggs, conditions affecting their quality

Eggs, selecting for hatching

Eggs, number in nest...........

Eggs, non-interference with when hatching ...............

Eggs, cost of in English markets

Eggs, preserving for winter use

Eggs, production for market...

Eggs, testing fertility

Egg-tester to make.

Fancy fowls useless for market Farm ponltry, improrement of Farm yard fowl of Bewick

Farm Y ard fowl of Braquemond Fasting before killing necessary

Fat house-seraps injurious

Fattening

Fattening, use of animal fat...

Feathers, cost of production four times that of flesh

Feeding

Feeding on soiled ground

Feeding, cost of

Feeding, ralue of different grains ....................

Fleteher Moss, Mr., on Old and Modern Game fowls .........

Fowler, Mr. J. K., on management of ducks

Fowls in small runs ............. 118

French table breeds ............

Frizzled fowls
$P \triangle G E$

100

?
PAGE

Game fowls, ancient and modern 7

Gapes $\quad . . . . . . . . . . . . . . . . . . . .100$

Gcese... ...................... 95

Goslings, food for ............. 96

Gninea fowl .................... 91

Guinea fowls, feediny young... 91

Hamburglıs ................... 38

Hatching .................... 51

Hearson's cramming machine... 79

Hearson's incubator ........... 55

Houdans, French and English contrasted .................... 26

Housing ...................... 45

Incubators, proper construction

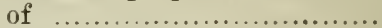

Incubator, Hearson's ............ 55

Inclian Game, eharacters of breed

Inclian Game, crosses for table poultry .....................

Jacque's, M., drawings of Crève Cœur ............

Houdan .............. 26

La Flêche ........ 29, 30

Jenkins, Mr. H. M., Sec. Royal Agric. Soc.. on present show system

Jess for tethering liens ......... 59

Johnston, Mr. Cuthbert, on the De Sora hoax ............... 107

Killing fowls ................. 80

La Flêche ..................... 29

Langshans ..................... 19

Langshans crossed with Game 19

Lanoshan crosses for table ... 69

Leghorns ..................... 37

Malays ......................... 23

Minoreas ....................... 33

Moonies ...................... 38

Morant, Major, on hens in confinement ................. 116

Moss, Mr. Fletcher, on Game fowls

Nests, best mode of making ... 51

Nichols, Mr., on the sterility of show Spanish 
Non-sitting varieties

Norris-Ely, on inutility of show

Brahmas

Offal, relative amount in good and barl table fowls............

Old English Game, use in crossing.

Orpingtons

Orpington disease

101

Parlett's, Mr., experiments in crossing Game.

Perches, right arrangement of

Pheasant fowl

Physick, Mr., on the deterioration of show Minoreas

Plymouth Rocks

Polish

Portable poultry house .........
Poultry shows encourage fancy points only

Poultry fanciers' motive in breeding show birds

Poultry farming, fallacies of $\ldots \ldots \ldots \ldots \ldots \ldots \ldots \ldots \ldots \ldots \ldots \ldots \ldots, 106$

Poultry farming in Germany... 111

Poultry farm disease ........... 101

Prize pigs, uselessuess of ..... 2

Rearing young chickens ..... 57

Red caps ...................... 40

Roup ............................... 100

Royal Agricultural Society's poultry prizes

Rumpless fowls

Rushiford, poultry farm at..... 110
PAGE

104

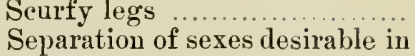
fowls for the table ......... 73

Silky fowls .................... 40

Stockieeper on nselessness of show Brahmas............. 77

Syauish ........................ 31

Sutherland, Mr. C.L., on turkey hens as incubators ........... 55

Sutherland, Mr. C. L.. on Indian Game and Dorking Cross ...

Sutherland, Mr. C. L., on nouexistence of French poultry farms ..................... 106

Testing eggs ................ 53

Tethering hens with clickens 59

'Trussing dead poultry ....... 82

Turkeys.......................... 88

Turkeys, food of young ........ 89

Turkeys, Cambridge, best breed for market .................. 88

Turkeys, hatcling ............. 89

Turkeys,management in France 90

Turner on separating sexes of chickens

Verrey, Mr. L. C., on necessity of two pens for breeding show birds

Waterloo Cup winner not a show $\log$.....................

Wire runs for feeding young chickens

Wyandottes

58

21

Yolk, the absorption of, at birth 54 


\title{
HEARSON'S CHAMPION INCUBATOR
}

\author{
At the HAGUH FXHIBITION.
}

In a trial carried on by the Judges under test conditions, Hearson"s Champinn Incubator hatched 95 CHICKS OCT OF 100 EGGS. We supply the world with

Incubators, and all who nse our machines acknowledge them to be without a rival.

THE PROBLEM SOLTED.

\section{CHICKENS ALL THE YEAR ROUND.}

All the Best Prizes and Medals hare been awarded to

HEARSON'S

CHAMPION

(BY ROYAL LETTERS PATENT).

을

层

The most complete and only Thermostatic Incubator in the world.

FITTED WITH COPPER TANK.

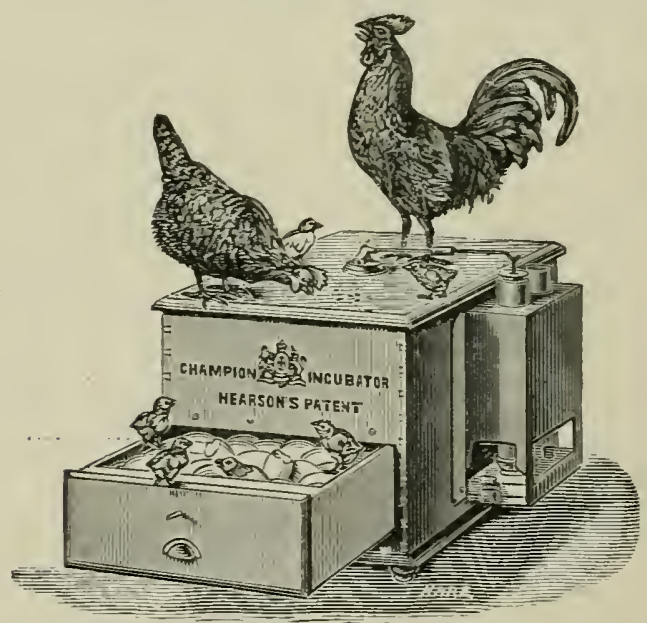

The CHAMPION has now superseded all others. Since its introduction no other incubator maker in the world has been awarded a first prize at any show at which this apparatus has been entered for competition. It is the only incubator in the world sold with a guarantee not to vary 5 deg. for 12 months together. without readjustment, and in no other incubator is the rentilationand damping so scientifically and practically carried out.

동

HEARSON'S PATENT HYDROTHERMIC FOSTER MOTHER.

An Outdoor Rearer for Cbickens.

\section{BEST IN TIE YYORID.}

Tllustrated Price List of above one stamp. Address $\mathrm{P}$ Department, Chas. Hearson \& Co., Limited, 235, Regent Street, London, W. 


\section{Poultry \\ FOR THE

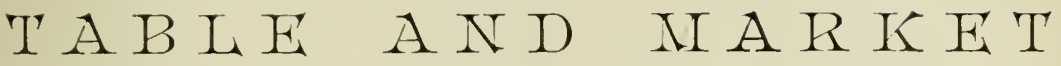 \\ VERSUS

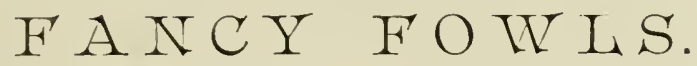

\section{NOTICES OF THE FIRST EDITION.}

\section{Daily Telegraph, Feb. 4, 1892.}

So many people are allured by works which promise them a handsome competence if they will only take to providing table fowls and eggs near some large centre of population that Mr. Tegetmeier is doing a public service in calling attention to the usually delusive nature of all such assurances. . . . It evidently behoves the authorities of poultry shows to reconsider their ways, and the would-be poultry farmer must take warning and see that that way ruination lies. It is of no use to try to compete with the foreigner without a preliminary understanding of how it is that the foreigner can rear poultry for next to nothing.

\section{Morning POST, FEB. 24.}

A remarkably practical and sensible book. The author, who has had a long and varied experience, ridicules the idea of endeavouring to breed fowls for useful and economic purposes on the principles adopted by the fancier and exhibitor. $\mathrm{He}$ explains what kind of poultry will be found the most profitable, and how they should be reared and managed. The chapter on the "Fallacies ef Poultry Farming" is a most valuable one.

\section{Daily Graphic, Feb. I9.}

Mr. IV. B. Tegetmeier is possibly better entitled than anyone else to a hearing on the subject of poultry, and a little book with which he has just come before the world is from every point of view most valuable. His aim in the work before us is to increase the quantity of marketable poultry and the quantity of eggs produced in this country, to expose current fallacies with regard to poultry keeping, and to show the best manner in which to establish poultry farming on a rational and profitable basis. Mr. Tegetmeier deals exhaustively with the whole subject, beginning with the most important breeds of fowls as they now exist, and then passing on to the management of profitable agricultural and market stock, while he also discusses the important questions of housing, feeding, hatching, cross breeding, and rearing, and the hundred and one causes which determine whether or no poultry farming shall be profitable. The book is well illustrated with drawings of typical birds, showing the very marked difference between those grown for use and for show.

\section{Evening Standard, Feb. i8.}

That the prize poultry craze is likely to be seriously affected by the scathing denunciation of Mr. Tegetmeier, the greatest authority upon the subject, and himself a judge at many of the principal poultry shows in the kingdom for the last thirty years, would be contrary to the ordinary course of affairs in such cases.

The Live Stock Journal, Feb. 5.

This volume is altogether trustworthy and well informed as to details of management by which good trable fowls may be reared and fattened. . . . The most useful book on poultry that has appeared. . . . Likely to serve as a text-bonk for generations. 


\section{Poultri, Feb. 5 .}

Few are able to speak with more authority on the subject of commercial poultrykeeping, which he has closely studied for nearly forty years. . . There can be only one opinion as to the earnest, clear, and practical manner in which he handles his subject. . . . We can heartily recommend it to every breeder, be he the fancier pure and simple, or the man who desires to take up poultry from a purely commercial point of view.

\section{ThE GaRdeN.}

The impartial reader cannot but agree with Mr. Tegetmeier that exhibition birds are not those which are adapted for agricultural and economical purposes.

The present volume will not please everyone, but to those who are anxious to raise the standard of their table poultry, and at the same time increase the production of eggs, no better instructor can be offered. It goes without saying that the chapter on general management cannot be improved upon, though some of the author's remarks may not be appreciated by every reader.

\section{THE FARM.}

At poultry shows, as at present conducted, fancy points are alone considered by the judges. The profitable value, from a consumer's point of view, is entirely ignored. Fancy points are cultivated to such an extent that one breed becomes a mass of useless feathers, another walks on stilts, a third class is endowed with crests as large as plates. In publishing the work under notice, Mr. Tegetmeier has but one object in view, the increase of marketable poultry and the quantity of eggs produced in this country.

\section{Feathered World, Feb. 5.}

That there is need for such a book goes without saying, for one has only to recollect the nondescript class of poultry usually kept about farmyards and small holdings to feel sure that the advice here given will prove of value to many, if only taken to heart and acted upon.

\section{Gardexer's Chroxicle, May 14.}

The pictures fully bear out his opinion, contrasting, as they do, common and fancy fowls when first introduced, with the deformities bearing the same names, which latter are generally not only more delicate in constitution, and less productive than the old varieties, but far less suited than those for the table.

\section{Athexæun, Avg. 27.}

The name and high reputation of the author are guarantees for thoroughness of treatment, and, indeed, the chapters on hatching, rearing, and breeding poultry for the market can hardly be rivalled.

\section{ACADEMY, ApriL 30.}

A more practical book on the subject was never written, it cannot be too widely circulated in rural districts.

\section{THE Zoologist.}

Mr. Tegetmeier compares fowls as they were with fowls as they are, and shows that for agricultural and economical purposes the modern fancy breeds are useless, as contrasted with the older varieties. He considers that agricultural societies are doing more harm than good by offering prizes for useless birds, and ignoring to a great extent the birds which would be of more benefit to the farmer and to the nation at large.

\section{Saturday Review, March 12.}

Mr. Tegetmeier thinks it is much to be regretted that useful poultry is cxcluded from our great agricultural exhibitions and fancy feather varieties favoured in their stead. As to the evidence, Mr. Tegetmeier has produced enough to engage the serious attention of farmers, and more than enough to stir the fancier to reply.

\section{Mark Lane Express, March 7 .}

Mr. Tegetmeier, in his wonderfully interesting work on "Table and Market Poultry," has shown how exhibitions have injuriously produced fancy animals. 
Lloy's NEWSPAPER, MAY I5.

Mr. Tegetmeier's most useful handbook deserves the closest possible study.

\section{Midland Counties Herald, Aug. il.}

At the present time, when so much attention is being paid to agricultural matters in the way of cottage allotments and small holdings, and the best means of developing the minor resources of the farm, its publication is most opportune, and we can recommend all who take an interest in such matters to obtain it.

\section{Echo, March 10.}

Mr. Tegetmeier is unquestionably one of the highest authorities on poultry, but he has no high opinion of the value of poultry shows in the production of marketable and useful birds.

\section{BAZAAR, MARch 16}

We cordially recommend this work, which not only teaches the poultry keeper all he requires to know to enable him to succeed, but also how to avoid the mistakes which are so commonly made. . . The book, too, is a practical protest against the miserable but too common idea that the fancier is an improver of breeds, and that poultry farming can be made to pay.

\section{ThE WORLD, MaRch 2.}

The small farmer and landed proprietor may learn much from the study of this interesting volume. Mr. Tegetmeier proves conclusively that poultry as a source of food has suffered materially by the attention bestowed on fancy poultry.

\section{Yorkshire Herald, FEB. 19.}

A useful guide to farmers who want to make a profit out of poultry. . . . Mr. Tegetmeier strongly deprecates poultry farms; he shows that all such attempts must be unremunerative, though it should be easy on every farm, at scarcely any appreciable cost, to keep a considerable stock of poultry and raise eggs and rear chickens in paying quantities for the market.

The Scotsman, Feb. 15.

A valuable manual for those who cultivate poultry. . . . A practical handbook of all the details of the industry, written from long experience of breeding poultry. Contains a number of illustrations which add considerably to its value.

\section{Devox Gazette, Feb. 13.}

Coming from one so well able to judge, and whose authority cannot well be questioned, his remarks will receive all the weight they deserve. The author's object is to increase the quality of marketable poultry. He is anxious to point out that poultry shows, as ordinarily conducted, have no connection with the breeding of market poultry. . . . Unquestionably the work is one to be carefully read by all who make poultry keeping a means of living. Every class of fowl is considered, and the instructions given are the outcome of practical observation. There is little doubt the book will be in popular demand.

\section{Norwich Argus, Feb. io.}

Mr. Tegetmeier's book must be noted the most trustworthy that has ever been published. He treats of the rearing for the table and market, speaks scornfully of fancy fowls, and exposes the fallacies of coultry farming in trenchant language. . Illustrated with pictures of beautiful ancient and distorted modern birds, among the former Bewick's true barn-door fowl, which is still without a rival. A work that must serve as a text-book.

\section{Essex County Chronicle, Feb. 19.}

For those who keep poultry for profit the book will be of the greatest value.

\section{Kildurn Times, Feb. i2.}

The keeping of fowls in small runs is ably dealt with, and the precautions necessary to ensure success are distinctly laid down. 
The kent herald, March 3 .

A remarkably practical and sensible book. The chapter on the "Fallacies of Poultry Farming" is a most valuable one, and should deter anyone endowed with an ordinary amount of sense from embarking on the enterprize.

\section{The Publishers' Circlitar, Feb. 27.}

This thoroughly practical little solume will be found of extreme interest to all who are concerned in the rearing of fowls.

\section{Bath Chronicle, Feb. is.}

The handiest and most complete, and, we will add, the most sensible, practical, and authoritative treatise on the subject that has been pub ished.

Somerset County Gazette, Feb. 20.

Well illustrated, and written in a very lucid style.

Kexdal Mercury, Feb. ig.

It has another excellence-that of cheapness-for what cannot fail to be the authoritative handbook on economic poultry keeping may be had at the expense of half a crown.

HaMpste.d Express, Feb. 20.

We consider it not only a desirable acquisition to the library of the British farmer, but also of value as regards the ordinary poultry fancier. who possibly may be led to see the error of his ways, and to endeavour to amend them.

\section{SALISBLRY JOL'RNAL.}

Everyone who is interested in the practical side of poultry rearing ought to read the book. The chapter on "fallacies of poultry farming" is especially important in view of the seemingly conclusive proofs the author brings forward in support of his statement that, "to produce poultry and eggs in large quantities for the market, and as part of the food supply of the country, has nerer yet been made to pay when carried on as a separate business, and liable to be charged with all the outgoings that are necessarily incurred."

\section{THE QUEE:.}

An interesting chapter is that devoted to the keeping of fowls in small runs by suburban residents. These attempts are usually successful in the first instance, the fowls when bought being young, healthy, and vigorous, but it kept on the ground it becomes tainted, and the laying falls off very much. By adopting a more rational system, Mr. Tegetmeier shows the mode in which, even in an area of somewhat limited size, a few fowls can be kept for egg production with moderate success. This is to be accomplished by a succession of new pullets; by careful feeding, with the elimination of all fat house scraps; the abundance of green food, with a constant renewal of fresh earth, and of means to be adopted whereby the fowls should not pick their food from the tainted ground.

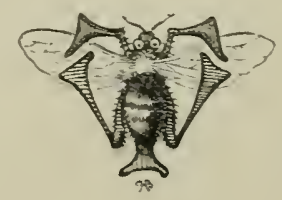




\section{BOULTON \& PAUL'S SPECIALTIES, NORWICH. THE ORIGINAI MAIXERS.}

New Water

Fountain.

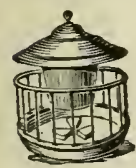

No. 3. Poultry Trough.

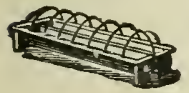

No. 18. Pcultrs Trough.

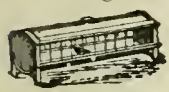

No. 45A. Fattening

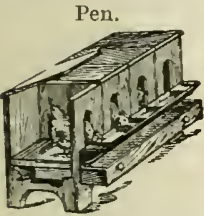

The "Morant" Rabbit Hutch.

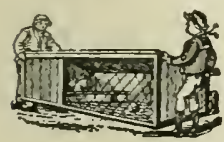

No. 66. House for Ducks.

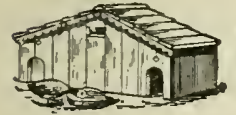

New Portable Coop with Run combined.

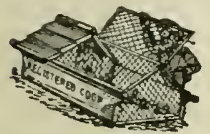

No. 100. Improved Poultry Fencing.

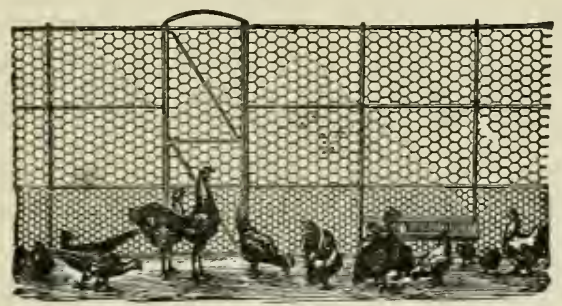

Morable Fowl House.

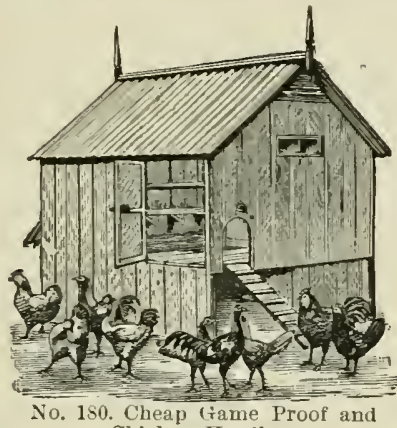

No. 180. Cheap tiame Proof and Chicken Hurdles.
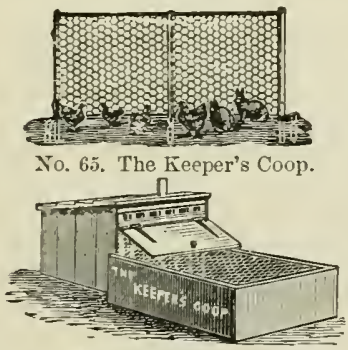

No. 47. New Portable Fowl House.

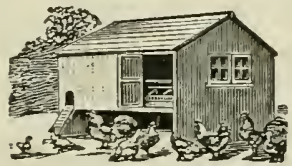

No. 64 . Hatching and Nest Box.

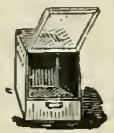

No. 5. Poultry Trough.

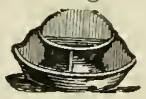

No. 19. Poultry Trough.

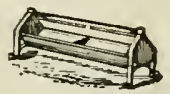

Xovable Poultry House for Farm Use.

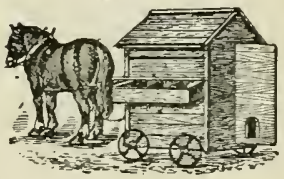

No. 46. Poultry Shelter and Dust Bath.

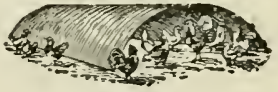

No. 61. Feeding Coop.

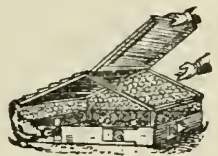

Cockerel Run or Bantau House.

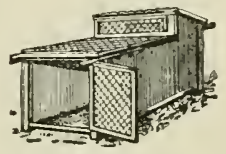

BEWARE OF INFERIOR IMITATIONS, OFFERED AT RIDIGULOUSLY LOW PRICES. Send for Illustrated Catalogue, including nevo designs for this season, vith prices, free on application. 


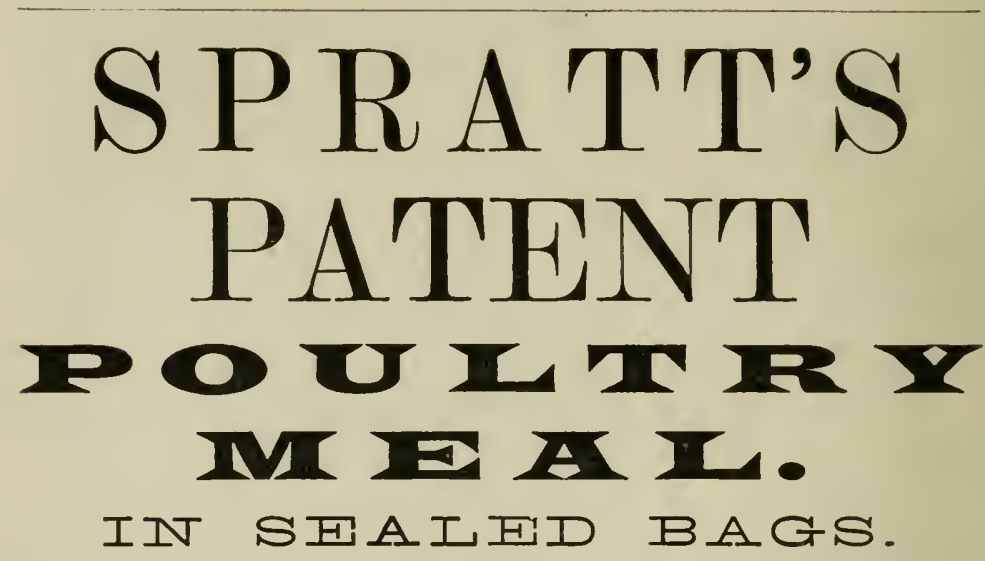

Price-Per cwt., 20s.; per half cwt., 10s. 6d.; per quarter cwt., 5s. 6d.; per 14lb., 2s. 9d.; per 71b., 1s. 6d.; also in $3 d$. and 6d. sample packets.

\section{GRANULATED PRAIRIE MEAT 66

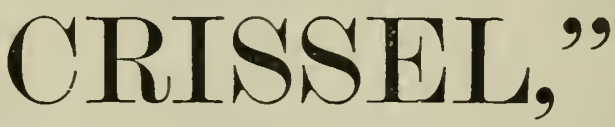

A SPECIAL PREPARATION OF MEAT, TAKING THE PLACE OF INSECT FOOD.

\section{IN SEALED BAGS.}

Price-Per cwt., 26s.; per half cwt., 13s. 6d.; per quarter cwt., 7s.; per 14lb., 3s. 9d.; per 7lb., 1s 11d.

SAMPLES POST FREE.

Samples and Pamphlet on Poultry Rearing Post Free for One Stamp.

SPRATT'S PATENT LIMITED, BERMONDSEY, LONDON, S.E,

The Word "CRISSEL" is our Registered Trade Mark. 


\title{
Catalogue of Books
}

REI.ATING TO

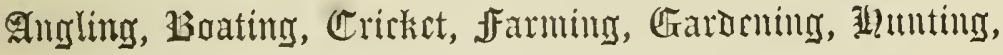
Shooting, Tenmis, Trabel, 侽achting, \$ct,

USEFUL FOR

\section{COUNTRY GENTLEMEN, TRAVELLERS, ETC.,}

\author{
PUBLISHED BY \\ HORACE COX,
}

"THE FIELD" OFFICE, WINDSOR HOUSE, BREAM'S BUILDINGS, E.C.

* * Orders for any of the following works, with postage stamps or post-office order (payable at the Money Order Office, Chancery Lane, W.C.) for the amount, should be sent to HoRACF. Cox, Publisher, at the above address, or the books may be obtained by order of any bookseller.

\section{AGENTS.}

AuSTRAliA.-Adelaide, S.A.: E. S. Wigg \& Son; W. C. Rigby, 74, King Williamstreet; George Robertson \& Co., Melbourne, Sydney, Adelaide, and Brisbane.

Perth, W.A.: E. S. Wigg \& Son.

INDIA.-Calcutta: 'Thacker, SPINK, \& Co.; King, Hamilton, \& Co. Bombay : Thacker \& Co. Limited; King, King, \& Co.

CANADA.-Grafton \& Sons, Montreal.

United STATES.-Brentanos, 5, Union-square, New York.

CAPE TOWN.-J. C. Juta \& Co., Port Elizabeth and Johannesburg.

No. 2. $-9 / 95$. 


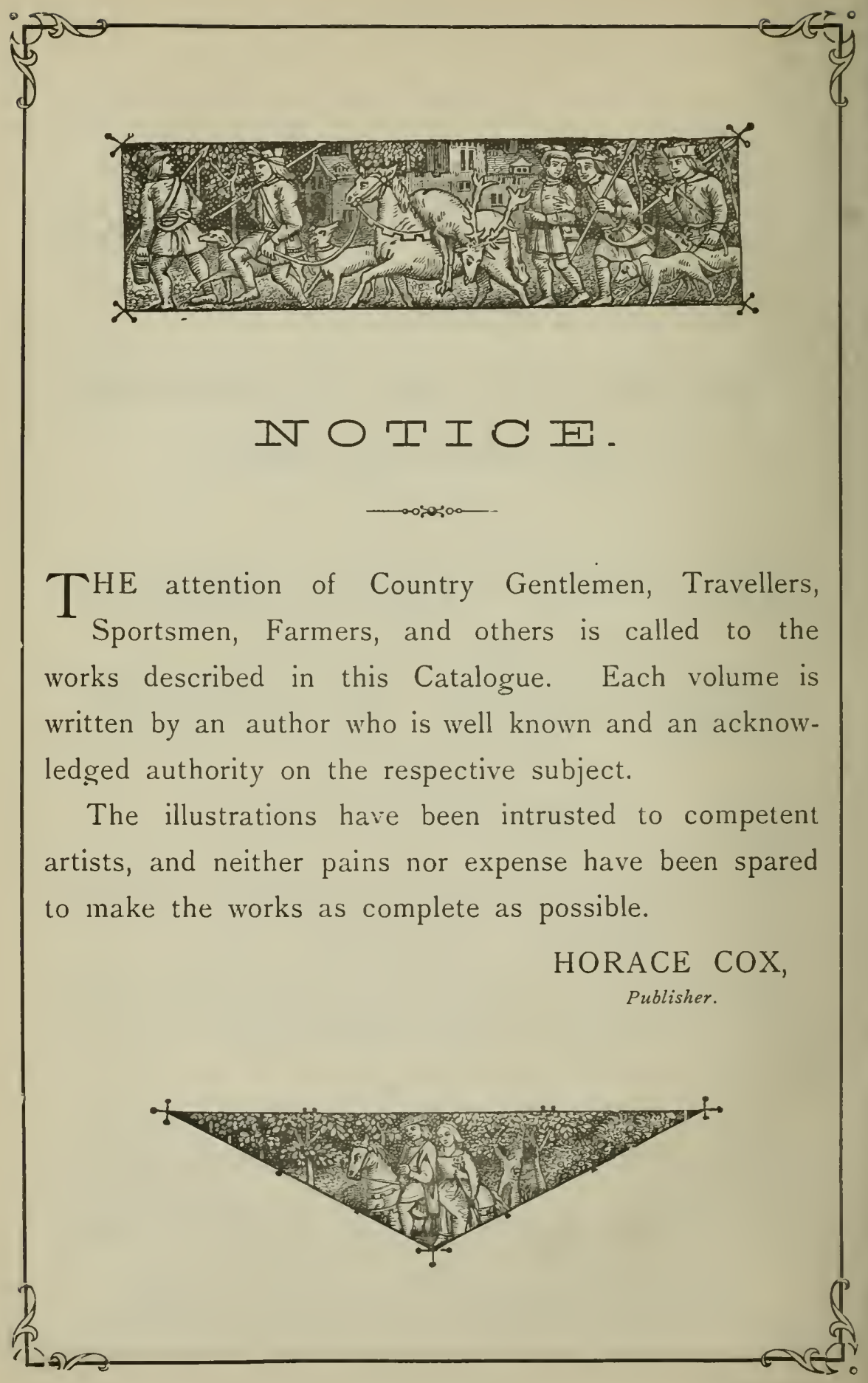




\title{
A \\ Catalogue of Books \\ PUBLISHED BY \\ HORACE COX.
}

SEGOND EDITION, GREATLY ENLARGED.

Royal 4to., bevelled boards, gilt edges, price $15 s$., by post $15 s .9 d$.

\section{PHE A S A N T :}

Trume

NATURAL HISTORY AND PRACTCALL MANGGEMENT.

By W. B. TEGETMEIER, F.Z.S.,

(Member of the British Ornithologists' Union.)

Author of "The natural History of the Cranes," \&c., \&c.

Illustrated with numerous full-page engravings drawn from Life by

T. W. WOOD.

DAY'S BRITISH AND IRISH FISHES.

In 2 vols., imperial 8vo., cloth, price 2 guineas, by post $£^{2} 3^{s .} .6 d$. THE FISHES OF GREAT BRITAIN AND IRELAND.

\author{
By FRANCIS DAY, F.L.S., F.Z.S., \&C.
}

The Standard Work for Zoological Students, Fishculturists, Fishermen, and the Public. The value of this grand work is much increased by nearly Two Hundred Plates and Woodcuts.

Mr. Day has personally delineated every Species from Nature, and incorporated many discoveries of recent times.

\section{DAY'S SAIMIONID平。}

In I vol., imperial 8vo., cloth, price I guinea, by post 2 Is. $6 d$. With 2 Coloured Plates and many Woodcuts.

\section{British and Irish Salmonidæ.} By FRANCIS DAY, C.I.E., F.L.S., AND F.Z.S.

This work is an exhaustive treatise on the Salmonidx of the British Islands, and will be interesting to the Fisherman, as well as a text-book to the Scientific Ichthyologist. The reduced price will place it within the reach of all.

A Few Copies to be had, beautifully bound in Whole Calf, Full Gilt, price 35s.

WINDSOR HOUSE, BREAM'S BUILDINGS, LONDON, E.C. 


\section{EIGHTH EDITION IN THE PRESS.} Super-royal 8vo., price 25s. net, or by post 26 s.

\section{A ManUal}

\section{OF \\ YACHT AND BOAT SAILING.}

\section{By DIXON KEMP,}

Associate Institute Naval Architects (Member of the Council).

Author of "Yacht Designing" and "Yacht Architrctlre."

(The Lords Commissioners of the Admiralty have ordered this work to be supplied to the Libraries of the ships of the Royal Navy.)

This Edition is largely rewritten, and contains a great number of new subjects, and the lines of many boats nerer before published, the total number of Plates oxceeding 100 , besides more than 350 woodcuts in the text.

Third Edition in the press, Super-royal 8vo., price £2 2s., by post $£ 23^{s}$.

\section{YACHT A \\ ARCHITECTURE \\ By \\ DIXON KEMP,}

Associate of the Institution of Naval Architects and Member of the Council.

THIS WORK enters into the whole subject of the laws which govern 1 the resistance of bodies moving in water, and the influence a wave form of body and wave lines have upon such resistance.

It also deals comprehensively with the subject of STEAMI PROPULSION as applied to yachts.

An easy SYSTEMI for DESIGNING is provided, and every necessary calculation is explained in detail.

The latter part of the work is devoted to YACHT BUILDING, and engravings are given of erery detail of construction and fitting, including laying off, taking bevels, \&c.

The List of Plates (exclusively of over thirty devoted to the elucidation of the text, and nearly two hundred woodcuts) exceeds fifty, and comprise the LINES of some of the most CELEBRATED IACHTS AFLOAT by the most successful builders and designers.

IVINDSOR HOUSE, BREAM'S BUILDINGS, LONDON, E.C. 
In demy 8vo., with Map and Illustrations, price Ios. 6 .

\title{
An AUSTRALIAN in CHINA:
}

BEING THE NARRATIVE OF A QUIET JOURNEY ACROSS CHINA TO BRITISH BURMA.

\section{By G. E. MORRISON, M.B.C.M. Edin., F.R.G.S.}

In the Spring of last year, the author, who has travelled widely over the world, and is a graduate of Edinburgh, made an interesting and remarkable journey through the centre of China. He started from Shanghai, went up the Yangtse River as far as the city of Chungking, and then, dressed as a Chinese, with a pigtail attached to the inside of his hat, crossed over the provinces of Szechuen and Yunnan, the upper Chinese Shan States, and Kachin Hills, to the frontier of Burma, at Nampoung. Dr. Morrison travelled without an interpreter although he does not speak Chinese; he had no European companion, and his only companions were Chinese coolies of the humblest class, whom he engaged to carry his things from point to point of the journey. He went unarmed and largely on foot. The book in which he recounts his experiences, besides giving the latest news about far inland China, bears strong testimony to the courtesy and hospitality of the Chinese, and to the uniform kindness with which they treated a traveller who placed unreserved confidence in their good faith. The book is well illustrated.

$$
\text { Price 5s., by post 5s. } 4 d \text {. }
$$

THE

\section{YACHT RACING CALENDAR AND REVIEW \\ FOR 1895.}

\author{
Bv DIXON KEMP, A.I.N.A., \\ Author of "Yacht and Boat Salling," \&c.
}

Crown 8vo., price 7s. 6d., by post 7s. Iod., with Maps and Illustrations.
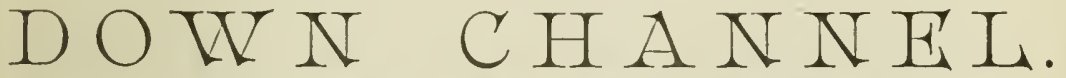

\section{BY R. T. MCMULLEN.}

With Introduction by DIXON KEMP.

The First Mishap.

The "Leo's" First Cruise, I850.

The "Leo's" Last Cruise, 1857.

To Scilly in the "Orion," I 868.

To Scilly and Ireland in the "Sirius, 1861 .

Round Great Britain in the "Sirius," 1861.

Voyage of the "Orion" to Bantry, IS69.

Visit to the Bull Rock.

From the Thames to the Forth, \&c., r87r.

\section{CONTENTS.}

From the Clyde to the Thames, IS7 1.

From the Thames to the West Coast of

Scotland, $\mathrm{IS}_{75}$.

How I came to Sail alone in a 19-Ton Yacht, I 877 .

From the Thames to the Wolf Rock with an Amateur Crew, 1882.

Experimental Cruise.

WINDSOR HOUSE, BREAM'S BUILDINGS, LONDON, E.C. 
8vo. pp. 463 , with 32 illustrations, price Ios. $6 d$., by post IIs.

\section{E S S A Y S}

ON

\section{SPORT AND NATURAL HISTORY.}

\section{By J. E. HARTING. CONTENTS.}

Shooting - Hawking - Fishing - Training Hawks - Lark Mirrors - Plover Catcbing - Fisbing with Cormorants-Decoss-The Irish Wolfhound-The Badger-Wild Turkess-The Great Bustard-SealsWild Swans, \&c

Thirty-eight Essays : concluding with Practical Hints on Bird Preserving for the use of Travellers and Collectors.

\section{Price 5s. net, by post 5s. $4 d$.}

\section{HORSES, ASSES, ZEBRAS, MULES,}

\section{MULE BREEDING.}

BY

W. B. TEGETMEIER, F.Z.S,, and C. I. SUTHERLAND.

This work, which is profusely illustrated, includes a detailed description of all the animals of the horse tribe, and demonstration of the advantages of mules for agricultural and draught purposes, as shown by their utilisation in Europe, America, and India.

"A curious, raluable, and interesting treatise, ... the usefulness of which is enhanced by the accurate drawings of the animals." - Sportsman.

"The book is not merely a popular treatise ; it is a work of considerable merit as a professional exposition of a subject regarding which there is much to be learned in this country." - Scotsman.

"The work should tind a place in every regimental library." - Admiralty and Horse Guards' Gezetie.

"A rerv interesting and readable work. Will be found to contain all that anrone may wish to know on the subject of mules and mule breeding. ... A valuable addition to the literature of stock breeding."- iive Siork four nal.

"The vol ume wil be much sought after in America, lndia, and the Cape, and it is pretty certain will be translated into other languages."-The Sporting Life.

"The authors have admirably succeeded." - Bell's Heekly. Messenger.

"Profusely illustrated, and well worth perusal."-Oxfor d Fournal.

"Not at all unlikely to lead to a more general emplorment of mules instead of horses for agricultural and general draught purposes."-Daily. News.

\section{LYRA PISCATORIA.}

Original Poems on the Nature, Habits, and Mode of Capture of all the British Fresh-vater Fishes, on Flies, Fishing, and Fishermen.

BY COTSWOLD ISYS, M.A.,

Author of "A Handy Guide to Dry-fy Fishing," \&c., and Hon. Member of the Fly-Fishers' Club.

$$
\text { Price 6d., paper coiers, or 1s. in cloth. }
$$

\section{SHIRTAITIS \& IMASITHIRS.}

The Law of Disputes, Rights, and Remedies, in Plain Language.

\section{BY A BARRISTER.}

Conrssts. - Introductory Chapter-Engagement of Servants-Character of Serrant-Duty of Servant-Duty of Employer-Employer's Liability for Servant's Negligence-Employer's Liability for Orders given by Servant-Dismissal of Servant-Right of Servant to Leare Service-IVagesCommission Paid to Servants-Concluding Chapter.

WINDSOR HOUSE, BREAM'S BUILDINGS, LONDON, E.C. 
NEW AND CHEAPER EDITION OF THE CATTLE, SHEEP. AND PIGS OF GREAT BRITAIN.

With Illustrations from the original drawings by Harrison Weir, in $I$ vol., price $12 s .6 d$., by post $13 s$.

THE

\section{CATTLE, SHEEP, AND PIGS}

$\mathrm{OF}$

\section{GREAT BRITAIN :}

\section{A SHRIFS OF ARTIOIFS}

ON THE VARIOUS

BREEDS OF THE UNITED KINGDOM, THEIR HISTORY, MANAGEMENT, \&c.

\section{Edited by the late JOHN COLEMAN,}

Editor of the Farm Department of "The Field," and formerly Prolessor of Agriculture at the Royal Agricultural College, Cirencester.

\section{CONTENTS.}

THE CATTLE OF GREAT BRITAIN.

1. Introductory,

I1. Breeding and General Management.

III. Principles of Feeding and Value of Different Kinds of Food.

IV. Buildings and the Management of Manure.

V. Dairy Management, the Milk Trade, \&c.

VI. Shorthorns. By John Thornton.

VII. The Hereford Breed of Cattle. By T. Duckham.

VIII. Devon Breed of Cattle. By Lieut.-Col. J. T. Dary.

IX. The Longhorns. By Gilbert Murray.

X. The Sussex Breed of Cattle. By A. Heas. man.

XI. Norfolk and Suffolk Red-Polled Cattle. By Thomas Fulcher.

\section{THE SHEEP OF}

I. Introductory.

II. The Management of Ewes up to Lambing.

I1i. Preparations for ad Attention during Lambing.

IV. Management from Birch to IVeaning.

V. From Weaning to Market.

VI. On Wool.

VII. Leicester Sheep.

VIII. Border Leicesters. By John Usher.

IX. Cotswold Sheep.

X Long-lVoolled Lincoln Sheep:

XI. The Devon Long-IVools. By Joseph Darby. XII. Romney Marsh Sheep.

XIII. Southdown Sheep.

THE PIGS OF GREAT BRITAIN.

1. Introductory,

II. The Berkshire Pig.

III. Black Suffolk Pigs.

IV. Large IVhite Breed of Pigs.

V. Small White Pigs.

VII. The Black Dorset Pig.

VIII. The Tamworth Pig.
XII. Galloway Cattle. By Gilbert Murray.

Xili. The Angus-Aberdeen Cattle.

XIV. The Ayrshire Breed of Cattle. By Gilbert Murray.

XV. IVest Higbland Cattle. By John Robertson. XVI. The Glamorgan Breed of Cattle. By NIorgan Evans.

XV11. Pembrokeshire or Castlemartin Cattle. By Morgan Evans.

XVIII. The Anglesea Cattle. By Morgan Evans.

XIX. The Kerry Breed of Cattle. By the late R. O. Pringle.

XX. The Jersey Breed of Cattle. By John M. Hall.

XXI. The Guernsey Breed of Cattle. By "A Native."

\section{GREAT BRITAIN.}

XIV. The Hampshire or IVest Country Down Sheep. By E. P. Squarey.

$\mathrm{XV}$. Shropshire Sheep.

XVI. Oxfordshire Down Sheep. By Messrs. A. F. M. Druce and C. Hobbs.

XVII. The Roscommon Sheep. By he late R. O. Pringle.

XVIII. Negrette Merino Sheep.

XiX. Exmoor Sheep.

XX. The Black-faced or Scotch Mountain Sheep.

XXI. Cheviot Sheep. By John Usher.

XXII. Dorset Horned Sheep. By Joseph Darby.

XXi1I. Welsh Mountain Sheep. ByMorgan Evans. XXiv. The Radnor Sheep. By Morgan Evans.

XXV. Herdwick Sheep. By H. A. Spedding.

VI. Niddle Bred White Pigs. 
In crown 8vo., price 5s., by post 5s. $4 d$.

\title{
BOA T - R A C I N G ; OR,
}

The ARTS of ROWING and TRAINING.

\section{BY EDWIN DAMPIER BRICKWOOD.}

(EX-AMATEUR CHAMPION OF THE THAMES.)

ROWING.

CHAP. Introduction: Past and Present Condition of Boatracing.

II.-Racing Boats: Their History and Fittings.

1II.-The Sliding Seat : Its Invention, Adoption, and Theory.

IV.- How to Use an Oar, and Sculls.

V.-Faults and Errors : W' bat to avoid.

VI.-Steering : Coxswain and Non-coxswain.

VII.-Teaching Beginners.

VIII.-Coaching for Races, and Selection of Crews.

IX.-The Varieties and Conduct of Boatraces.

X.-The Laws of Boatracing. chap.

XI.-The Qualifications of Amateurs.

XII.-Boat Clubs: Their Organisation and Administration.

XIII-Historical Records, A.D. I715 to 1838 .

XIV: " " A.D. 1839 to 1855.

XV. " " " A.D. 1856 to 1875 .

XVI.-Its Principles.
XVII.-Its Practice.

TRAINING.

XVIII.-Prohibitions, Ailments, \&c.

APPENix.-Rules for Betting.

INDEX.

Published Annually, price is., by post is. Id.

\section{THE ROWING ALMANACK AND OARSMAN'S COMPANION}

\author{
For 1895.
}

Edited by "ARGONAUT."

Aquatic Editor of "The Field." Author of "Boat Racing."

\section{CONTENTS.}

Review of the Season, I 894 .

Record of Races.

Amateur Rowing Association.

The Laws of Boat Racing.

Wingfield Sculls Rules.

Length of Racing Courses.

The Rowing Directory.
Tradesmen's Clubs.

Sea Coast Clubs.

Distance Tables.

Rules \& Regulations for Punting.

Appendix.-Table of Winners.

Oxford and Cambridge Eight-oared Races.

Oxford University Boat Cluh.

Cambridge University Boat Club.

Wingfield Sculls.

Henley-on-Thames Royal Regatta.

Metropolitan Amateur Regatta.

Royal Thames Regatta.

Thames National Regatta.
British Regatta in Paris.

Thames Regatta.

Thames International Regatta.

The National Regatta.

The Championship.

Doggett's Coat and Badge.

Punting Professional and Amateur Champion. ship.

Second Edition. Price 2s. 6d., by post 2s. 8d., in limp cloth.

\section{RABBITS FOR PROFIT AND RABBITS FOR POWDER.}

A Treatise upon the New Industry of Hutch Rabbit Farming in the Open, and upon Warrens specially intended for Sporting purposes; with Hints as to their Construction, Cost, and Maintenance.

ĐI R. J. IIOYD PEICE.

Fcap. Swo., price 6d., by post $7 d$.

BORES AND LOADS FOR SPORTING GUNS FOR BRITISH GAME SHOOTING. By W. A. ADAMS.

IVINDSOR HOUSE, BREAM'S BUILDINGS, LONDON, E.C. 


\section{PUBLISHED ANNUALLY AT THE END OF MAY.}

Price 5s., by post 5s. $4 d$.

THE

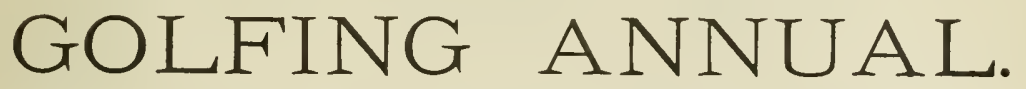

EDITED BY D. S. DUNCAN.

THIS WORK CONTAINS ABOVE 700 PAGES, AND NEARLY 400 ILLUSTRATIONS.

Second Edition, with additions, price I5s., by post I5s. yd., cloth gilt.

\section{Shifts and Expedients}

$\mathrm{OF}$

Camp Life, Travel, and Exploration. BY

W. B. LORD and T. BAINES.

(Roya' Artillery.) (F.R.G.S.)

INTRODUCTION.

Chap.

1.-Outfit to take abroad.

II.-Boats, Rafts, and Makeshift Floats.

III.-Working in Metal.

IV.- - Huts and Houses.

V.-Extempore Bridges and Makeshifts for Crossing Rivers and Ravines.

VI.-Timber and its Utilisation.

VII.-Sledges and Sledge Travelling.

VIII.-Boots, Shoes, and Sandals.

IX.-Waggons and other Wheeled Vehicles.

$\mathrm{X}$.-Harness and Pack Animals.

XI.-Camels.

XII.-Cattle Marking.

XIII.-Water, and the Sap of Plants.

XIV.-Camp Cookery.
XV.-Fish and Amphibious Animals.

XVI.-Poisoned Weapons, Arrows, Spears, \&c.

XVII.-Tracking, Hunting, and Trapping.

XVIII.-Palanquins, Stretchers, Ambulances, \&c.

XIX.-On Sketching and Painting under the Ordinary Difficulties of Travel.

XX.-The Estimation of Distances and Hints on Field Observing.

XXI.-Hints to Explorers on Collecting and Preserving Objects of Natural History.

XXII.-Ropes and Twines.

XXIII.-Bush Veterinary Surgery and Medicine. 
Large post Svo., price 3s. 6d., by post 3s. 9d.
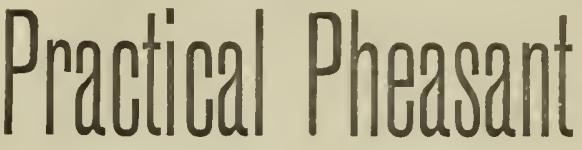

WITH

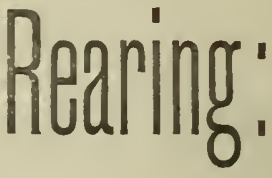

AN APPENDIX ON GROUSE DRIVING.

By RICHARD JOHN LLOYD PRICE.

Author of "Rabbits for Profit and Rabbits for Powder," \&c.

In Handy Pocket Size, price is. 6d., by post is. $7 d$.

\section{THE GAMEKEEPER'S SHOOTIMG MEMORANDUM BOOK} FOR THE

REGISTRATION OF GAME SHOT, MEMORANDA OF SALE, \&C.

$$
\text { BY “工. 王. B. C.,” }
$$

Editor of "Facts and Useful Hints relating to Shooting and Fishing," "The Gamekeeper's and Game Preserier's Account Book and Diary," Ëc.

Bound together in cloth, gilt edges, price $6 d$., by post $7 d$.

THE

\section{RULES OF PIGEON SHOOTING.}

PUBLISHED BY SPECIAL PERIIISSION,

The Hurlingham Club and the Gun Club Rules of Pigeon Shooting.

Third Edition, Exlarged and Revised. Large post 8vo., with Illustrations, price $5^{s}$. cloth, by post $5^{s} .4 d$.

THE COUNTRY HOUSE:

A COLLECTION OF USEFUl INFORMATION AND RECIPES,

Adapted to the Country Gentleman and his household, and of the greatest utility to the housekeeper generally.

$$
\text { BY I. E. B. C., }
$$

Editor of "Facts and Useful Hints relating to Fishing and Shooting," and " The Gamekeeper's and Game Preserver's Account Book and Diary."

IVINDSOR HOUSE, BREAM'S BUILDINGS, LONDON, E.C. 
Price 5s. net, by post 5s. 4 d.

THE ART OF CHESS.

\title{
By JAMES MASON.
}

CONTENTS.

I. The End Game.-Pawns v. Pawns-Minor Pieces, \&c.-Rook v. Pawns-Rook,

Sole or Supported, Against Various Forces-Queen v. Various Forces.

II. The Middle Game.-Combination in General.

III. The Opening.-Introduction-King's Knight's Game-Centre Game-King's

Gambits-King's Gambit Declined-French Defence-Centre Counter Game-

Sicilian Defence-Fianchetto, \&c.-Queen's Innight's Game-Queen Pawn

Opening-Appendix-The Problem Art.

Crown Svo., limp cloth, 2s. 6d., net; bevelled boards, gilt edges, price 5 s. by post $3 d$. extra.

THE PRINCIPLES OF CHESS In Theory and Practice. By JA MIES MIASON.

CONTENTS.-I. Elements of Chess-II. General Principles-III. CombinationIV. Exposition of Master Play Complete.

Crown 8vo., cloth boards, price $5^{\text {s. }}$

\section{THE KNIGHTS AND KINGS OF CHESS.}

\author{
CONTAINING
}

Biographical Sketches of Steinitz, Blackburne, Zukertort, Mackenzie, \&ic.

CAISSANA and ANECDOTES. BY

THE REV. G. A. MACDONNELL, B.A. With Portrait by Arthus Hacker, A.R.A.

In royal 8vo., with Maps, Photographs, and Drawings, price 2 Is.

\section{MAN HUNTING IN THE DESERT.}

A NARRATIVE OF THE PALMER SEARCH EXPEDITION, CONDUCTED BY SIR CHARLES WARREN.

By CAPTAIN ALFRED IAYNES, R.E.

WINDSOR IIOUSE, BREAM'S BUILDINGS, LONDON, E.C. 
Demy 8vo., price 2s., by post 2s. $2 d$.

THE

\section{SPORTSMAN'S VADE-MECUM} FOR THE

\section{HIMALAYAS.}

CONTAINING

NOTES ON SHOOTING, CAMP LIFE, \&C. FUILY IIIUSTRATHD.

\section{BY IX. C. A. J.}

Third Edition, demy 8vo., printed on plate paper, with Illustrations on toned paper, price $5 s .$, by post $5 s .4 d$.

A HISTORY AND DESCRIPTION, WITH REMINISCENCES, OF

\section{THE FOX TERRIER.}

By RAWDON B. LEE, Kennel Editor of "The Field."

THE ILLUSTRATIONS BY ARTHUR WARDLE.

A FEW COPIES ON LARGE PAPER, Price 10s. 6d., by Post 11s. Demy 8vo., printed on plate paper, with Illustrations by Arthur Wardle, price $3 s .6 d$., by post $3 s$. I I $d$.

A HISTORY AND DESCRIPTION OF THE

\section{COLLIE IN HIS BRITISH VARIETIES.

BY RAWDON B. LEE,

Kennel Editor of "The Field," and Author of "The Fox Terrier."

A FEW COPIES ON LARGE PAPER, Price 10s. 6d,, by Post $11 \mathrm{~s}$.

IVINDSOR HOUSE, BREAM'S BUILDINGS, LONDON, E.C. 
Demy 8vo., in Troo Volumes, price I5s. each, by post I5s. 6d. each. THE

\section{MODERN SPORTSMAN'S GUN AND RIFLE,} INCLUDING

GAME AND WILDFOWL GUNS, SPORTING AND MATCH RIFLES, AND REVOLVERS. IN TWO VOLUMES.

Vol. I.-GAME AND WILDFOWL GUNS. Vol. II.-THE RIFLE AND REVOLVER.

By THE LATE J. H. WALSH, "Stonehenge," Editor of "The Field,"

Author of "Dogs of the British Islands," "The Greyhound," "British Rural Sports," Ec.

Demy 4to., with 12 full-page illustrations, some of which contain Portraits of Sporting Celebrities, and 24 vignettes, price Ios. $6 d$., by post IIs.

SPORXXE SWXEXX WITH

\section{PEN AND PENCIL.}

FRANCIS FRANCIS AND A. W. COOPER.

CONTENTS.

The First of September.

A Day in a Punt.

Mark Cock!

Trouting.

Long Tails and Short Ones.

Paying the Pike.
Rabbit Shooting.

Roaching.

Grouse Shooting.

Salmon Fishing.

Snipe Shooting.

Grayling Fishing.

WINDSOR HOUSE, BREAM'S BUILDINGS, LONDON, E.C. 


\section{SIKATING CARIS.} Now Ready, Price is., by post, Is. Id.

\section{COMBINED FIGURE CALLS}

Skating Cards, giving the Calls of 50 Combined Figures. alternating.

By R. H. FULLER, First-Class Badge Holder, N.S.A.

Demy 8vo., 600 pages, price 15s., by post i5s. 6d.

THE SPORTING DIVISION OF THE

\section{MI
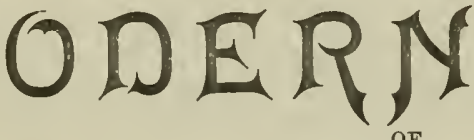

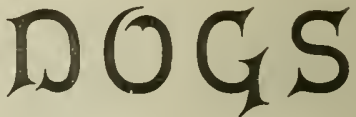

Great Britain and Erelanir.

\section{RAWDON B. IFF}

Kennel Editor of the "Field," Author of the "History and Description of the Fox Terrier," of the "Collie or Sheepdog," \&c.

PROFUSELY ILLUSTRATED IN COLLOTYPE, FROM DRAWINGS BY AITIU⿴囗十、凡DIE.

Now Ready, price Ios. 6d.; by the same Author,

THE NON-SPORTING DIVISION OF THE MODERN DOGS OF GREAT BRITANN AND IRELAND.

Illustrated in Collotype, from Drawings by Arthur Wardle. Also, Nore Ready, pruce Ios. 6d.; by the same Author,

\section{The Terriers of Great Britain and Ireland.}

Illustrated in Collotgpe, from Drawings by Arthur Wardle.

The Volumes are well printed, the Illustrations are full page on plate paper, and the binding and general arrangement are of the highest quality.

WINDSOR HOUSE, BREAM'S BUILDINGS, LONDON, E C. 
Price I 5s., by post I 5s. 6d., beautifully Illustrated.

\section{HORNS AND HOOFS;}

CHAPTERS ON HOOFED ANIMALS.

\section{By R. LYDEKKER.}

NOW READY, price 5s., Vol. 77.

TFE COURSING CAIFNDAE, FOR THE WINTER SEASON, 1894-95,

Containing Returns of the Principal Public Courses run in Great Britain and Ireland; a Revised List of Addresses of Coursing Secretaries, Judges, Slippers, and Trainers; IVinners of the IVaterloo Cup, Kempton Park Champion Stakes, and Gosforth Park Gold Cup; Greyhound Sales, and IVaterloo Cup Nominators for 1895.

Edited by B. C. EVELEGH ("Allan-a-Dale").

\section{Price 5 s.}

PUBLISHED UNDER THE AUTHORITY OF THE NATIONAL COURSING CLUB. THE

\section{GREYHOUND STUD BOOK}

(YOI. XIII.)

Compiled by WV. F. IAMIONBY

(KEEPER OF THE "STUd Book").

\section{CONTENTS.}

Index of 4346 Greyhounds registered, and Addresses of their Owners-Register of Litters under the Rule which came in force on Jan. I, I $895-$ List of sires and the bitches that have whelped to them under the same. Rule-Review of last Season's Coursing, by "Dromas," interspersed with several portraits of leading coursers--Statistics of Winning Strains-Tabulated Pedigrees, and Index of WVinning Greyhounds-Revised Rules of Coursing--Sales of Greyhounds-Winners, Dividers, and Runners-up for all Stakes during the preceding season, and other important matter.

Demy 8zo., cloth boards, price $4 s$. by post $4 s .4 d$.

\section{A DAY AT MONTE CARLO.}

By W. J. A. STAMER,

Author of "Dolce Napoli," \&c.

$$
\text { Price } 6 d \text {., by post } 6 \frac{1}{2} d \text {. }
$$

A REMEDY FOR BAD TIMHS. BY "A FARMER."

WINDSOR HOUSE, BREAM'S BUILDINGS, LONDON, E.C. 
NEW NOVEL, BY ESME STUART.

In Two Volumes, crown Svo., price 2is.

M A R R ED TO ORDER.

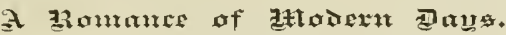

By ESMẼ STUART,

Author of "Joan Vellacot," "A Woman of Forty," "Kestell, of Greystone," \&c.

Now ready, crown 8vo., price 6 s.

A SIN OF THE SOUL.

By LADY FAIRLIE CUNINGHAME.

Crown Svo., cloth boards, price $6 s .$, by post $6 s .3 d$.

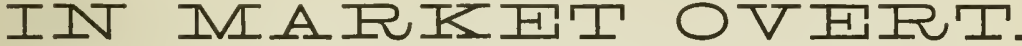

By JAMES PAYN,

Author of "By Proxy," "The Contidential Agent," "A Stumble on the Threshold," \&ic.

WITH ILLUSTRATIONS BY WALTER PAGET.

New Novel by Mrs. ALEC TWEEDIE. Second Edition. Price 6s.

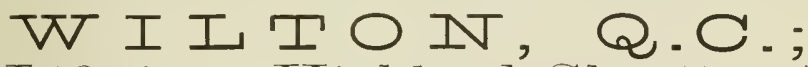

Or, Life in a Highland Shooting Box. By MRS. ALEC TWEEDIE

(NÉE HARLEY).

Author of "A Vinter Jaunt to Norway" (with Personal Accounts of Nansen, Ibsen, Bjornson, Brandes); "A Girl's Ride in Iceland," \&c.

Crown Svo., price 6s.

\section{WHEN FORT UNE FROWN S:} BEING THE LIFE AND ADVENTURES OF

$$
\text { GIIB正T O OSWA RTE, }
$$

How he fought for Prince Charles in the years $1745-46$, and what befell him thereafter.

By KATHARINE LEE (MRS. HENRY JENNER).

Author of "A IVestern Wildflower," "In London Town," "Katharine Blyth," "An Imperfect Gentleman," "Love or Money," "In the Alsatian Mountains," \&-c.

Crown 8vo., price 6s.

AT F开A卫T A 民A K耳. By MISS FLORENCE MARRYATT.

New Novel, price is.

CAUGHT BY A COOK. By EDITH E. CUTHELL, Author of "Only a Guardroom Dog," "Indian Memories," "A Baireuth Pilgrimage," \&c. WINDSOR HOUSE, BREAM'S BUILDINGS, LONDON, E.C. 


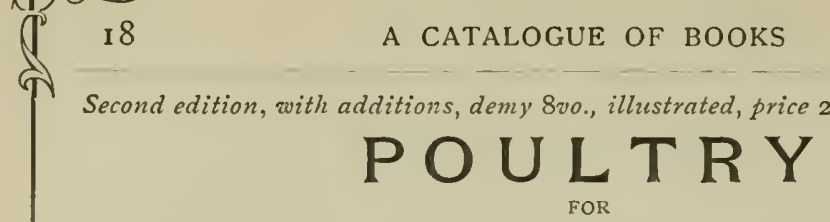

THE TABIF AND MARKFT VERSUS

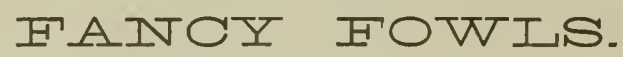

WITH AN EXPOSITION OF THE

\section{FALLACIES OF POULTRY FARMING.}

By W. B. TEGETMEIER, F.z.S.

\section{CONTENTS.}

Introductory-Game Fowls-Dorking-Cochins-Brahmas-Langshans, Plymouth Rocks, and Wyandottes-Malays, Indian Game, and Azeels-French Table Breeds, Houdans, Crevecour, and La FlecheNon-sitting Varieties, Spanish, Minorcas, Andalusian, and Leghorn-Non-sitting and other V'arietiesHousing-Feeding-Hatching-Rearing the Chickens-Breeding for the Market, Eggs-Breeding for the Market, Chickens-Fattening-Turkeys and Guinea Fowl-Ducks-Geese-Iiseases of Poultry-Fallacies of Poultry Farming-Fowls in Small Runs-Caponising.

\section{Price 6d., stiff covers.}

\section{THE COTTAGER'S MANUAL OF POULTRY KEEPING.}

BEING CHAPTERS FROM THE SECOND EDITION OF

\section{W. B. TEGETMEIER'S}

\section{Poultry for the Table and Market}

\section{FANOY FOWIS.}

This pamphlet consists of the practical chapters on Feeding Fowls, Hatching and Rearing Chickens for the Market, and the Production of Eggs. On Fattening, Trussing, and Showing Dead Poultry, and on Improving Ordinary Stock, from the last edition of Mr. Tegetmeier's well-known work on Table and Market Poultry.

Third Edition now ready, price is., by fost Is. Id.

\section{The Science \& Art of Training.}

A I Handbook for Athletes. BY DR. H. HOOLE.

Introduction.

$$
\text { CONTENTS. }
$$

Chap. I.-The Preparation for Athleticism.

Chap. II.-The Formation and Development of the Human Body.

Chap. III.-Food.

Chap. IV.-The Nutrition of the Body-Hunger and Thirst-Diet and Digestion.

Chap. V.-The Muscular System.

Chap. VI.-Exercise and Rest.

Chap. VII.-Personal Hygiene.

Appendix.

IVINDSOR HOUSE, BREAM'S BUILDINGS, LONDON, E.C. 
Crown 8vo., price Is., by post Is. 2d., in Coloured Wrapper, and Page Illustrations draion by IVHYMPER.

TWENTY-SIX YEARS' REMINISCENCES

OF

SCOTCH GROUSE MOORS.

BY W. A. A D A M S.

\section{CONTENTS.}

Seasons I 863 to I 888 - A Hare Day-Remarks on the Outcome of Disease-Heather-Burning and Draining-Surfare DrainingDogs-Disease-Wildfowl-Conclusion-Summary.

Demy 8zo., with folding plates and full-page illustrations printed on toned paper, price ios. 6d., by post i Is.
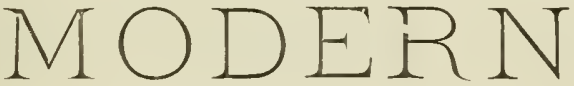

WI
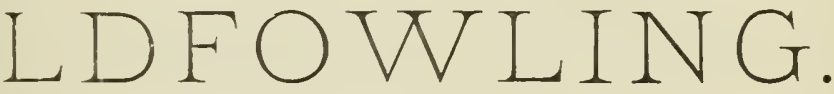

BY

LEWIS CLEMENT,

"WilldFowler."

OPINIONS OF THE PRESS.

"An excellent work indeed, and full of capital illustrations, is "Nodern W'ildfowling ;' to recommend It aright I shoulc' have, if 1 were clever enough, and it did not already exist, to invent the famous phrase, "a book no gentle man's library should be without." "- T'ruth, March 17 , 1881.

"This book azals not only with the various modes of approaching, or decoying, and killing wildfowl of all kinds, but eniers into minute details upon the construction of punts, both single and double handed sails; punt guns, rauzzle-loading as well as breechloading; recoil apparatus; and shoulder guns of all patterns, with the varying loads required for different bores. In addition to this are several chapters devoted to a narration of the adventures of the author while in pursuit of wildlowl, both at home and abroad-which are very pleasant reading. ...... With the addition of a good index, sportsmen will have in this work a capital vade mecum on the art of wildfowling."-The Zoologist for November, 1880.

Crown 8vo., price 2s. $6 d$., by post $2 s .8 d$.

\section{H A R E H U N T I G. BY "TINTARA."}




\section{The Archer's Register PUBLISHED ANNUALLY.}

Edited by F. T. FOLLETT,

Archery Correspondent of "The Field."

Royal 8vo, price 10s. 6d., by post I1s.

\section{HORSE BREEDING RECOLLECTIONS.}

\section{COUNT G. LEHNDORFF.}

Containing Notes on the Breeding of Thoroughbreds-In-breeding and Out-crossing -Pedigrees of all the Principal Sires-and Genealogical Tables of Celebrated Thoroughbreds.

Crown 8vo., profusely Illustrated, price 2s. 6d., by post 2s. 9d.

\section{GIPSY TENTS, AND HOW TO USE THEM.}

A HANDBOOK FOR AMATEUR GIPSIES.

\section{BY G. R. LOWNDES.}

In post 8vo., with Illustrations, price $3^{s .} 6 d$., by post 3 s. $9 d$.

\section{The Practical Management of Fisheries.}

A BOOK FOR PROPRIETORS AND KEEPERS.

By the late FRANCIS FRANCIS,

Author of "Fish Culture," "A Book on Angling," "Reports on Salmon Ladders," Ec.

\section{CONTEITS.}

Chap.-Fish and Fish Food.

II.-How to Grow Fish Food and how to Make Fishes' Homes.

III.-On the Management of Weeds and the Economy of Fishing.

IV.-The Enemies of Trout and how to Circumvent them.

V.-The Artificial Incubation of Ova.
VI.-On the Rearing of Fry and the Conduct of Ponds, Stews, \&c.

VII.-Some Hatcheries.

VIII.-Coarse Fish.

IX.-On Salmon and Trout Ladders and Passes.

Appendix.-Notes, \&c. 
Fcap. 8vo., cloth lettered, price $3 s .6$.

\section{LETTERS FROM A COUNTRY HOUSE.} By THOMAS ANDERTON.

Post free, 6\%., cloth gilt.

RULES OF THE GAME OF HOCKEY AND OF

THE HOCKEY ASSOCIATION.

Crozen 8vo., limp cloth, price [s. 6d., by post Is. $8 d$.

\section{HINTS TO HORSEWOMEN.}

By Mrs. HARRY ALLBUT'T

(ANNIE BLOOD-SMYTH).

Contents. -Chap. I.-Ladies' Horses. II.-Side Saddles. III.--Riding Habits. IV.-Riding Hats, Whips, Gloves, Spurs, V.-Riding. VI.--Bridles.

$$
\text { Price Is., by post Is. Id. }
$$

\section{NOTES ON THE PROOF OH GUNS.}

TOGETHER WITH THE NEW RULES AND SCALES OF PROOF PASSED BY THE SECRETARY FOR WAR, AND COMMENTS THEREON.

Official Edition of tne Laws of Lawn Tennis.

Now ready, price $6 d$., by post $7 d$. THE LA WS of LA WN TENNIS for the Year 1895 ,

Official Edition of the Regulations for the Management of Lawn Tennis Prlze Meetings 1895.

Now ready, price $6 d$., by post $7 d$.

REGULATIONS for the MANAGEMENT of 1 LAWN TENNIS PRIZE MEETINGS and INTER-COUNTY and INTERCLUB MEETINGS, issued under the authority of the Lawn Tennis Association. I895.

In crown 8vo., with Thirteen full-page Plates, price 2s. $6 d$., by post 2 s. $9 d$.

\section{The Swimming Instructor:}

A TREATISE ON THE ARTS OF SWIMMING AND DIVING.

By WILLIAM WILSON,

Author of "Swimming, Diving, and How to Save Life," "The Bather's Manual," "Hints on Swimming."

WINDSOR HOUSE, BREAM'S BUILDINGS, LONDON, E.C. 
Demy 8vo., with Illustrations and Map, price I2s. net.

\section{SIX MONTHS IN A SYRIAN MONASTERY.}

Being the record of a visit to the Headquarters of the Syrian Church in Mesopotamia, with some account of the Yazidis, or Devil WVorshippers of Mosul, and El Jilwah, their sacred book.

By OSWALD H. PARRY, B.A.

(Of Magdalen College, Oxforr).

ILLUSTRATED BY THE AUTHOR.

With a Prefatory Note by the Right Reverend the LORD BISHOP of DURHAM.

\section{Demy 8vo., cloth boards, price 7s. 6d. net.

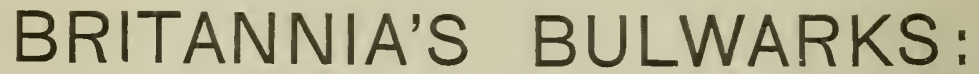

Qun 互ístorical poem,

Descriptive of the Deeds of the British Navy from the Battle of Sluys to the present day.

\section{BY CHARLES R. LOW.}

The metre is that of Scott's "Marmion," which is considered effective for a poem of action. The work is divided into two books, consisting of ten cantos, and contains, beside the history proper, a record of the services of distinguished seamen, and of historic ships of war. In the case of those bearing the names of classical celebrities, a sketch of these is given. The work is made easy of reference by a copious index.

With Illustrations, price 2s. $6 d$.

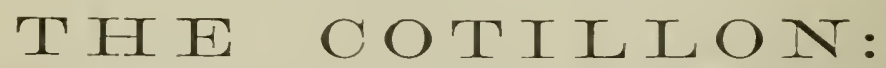

DETAILS OF ALL THE NEWEST FIGURES WITH AND WITHOUT ACCESSORIES.

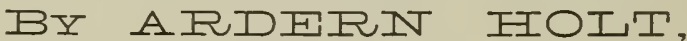

Author of "Fancy Dresses Described; or, What to Wear at Fancy Balls," and "Gentlemen's Fancy Dress."

\section{NI Y $O$ 王 I \\ $\mathrm{BY}$}

\section{A FORMER ASSISTANT MASTER.}

My First Chief : Rev. Evan Jellicle, M.A.-My Second Chief : Herbert Strong, M.A.My Third Chief: Rev. Uriah Meek, B.A.-My Fourth Chief : Rev. Algernon Fitzport, M.A.-My Fifth Chief: Frank Beaton, LL.D.- "De Rebus Scholasticis": Looking Backward and Forward.

WINDSOR HOUSE, BREAM'S BUILDINGS, LONDON, E.C. 
I Vol., cloth, price $7 s .6 d .$, by post $7 s .9 d . ; 2$ Vols., flexible morocco, price 10s., by post IOs. $3 d$.

\section{FIGURE-SKATING,}

\section{SIMP L E \\ A ND \\ COMBINED;}

BEING AN ENLARGED EDITION OF

\section{"COMBINED FIGURE-SKATING."}

Arranged as a complete text-book of the Art of Skating as practised in the leading Skating Clubs of Great Britain.

By MONTAGU S. MONIER-WILLIAMS, M.A., Oxon; WINTER RANDELL PIDGEON, M.A.., Oxon; and ARTHUR DRYDEN, B.A., Cantab.

With 18 lllustrations by Ronald Gray and others including four full-page plates, 28 Diagrams of Simple Figures, 275 Combined Figures illustrated by 168 Diagrams, and 8 Sets of Alternating Calls.

$$
\begin{aligned}
& \text { Part I. Simple Figure-Skating. } \\
& \text { Part II. Combined Figure-Skating. } \\
& \text { Part III. Supplementary. }
\end{aligned}
$$

The Calls are in accordance with the Revised Code of Rules of Combined Figure-Skating authorised by the Conference of Skating Clubs, July, 189 .

Fourth Edition (1894). Price 5s.6d., by post 5s. 9d.

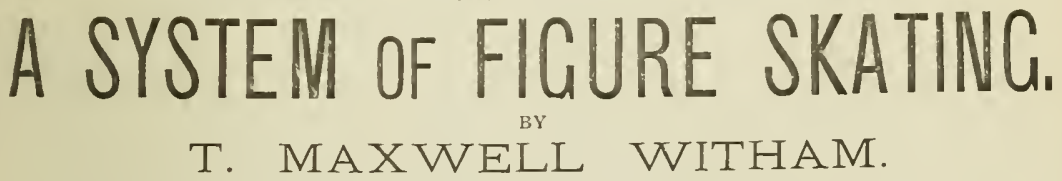

This is the Fourth Edition of a work which has been the text-book of all Figure Skaters since 1569 . The present Edition is practically a new book, all the letterpress having been revised and brought up to date, and all the diagrams, 276 in number, having been redrawn. The diagrams of the "Skating Club" figures are drawn in accordance with the manner of skating them authorised by the Committee of the Skating Club, and a new departure in diagrams has been made by illustrating the "Hand-in-Hand" figures with little diagramatic representations of the skaters, thus clearly showing their relative positions in the various changes.

Now ready, demy 8vo., with numerous Plates, price 10 . 6 d.

\section{THE THEORY AND PRACTI
TARGET SHOOTING,}

Including a series of Practical Hints on the use of Military and Match Rifles, a description of the Effects of Different Atmospheric Conditions, and Instructions in the Use of various Aids to Rifle Shooting.

By ARTHUR GLYNDWR FOULKES, MI.A.,

Captain 3 rd V.B. Cheshire Reyiment; Winner of Spencer Cup I879, Harrow; Oxford Team four years; Elcho Shield Match (England), two years; Record Score, 189 r.

IVINDSOR HOUSE, BREAM'S BUILDINGS, LONDON, E.C. 
(1) Now ready, demy 8vo., price $2 s .$, by post $2 s .3$.

\section{VALUATION OF PROPERTY (CORPOREAL AND INCORPOREAL).}

\section{By Charles E. Gurtis, F.S.I., F.S.S.}

Professor of Forest Economy, Field Engineering, and General Estate Management at the College of Agriculture, Downton, Salisbury; Member of the American Academy of Political and Social Science; Consulting Forester to the Right Hon. Lord O'Neill, Shanes Castle, Antrim, Ireland; Author of "Estate Management." "Practical Forestry," \&c.

\section{CONTENTS.}

Valuation of Land.

Valuation of Leaseholds and Reversions. Valuations for Probate and Succession Duties.
Valuation of Copyholds.

Valuation for Mortgage.

Valuation for the Purpose of Parochial Assessment.

Fourth Edition. In demy 8vo, price IOs. 6d., by post IIs.

\section{Estate Management:}

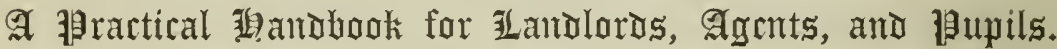
BY CHARLES E* CURTIS.

WITH A

\section{LEGAL SUPPLEMENT BY A BARRISTER.}

Extract from Preface.- "He who intends to qualify himself for such interesting and responsible work as the care and oversight of landed property must, in these days of keen competition, give up the idea that he need only abandon himself to the pleasures of a country life, and that all needful information will be picked up by the way."

Chap.

I.-Letting and Leases.

II.-Farm Valuations.

III.-Forestry.

IV.-Underwood.

V.-Fences.

VI.-Grasses suitable for Woods and Plantations.

VII.-The Home Farm.
CONTENTTS.

Chap.

VIII. Repairs and Materials.

X. - The Blights of Wheat and other Cereals.

XI.-Accounts.

XII.-Useful Rules of Arithmetic and Mensuration.

In crown 8vo., price Is., by post is. Id.

\section{CATECHISM OF ESTATE MANAGEMENT.}

\section{SECTION I.-LETTING AND LEASES.}

BY CHAS. E. CURTIS, F.S.I.,

Professor of Estate Management at the College of Agriculture, Principal of the School of Estate Mlanagement, Author of "Estate Management," \&ic.

IVINDSOR HOUSE, BREAM'S BUILDINGS, LONDON, E.C. 
Demy 8vo., price 5s. 6d., by post 5s. 10d.

THE

\section{ROTHAMSTED EXPERIMENTS} ON THE

GROWTH OF WHEAT, BARLEY, AND THE

MIXED HERBAGE OF GRASS LAND. BY

WILLIAM FREAM, B.SC. LOND., F.L.S., F.G.S., F.S.S.

In crown 8vo., price 2s. 6 d., by post 2s. $8 d$.

\section{A N U R E S :}

Their Respective Merits from an Economical Point of View. By A. W. CREWS,

Author of "Guano: its Origin, History, and Virtues," "The Potato and its Cultivation," \&c.

In crown 8vo., price 2s., by post $2 s .2 d$.

\section{THE POTATO AND ITS CULTIVATION. \\ By A. W. CREWS,}

Author of "Guano: its Origin, History, and Virtues," "Manures: their Respective Merits," \&c.

\section{CONTENTS.}

Derivation - History - Constituents - Varieties - Sprouting - Soils - PlantingManures-Earthing up-Disease-Scab-Storing-Forcing-Producing New Varieties-Substitutes for the "Potato"-Miscellaneous Information.

Price 6d., by post $7 d$.; or 2s. 6d. the half-dozen., by post $2 s$. II $d$.

\section{"THE FIELD"}

DUPLICATE JUDGING BOOK

Facilitates the work of the Judges at Poultry and other Shows, by a very simple method of entering and preserving a duplicate judging list.

Price One Shilling, postage extra.

\section{THE CHESS MONTHLY.}

\section{Edited By L. HOFFER.}

WINDSOR HOUSE, BREAM'S BUILDINGS, LONDON, E.C. 


\section{"PASTIME" SERIES. \\ Price is., post free is. $1 \frac{1}{2} d$.}

THE

\section{LAWN TENNIS HANDBOOK FOR 1895.}

Contains Portraits of the All England Champions, and Messrs. IV. H. Collins and Herbert Chipp, hon. secretary and ex-secretary Lawn Tennis Association; numerous Articles, including "The Service," "Lawn Tennis Courts," "How to Mark a Court," \&c. Laws of the Game; Laws of the Lawn Tennis Association; List of Champions; Fixtures for the Season ; Regulations for County and Inter-Club Matches, and the County Challenge Cup; List of Lawn Tennis Prize Winners, and Directory of Lawn Tennis Clubs and Tournaments.

Price 6 d., by post $7 \frac{1}{2} d$.

THE "PASTIM E"

\section{LAWN TENNIS SCORE-SHEET BOOK} (Sixty Sets),

WITH INSTRUCTIONS FOR THE USE OF UMPIRES.

Adapted for the Use of Umpires, as used at the Championship Meetings. Crown Swo., price Is., by post is. Id.; in cloth, Is. $6 d$., by post Is. $8 d$.

$\mathrm{THE}$

\section{IMPROVEMENT OF CRICKET GROUNDS ON ECONOMICAL PRINCIPLES. \\ By J. A. GIBBS.}

\section{Price 6d., post free $7 d$.}

\section{THE CRICKET HANDBOOK FOR 1895.}

Containing numerous Portraits of Prominent County Cricketers; Notes on the Counties, and much other useful information.

Now ready, price $6 d$. each, post free $7 \frac{1}{2} d$.

THE

\section{RUGBY AND ASSOCTATION FOOTBALL HANDBOOKS.}

Containing Articles by N. L. Jackson, I. Conway-Rees, T. C. Graham, P. Maud, and others, with several Portraits; the Laws of Football; the Bye-laws and Rules of the Rugby Union and the Football Association; Complete Lists of International Players and the Results of Principal Matches; Interesting Curiosities and Records; Club Directory; \&c.

\section{THE LAWS Of FOOTBALL (RUGBY and ASSOCIATION).}

In Stiff Paper Covers. Suitable for the IVaistcoat Pocket. Price $1 d$., post free $I_{\frac{1}{2}} d$. WINDSOR HOUSE, BREAM'S BUILDINGS, LONDON, E.C. 
Published Annually. In large post $8 v o$.

THE

\section{KENNEL CLUB STUD BOOK:}

RECORD OF DOG SHOWS AND FIELD TRIALS,

WITH

PEDIGREES OF SPORTING AND NON-SPORTING DOGS.

Vol. I., from 1859 to 1873 , price $12 \mathrm{~s}$. $6 \mathrm{~d}$., by post $13 \mathrm{~s}$. Price 10s. 6d., by post 10s. 10d. each-

Vol. V., I 877 ; Vol. VI., I 878 ; Vol. VII., I 879 ; Vol. VIII., I 880 ; Vol. IX., I 88 I ; Vol. XI., I 883 ; Vol. XII., I 884 ; Vol. XIII., I 885 ; Vol. XV., I 887 ; Vol. XVI., I 888 ; Vol. XVII., I 889 ; Vol. XVIII., I 890; Vol. XIX., I 89ı; Vol. XX., I 892; Vol. XXI., i 893 .

Price Is., by post Is. $2 d$.

THE MANIFESTATION OF DISEASE FOREST TREES,

THE CAUSES AND REMEDIES.

BY O. E. CURTIS, F.S.I., F.S.S. Price Is., by post Is. I d.

TATTERSALL'S RULES ON BETTING, WITH EXPLANATORY NOTES AND COMMENTS,

Containing an Account of Cases decided by Tattersall's Committee, with a Copious Index, and the Rules of Racing appended.

By G. HERBERT STUTFIELD, Barrister-at-Law.

Author of the "Law Relating to Betting, Time Bargains, and Gaming."

New Edition, demy 8vo., $3 s .6 d$., by post $3 s .9$ d., Illustrated with several Diagrams.

THE

PRACTICAL SURVEYOR: A TREATISE UPON SURVEYING.

Specially arranged for the Guirlance of Pupils, Stewards, the Scholastic Profession, and intending Emigrants. By THOMAS HOLLOWAY.

WINDSOR HOUSE, BREAM'S BUILDINGS, LONDON, E.C. 
A CATAlogue OF BOOKS

\section{Now ready, price is.; by post is. $3 d$. \\ The Rural Almanac}

\section{SPORTSMAN'S ILLUSTRATED CALENDAR FOR 1895.}

Articles on the following Subjects are included in the List of Contents:

BLACK POIVDERS AND NITRO COMPOUNDS.

NITRO POIVDERS AND THEIR PRESSURES IN GUN BARRELS. STANDARD RECORDS WITH I2, I6, AND 20-BORE GUNS.

CARTRIDGE CASES FOR NITRO POWDERS.

RIFLES FOR LARGE GAME SHOOTING.

THE RACING SEASON OF I894.

STRIKING SALMON. MARCH BROWNS. SILKWORM GUT. CANINE MATTERS. FIFI.D TRIALS. DOG CLUBS.

LAYING DOWN I.AND. MANURING PASTURES.

SEEDING AND MANAGEMENT OF YOUNG GRASS.

HAY-MAKING. FEEDING OF FARM HORSES.

FRUIT TREES ON HEAVY SOILS.

GARDEN PEAS AND THEIR CULTURE.

LIST OF HOUNDS, THEIR MASTERS, WHIPS, KENNELS, \&C.

THE FEEDING OF THE YOUNG OF BIRDS.

COUNTY AND FIRST-CLASS CRICKET AVERAGES.

STALLIONS FOR BREEDING THOROUGH-BREDS, \&c.

Royal Svo., cloth, profusely Illustrated, price 12s. $6 d$. net.

\section{TEXAN RANCH LIFE: WITH}

Three Months through Mexico in a "Prairie Schooner."

By MARY J. JAQUES.

Croz'n 8vo., cloth boards, price 2s. net.

\section{FAST DAY and VEGETARIAN COOKERY.}

BY

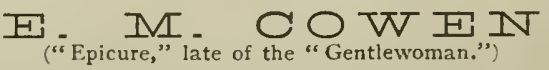

AND

S. BEATY-POWNAII.

IVINDSOR HOUSE, BREAM'S BUILDINGS, LONDON, E.C. 
Now ready, Third Edition, price is.

\section{A GIRL'S RIDE IN ICELAND.}

MRS、 ALEC TWEEDIE

(NÉE HARLEY),

Author of "A Winter Jaunt to Norway" (with personal accounts of Nansen, Ibsen, Bjornson, Brandes, \&tc.). Fully Illustrated.

REVIEIVS OF THE FIRST EDITION.

"A Girl's Ride in Iceland" is a most attractive little volume, wherein Mrs. Alec Tweedie gives a spirited account of a spirited jaunt.... Mrs. Tweedie has persuaded her father, Mr. George Harley, F.R.S., to add a chapter on Geysers, which forms an instructive and valuable appendix to this charming little book."-Athenceum.

"A very pretty and clever little volume. . . . Altogether the impression her excellent book gives is that the land of the Sagas is more interesting than many a stock holiday resort, while many tourists should be obliged to Mrs. Alec Tweedie for showing how conveniently lceland may be explored with the help of a little courage and cheerfulness."-Daily Telegraph.

In crown 8vo., cloth, price $2 s .6 d$.

\section{A YACHT RACING RECORD:}

BEING SOME REMINISCENCES OF

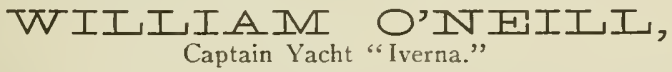

EDITED BY CHARLES BESLEY.

\section{IN THE PRESS.}

In post 8vo., cloth, with $M a p$ and Illustrations.

THE COASTS OF DEVON AND

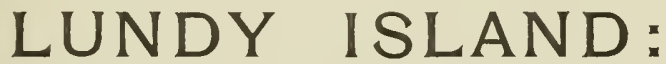

THEIR TOWNS, VILLAGES, SCENERY, ANTIQUITIES, and LEGENDS.

\section{JOHN LLOYD WARDEN PAGE,}

Author of "An Exploration of Dartmoor and its Antiquities," "An Exploration of Exmoor and the Hill Country of West Somerset," "The Rivers of Devon from Source to Sea," "Okehampton: Its Castle," \&c., \&c.

In demy Svo., with Charts.

THE

NEW NAVIGATION FOR YACHTSMEN. BY VINCENT J. ENGLISH. 


\section{The

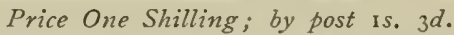

And LADY'S CALENDAR for 1895 .

AMONG ITS CONTENTS WLL BE FOUND

\section{A SUPPLEMENT OF FANCY KNITTING.}

HINTS TO LADIES ABOUT TO TRAVEL. By the Tourist Editor of the Queen.

Designs for Leather Work, executed by H.R.H. the Princess of WVales and her daughters; Amateur Art Work; Specimens of Carving from various Amateur Art Exhibitions; Historical Relics Exhibited at the Grafton Galleries; Screens of the Season; Metal Work Exhibited by the Home Arts and Industrial Association; Suggestions for Novel and Seasonable Floral Arrangements; Cot Coverlet for the Infant Prince Edward Albert of York; Specimens of Carved WVork selected from various Industrial Schools, \&cc.

PIROIUSEIT IIIUSTIRATED.

Crown 4to., with Illustrations, price ros.; by post 10s. $6 d$.

\section{OLD ENGLISH EMTROIDERY:}

ITS TECHNIQUE AND SYMBOLISM, OR

Ecclessiastical and Domestic Embroidery of the Middle Ages. By FRANCES and HUGH MARSHALL.

\section{POETRY AND THE DRAMA.}

SONGS GRAVE AND GAY. By F. B. Doveton, Author of "Snatches of Song," "Sketches in Prose and Verse," "Maggie in Mythica," \&c. In cloth lettered, gilt edges, $5 \mathrm{~s}$.

LYRICS. By DR. J. A. GOOdCHILd. Cloth lettered, price 5 s.

TALES IN VERSE. By Dr. J. A. GoOdCHILD. Cloth lettered, price 5 s.

SONGS OF THE CASCADES. By ERL Viking. Fcap. 8vo., cloth boards, $6 \mathrm{~s}$.

THE FAIREST OF THE ANGELS, and other VERSE. By Mary Colborne-Veel. Fcap. Svo., cloth boards, 3s. 6d.

THE WANDERER IN THE LAND OF CYBI, and other Poems (I886-93). By Clifford BRooks. Fcap., cloth boards, 3s. 6d.

POEMS. By Lewis Brockman. Crown 8vo., cloth boards, 5 s.

POEMS. By Thomas BARLow. Crown Svo., bevelled boards, gilt edges, price 5 s.

NORTH COUNTRY BALLADS. By Henry TOdD. Cloth, gilt edges, 3 s. $6 \mathrm{~d}$.

SONGS OF THE PINEWOODS. By ARTHUR CAMPBEll. Price 35. 6d.

WINDSOR HOUSE, BREAM'S BUILDINGS, LONDON, E.C. 
In Three Vols., price $3 \mathrm{Is}$. $6 \mathrm{~d}$.

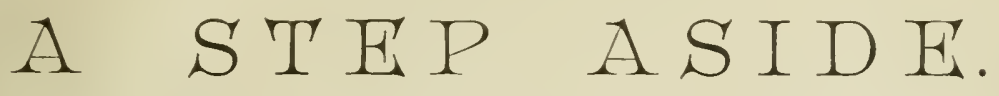

\section{Br GWENDOLEN DOUGLAS GALTON}

(Mrs. TRENCH GASCOIGNE).

" 'A Step Aside' is a stirring story, in which deep tragedy alternates with light comedy and tender pathos with sparkling humour. . . . In 'A Step Aside' there is not a single dull or redundant page. . . In a word, the book is worthy of unqualified praise." -Daily " qelegraph, Oct. 20 .

"A most interesting novel, in which the humour, pathos, and vivacity of the numerous characters are happily blended with some capital descriptive writing of Italian scenery." -Essex Times, Oct. 20.

\section{In Tie'o Vols., crozen 8vo., price 2 Is.

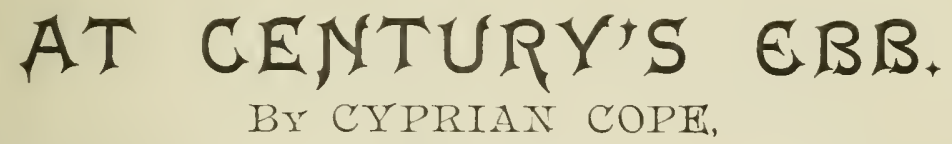

"A novel containing a good deal of strong incident, much variety of cliaracter, and 2 love interest of an unforced and natural kind." - Daily Telegraph.

"An ambitious novel."-Manchester Guardian.

"A capital novel. A love story of eonsiderable incident, and strikingly varied characterisation. A novel that will be widely and appreciatively read."-Kentish Observer.

"A novel of great excellence, will be perused with great interest, not a single dull page."Derwsbury Reporter.

"An extremely clever novel, characters admirably drawn. The hunting scenes, the sketches of life in a big country house, and the air of shallow dilettantism which play over it all are remarkably vivacious, and altogether the book is one which once begun it is not easy to abandon till the end is reached." W" Whmorland Gazette.

\section{Crown Sio., with Illustrations, price 3s. $6 d$.}

\section{THE MARTYRDOM OF SOCIETY.}

\section{QUILLI M RITTER.}

"For his satırical arrows he has chosen promising game-the heiress who would reclaim the East. end and all humanity; the working man M.P., who thinks to run the nation as easily as a Hyde Park demonstration; the man about town who, to be in the swim, forswears drink to talk about the inequality of social punishment and the mystery of human misery; the irrepressible busybody, who start societies for the suppression of vice in high life; all familiar types in an age of sentiment and fads and Mrs. Besants. The most successful passage is that recording the final catastrophe, when the benevolence of the West leads, not to the building of palaces of delight, but to its own destruction by an East-end weary of being patronised; and there is a laugh in the fate of heiress and working man left to punt in peace on a placid river."-Pall Mall Gaxette.

"This is a powerful one volume story."-Puhlisher's Circular.

"It is an odd world that Henry Jacobson sways. ; . . . Mr. Quillim Ritter has put it all very cleverly, and added some neat epigrams of his own."-Black and $t$ ihite.

NEW NOTEL BY JAMES PAYN. CHEAP EDITION, Illustrated, price 3 s. 6 d..

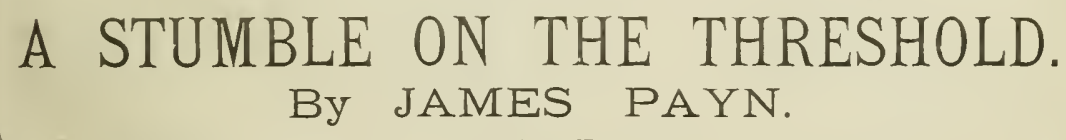

IVINDSOR HOUSE, BREAM'S BUILDINGS, LONDON, E.C. 


\section{INDEX TO BOOKS.}

PAGE

$\begin{array}{lllll}\text { A Ding at Monte Carlo } & \ldots & \ldots & \ldots & 15\end{array}$

Letters from a Country House

$\begin{array}{lllll}\text { A Girl's Ride in Iceland } & \ldots & \ldots & \ldots & 29\end{array}$

A Remedy for Bad Times... $\quad \ldots . \quad \ldots \quad 15$

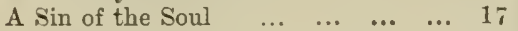

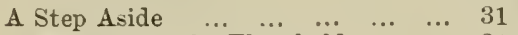

$\begin{array}{lllllll}\text { Lyra Piscatoria } & . . . & \ldots & \ldots & \ldots & \ldots & 6\end{array}$

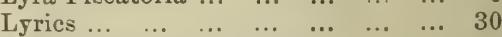

IIan Hanting in the Desert $\quad \ldots . \quad \ldots \quad 11$

A Stumble on the Threshold ... $\quad . .3 \quad 31$

An Australian in China $\quad \ldots \quad$... $\quad \ldots \quad 5$

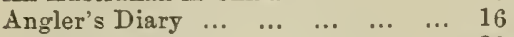

$\begin{array}{llllll}\text { Archer's Register } & \ldots & \ldots & \ldots & \ldots & 20\end{array}$

$\begin{array}{lllllll}\text { Art of Chess } & \ldots & \ldots & \ldots & \ldots & \ldots & 11\end{array}$

$\begin{array}{llllll}\text { At Century's Ebb } & \ldots & \ldots & \ldots & \ldots & 31\end{array}$

$\begin{array}{lllllll}\text { Betting Rules } & \ldots & \ldots & \ldots & \ldots & \ldots & 27\end{array}$

$\begin{array}{lllll}\text { Britannia's Bulwarks } & \ldots & \ldots & \ldots & 22\end{array}$

$\begin{array}{lllll}\text { British and Irish Fishes } & \ldots & \ldots & \ldots & 3\end{array}$

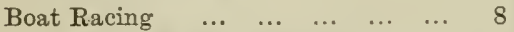

Bores and Loads for Sporting Guns... \&

Catechism of Estate Management ... 24

$\begin{array}{lllll}\text { Cattle of Great Britain } & \ldots & \ldots & \ldots & 7\end{array}$

$\begin{array}{llllll}\text { Canght by a Cook } & \ldots & \ldots & \ldots & \ldots & 17\end{array}$

$\begin{array}{llllll}\text { Coasts of Deron... } & \ldots & \ldots & \ldots & \ldots & \end{array}$

$\begin{array}{llllll}\text { Collie or Sheep Dog } & \ldots & \ldots & \ldots & \ldots & 12\end{array}$

Cottager's Manual of Poultry Keeping 18

$\begin{array}{llllll}\text { Coursing Calendar } & \ldots & \ldots & \ldots & \ldots & 15\end{array}$

$\begin{array}{lllllll}\text { Country House } & . . & \ldots & \ldots & \ldots & \ldots & 10\end{array}$

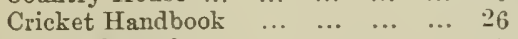

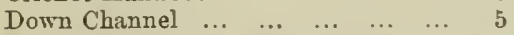

$\begin{array}{llllll}\text { Estate Mlanagement } & . . & \ldots & \ldots & \ldots & 24\end{array}$

Essays on Sport and Natural History 6

$\begin{array}{lllllll}\text { Fairy Tales } & \ldots & \ldots & \ldots & \ldots & \ldots & 16\end{array}$

Fast Day and Vegetarian Cookery ... 28

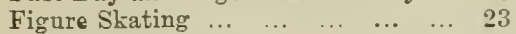

$\begin{array}{llllll}\text { Football Handbooks ... } & \ldots & \ldots & \ldots & 26\end{array}$

$\begin{array}{lllllll}\text { Forest Trees } & \ldots & \ldots & \ldots & \ldots & \ldots & 27\end{array}$

$\begin{array}{lllllll}\text { Fox Terrier... } & \ldots & \ldots & \ldots & \ldots & \ldots & 12\end{array}$

Gamekeeper's Shooting Book ... ... 10

Gipsy Tents, and How to Use Them 20

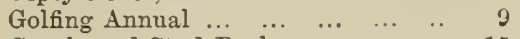

$\begin{array}{llllll}\text { Greyhound Stud Book } & \ldots & \ldots & \ldots & 15\end{array}$

$\begin{array}{llllll}\text { Hare Hunting } & \ldots & \ldots & \ldots & \ldots & 19\end{array}$

$\begin{array}{lllll}\text { Hints to Horsewomen } & \ldots & \ldots & \ldots & 21\end{array}$

$\begin{array}{lllllll}\text { Hockey Rules } & \ldots & \ldots & \ldots & \ldots & \ldots & 21\end{array}$

$\begin{array}{llllll}\text { Horns and Hoofs } & \ldots & \ldots & \ldots & \ldots & 15\end{array}$

Horse Breeding Recollections ... ... 20

$\begin{array}{llllll}\text { Hunting Countries } & \ldots & \ldots & \ldots & \ldots & 17\end{array}$

Improvement of Cricket Grounds ... 26

$\begin{array}{llllll}\text { In Market Orert } & \ldots & \ldots & \ldots & \ldots & 16\end{array}$

$\begin{array}{lllllll}\text { Judging Book } & \ldots & \ldots & \ldots & \ldots & \ldots & 25\end{array}$

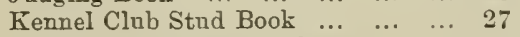

$\begin{array}{llll}\text { Knights and Kings of Chess } & \ldots & \ldots & 11\end{array}$

$\begin{array}{lllll}\text { Lawn Tennis Handbook } & \ldots & \ldots & \ldots & 26\end{array}$

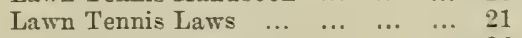

Lawn Tennis Score Book ... $\quad \ldots \quad \ldots . \quad 26$

Lawn Tennis Regulations... $\quad \ldots \quad \ldots \quad . \quad 21$

$\begin{array}{llllll}\text { Laws of Football } & \ldots & \ldots & \ldots & \ldots & 26\end{array}$

$\begin{array}{lllllll}\text { Laws } \text { of Golf } & \ldots & \ldots & \ldots & \ldots & \ldots & 16\end{array}$

$\begin{array}{lllll}\text { Management of Fisheries ... } & \ldots & \ldots & 20\end{array}$

$\begin{array}{llllllll}\text { Manures } & \ldots & \ldots & \ldots & \ldots & \ldots & \ldots & 25\end{array}$

$\begin{array}{llllll}\text { Married to Order } & \ldots & \ldots & \ldots & \ldots & 16\end{array}$

$\begin{array}{lllll}\text { Martyrdom of Society } & \ldots & \ldots & \ldots & 31\end{array}$

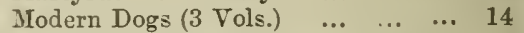

Modern Sportsman's Gun and Rifle... 13

Modern Wildfowling ...

Mules and Mule Breeding $\quad \ldots .6 .6$

$\begin{array}{llllllll}\text { My Chiefs } & \ldots & \ldots & \ldots & \ldots & \ldots & \ldots & 22\end{array}$

$\begin{array}{lllll}\text { North Country Ballads } & \ldots & \ldots & \ldots & 30\end{array}$

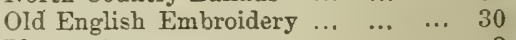

$\begin{array}{llllllll}\text { Pheasants } \ldots & \ldots & \ldots & \ldots & \ldots & \ldots & 3\end{array}$

$\begin{array}{lllllll}\text { Pheasant Rearing } & \ldots & \ldots & \ldots & \ldots & \ldots & 10\end{array}$

$\begin{array}{lllll}\text { Pigeon Shooting Rules } & \ldots & \ldots & \ldots & 10\end{array}$

$\begin{array}{llllllll}\text { Poems ... } & \ldots & \ldots & \ldots & \ldots & \ldots & \ldots & 30\end{array}$

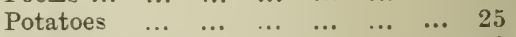

$\begin{array}{lllllllll}\text { Poultry } & \ldots & \ldots & \ldots & \ldots & \ldots & \ldots & 18\end{array}$

$\begin{array}{llllll}\text { Practical Surveyor } & \ldots & \ldots & \ldots & \ldots & 27\end{array}$

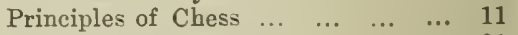

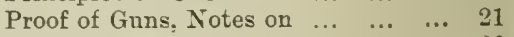

$\begin{array}{lllllll}\text { Queen Almanac ... } & \ldots & \ldots & \ldots & \ldots & 30\end{array}$

$\begin{array}{lllllllll}\text { Rabbits } & \ldots & \ldots & \ldots & \ldots & \ldots & \ldots & 8\end{array}$

$\begin{array}{lllll}\text { Rothamsted Experiments ... } & \ldots & \ldots & 25\end{array}$

$\begin{array}{llllll}\text { Rowing Almanac } & \ldots & \ldots & \ldots & \ldots & 8\end{array}$

$\begin{array}{lllllll}\text { Rural Almanac } & \ldots & \ldots & \ldots & \ldots & \ldots & 28\end{array}$

Science and Art of Training $\quad \ldots . \quad \ldots \quad 18$

Servants and Masters $\quad \ldots . \quad \ldots \quad \ldots \quad 6$

Shifts and Expedients of Camp Life.. 9

$\begin{array}{lllllll}\text { Skating Cards } & \ldots & \ldots & \ldots & \ldots & \ldots & 14\end{array}$

$\begin{array}{lllll}\text { Songs Grave and Gay } \quad \ldots & \ldots & \ldots & 30\end{array}$

$\begin{array}{lllll}\text { Songs of the Cascades } & \ldots & \ldots & \ldots & 30\end{array}$

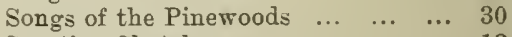

$\begin{array}{llllll}\text { Sporting Sketches } & \ldots & \ldots & \ldots & \ldots & 13\end{array}$

$\begin{array}{lllll}\text { Sportsman's Vade-Mecum... } & \ldots & \ldots & 12\end{array}$

$\begin{array}{lllll}\text { Swimming Instructor } & \ldots & \ldots & \ldots & 21\end{array}$

$\begin{array}{llllll}\text { Syrian MIonastery } & \ldots & \ldots & \ldots & \ldots & 22\end{array}$

$\begin{array}{llll}\text { System of Figure Skating } \quad \ldots & \ldots & 23\end{array}$

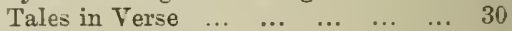

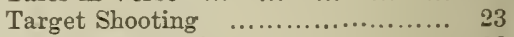

$\begin{array}{llllll}\text { Texan Ranch Life } & \ldots & \ldots & \ldots & \ldots & 28\end{array}$

$\begin{array}{lllllll}\text { The Cotillon } & \ldots & \ldots & \ldots & \ldots & \ldots & 22\end{array}$

The Fairest of the Angels $\quad \ldots \quad \ldots \quad 30$

The Wanderer in the Land of Cybi... 30

Twenty-six Years' Reminiscences, \&c. 19

Valuation of Property $\quad \ldots . \quad \ldots \quad \ldots .24$

$\begin{array}{lllll}\text { When Fortune Frowns } & \ldots & \ldots & \ldots & 17\end{array}$

$\begin{array}{lllllll}\text { Wilton. Q.C. } & \ldots & \ldots & \ldots & \ldots & \ldots & 17\end{array}$

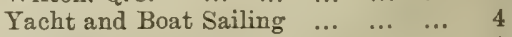

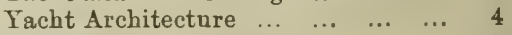

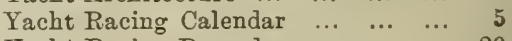

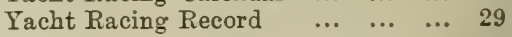






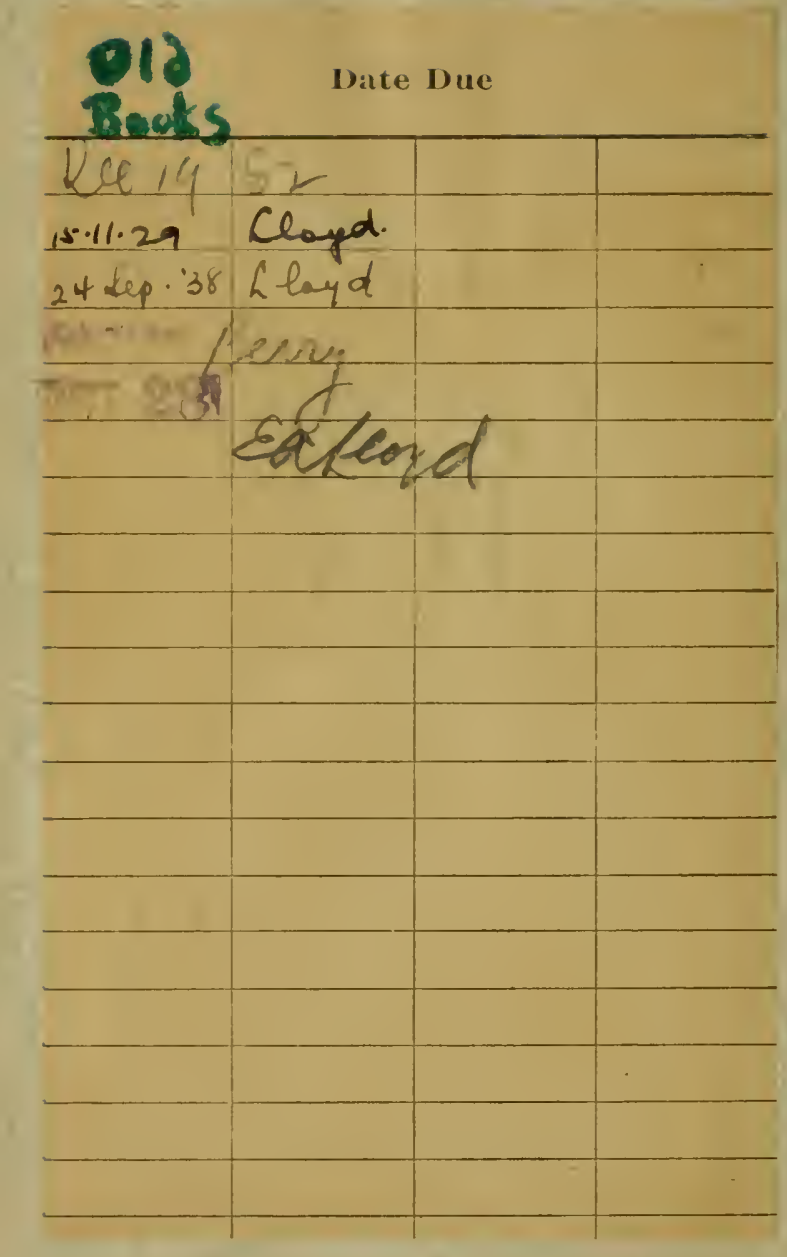




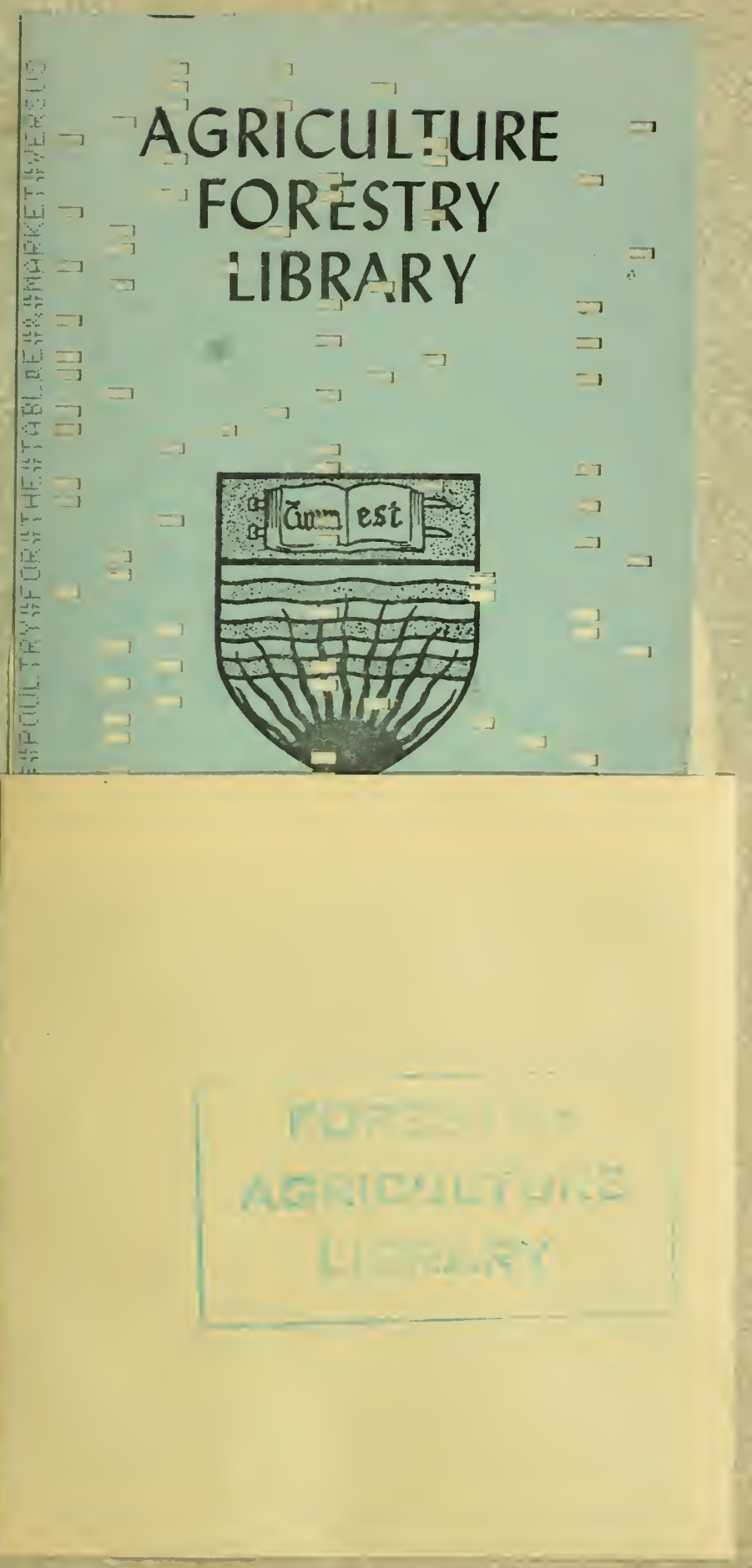


